
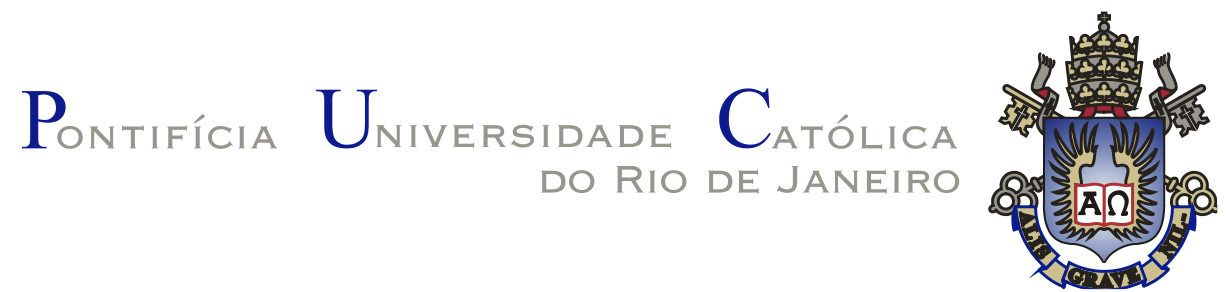

Gilcyvania Castro Corvelo Costa

\title{
Análise de Vigas de Concreto Armado Baseada na Abordagem Momento-Rotação
}

\section{Dissertação de Mestrado}

Dissertação apresentada como requisito parcial para obtenção do grau de Mestre pelo Programa de PósGraduação em Engenharia Civil do Departamento de Engenharia Civil e Ambiental da PUC-Rio.

Orientador: Prof $^{\circ}$. Daniel Carlos Taissum Cardoso 

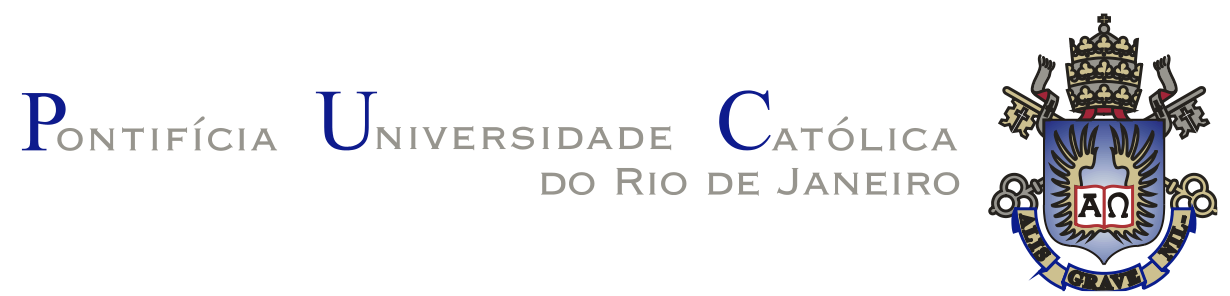

Gilcyvania Castro Corvelo Costa

\section{Análise de Vigas de Concreto Armado Baseada na Abordagem Momento-Rotação}

Dissertação apresentada como requisito parcial para obtenção do grau de Mestre pelo Programa de Pós-graduação em Engenharia Civil da PUC-Rio. Aprovada pela Comissão Examinadora abaixo.

Prof. Daniel Carlos Taissum Cardoso

Orientador

Departamento de Engenharia Civil e Ambiental - PUC-Rio

Prof. Luiz Fernando Campos Ramos Martha Departamento de Engenharia Civil e Ambiental - PUC-Rio

Giuseppe Barbosa Guimarães GBG Engenharia e Consultoria Ltda.

Rio de Janeiro, 13 de março de 2019. 
Todos os direitos reservados. É proibida a reprodução total ou parcial do trabalho sem a autorização da universidade, da autora e do orientador.

\section{Gilcyvania Castro Corvelo Costa}

Graduou-se em Engenharia Civil pela Universidade Estadual do Maranhão (UEMA) em 2016. Durante a graduação atuou como pesquisadora de iniciação científica na área de estruturas de concreto, estagiou com projeto estrutural de concreto armado e publicou artigos científicos correlacionados ao tema. No ano de 2017 ingressou no curso de Mestrado em Engenharia Civil, da Pontifícia Universidade Católica do Rio de Janeiro, onde concentrou seus estudos na linha de pesquisa de Estruturas de Concreto.

Ficha Catalográfica

Costa, Gilcyvania Castro Corvelo

Análise de vigas de concreto armado baseada na abordagem momento-rotação / Gilcyvania Castro Corvelo Costa ; orientador: Daniel Carlos Taissum Cardoso. 2019.

100 f. : il. color. ; $30 \mathrm{~cm}$

Dissertação (mestrado) - Pontifícia Universidade Católica do Rio de Janeiro, Departamento de Engenharia Civil e Ambiental, 2019.

Inclui bibliografia.

1. Engenharia Civil e Ambiental - Teses. 2. Abordagem Momento-Rotação. 3. Interação Parcial. 4. Rigidez. 5. Concreto Armado. I. Cardoso, Daniel Carlos Taissum. II. Pontifícia Universidade Católica do Rio de Janeiro. Departamento de Engenharia Civil e Ambiental. III. Título. 
Dedico este trabalho à minha mãe, Dilvania, por ser meu melhor exemplo de força e determinação. 


\section{Agradecimentos}

Primeiramente, agradeço a Deus, pela fé inabalável que me fez renovar minhas forças em meio aos desafios enfrentados e pela chance de viver a cada dia.

À minha mãe, Dilvania, por ser minha grande motivação e por me acompanhar em todas as etapas da vida, sempre com muito amor e cuidado. Ao meu pai, Gilberto, pelo auxílio nesses anos e por sempre acreditar no meu potencial. Às minhas irmãs, Glayci e Gilvania, pelo incentivo, e às minhas sobrinhas, Sarah e Júlia, por alegrarem os meus dias com amor e ternura.

Ao meu orientador, Daniel Carlos Taissum Cardoso, pela confiança, pelos conhecimentos transmitivos e, sobretudo, pela empatia e pelo grande e importante incentivo dado ao longo desse trabalho.

Ao meu namorado, Rafael Abreu, por ser o meu melhor amigo, me aconselhar e acreditar em mim mais que eu mesma. Por ser meu exemplo de disciplina, resiliência e bondade. Pela companhia nos dias de saudade de casa, nos dias de estudo árduo, pela alegria diária e por enfrentarmos juntos todas as situações.

Ao meu mentor, Luís Fernando Soares, por fomentar meu interesse por estruturas ainda no curso técnico, pela atenção e ajuda de sempre, pelos conselhos e pelo incentivo a cada passo que dou na minha carreira.

Às minhas melhores amigas, Fernanda e Cleia, pela presença em todos os momentos e por nossas amizades de anos, baseadas no amor, no respeito e na compreensão.

Ao amigo querido, José Vitor Araújo, pelo apoio e incentivo. 
À Fundação de Amparo à Pesquisa e ao Desenvolvimento Científico e Tecnológico do Maranhão (FAPEMA), à Secretária da Ciência, Tecnologia e Inovação do Maranhão (SECTI-MA) e ao Governo do Estado do Maranhão, pela bolsa de estudos concedida.

À PUC-Rio, pelos auxílios concedidos, que viabilizaram a realização deste trabalho.

O presente trabalho foi realizado com apoio da Coordenação de Aperfeiçoamento de Pessoal de Nível Superior - Brasil (CAPES) - Código de Financiamento 001. 


\section{Resumo}

Costa, Gilcyvania Castro Corvelo; Cardoso, Daniel Carlos Taissum (Orientador). Análise de Vigas de Concreto Armado Baseada na Abordagem Momento-Rotação. Rio de Janeiro, 2019. 100p. Dissertação de Mestrado - Departamento de Engenharia Civil e Ambiental, Pontifícia Universidade Católica do Rio de Janeiro.

A avaliação da rigidez de elementos lineares de concreto armado realizada por meio da abordagem momento-curvatura apresenta bons resultados, destacando como premissa a interação completa entre materiais. Entretanto, tal premissa ignora efeitos importantes que tem como base a fissuração do concreto e o deslizamento entre interfaces. Devido ao surgimento de fissuras o elemento deixa de ter deformações contínuas e passa a ter deslocamentos discretos na face fissurada, tendo como consequência deslizamentos na interface concreto-barra. Esses deslizamentos são incorporados em um modelo mecânico por meio das propriedades bond-slip da interface, que é base para o mecanismo de interação parcial conhecido como enrijecimento à tração. Além disso, na região comprimida, ao atingir deformações elevadas, o concreto pode estar sujeito à formação de cunhas de concreto delimitadas por fissuras, que formam o plano de cunha. Esse, por sua vez, sofre deslizamentos que são responsáveis pelas deformações efetivas crescentes no concreto, que representam outro mecanismo de interação parcial, o amolecimento do concreto. Para que esses mecanismos de interação parcial sejam inseridos na análise de vigas de concreto, um modelo mecânico chamado abordagem momento-rotação é apresentado. São realizadas ainda, comparações com o modelo tradicional de momento-curvatura, implementações para análise de vigas que contempla ambos modelos, e por fim, realizam-se validações com ensaios experimentais da literatura.

\section{Palavras-chave}

Concreto Armado; Rigidez; Abordagem Momento-Rotação; Interação Parcial. 


\section{Abstract}

Costa, Gilcyvania Castro Corvelo; Cardoso, Daniel Carlos Taissum (Advisor). Analysis of Reinforced Concrete Beams Based on a MomentRotation Approach. Rio de Janeiro, 2019. 100p. Dissertação de Mestrado Departamento de Engenharia Civil e Ambiental, Pontifícia Universidade Católica do Rio de Janeiro.

The evalutation of the stiffness of one-dimensional reinforced concrete elements is performed through the moment-curvature approach. The presented results are satisfactory, owing to that an analysis of full-interaction between materials is a premise. However, this consideration ignores important effects as crack formation and sliding between the interfaces. The cracked element no longer undergoes continuous strain and beggings to experience discreet displacements at the crack face. The crack formation is possible due to the sliding capacity between the reinforcement-concrete interface. These slides are being incorporated in a mechanical model through the bond-slip interface properties by the PartialInteraction mechanism known as tension-stiffening. Furthermore, in the compressed region, on reaching elevated strains, the concrete may be subject to formation of concrete wedges delimited by cracks, which form the wedge plane. This plane undergoes slides that are responsible for crescent effective strains in the concrete, these represent a further partial-interaction mechanism: the concretesoftening. The partial-interaction mechanisms presented are used in the analysis of concrete beams through a mechanical model known as rotation-moment approach. Comparisons with the traditional moment-curvature model are presented. Also, implementations of the beams analysis by moment-curvature and moment-rotation models are developed. Lastly, validations are perfomed with experimental tests, based on literatures.

\section{Keywords}

Reinforced Concrete; Stiffness; Moment-Rotation Approch; PartialInteraction. 


\section{Sumário}

1 Introdução 18

$\begin{array}{ll}\text { 1.1. Motivação } & 18\end{array}$

1.2. Objetivos 21

1.3. Estrutura da dissertação 22

2 Revisão da Literatura e Conceitos Fundamentais 23

2.1. Considerações Iniciais 23

2.2. Relações Constitutivas dos Materiais 26

2.2.1. Concreto 26

2.2.2. Aço Estrutural 27

2.2.3. Barras de FRP 28

2.3. Abordagem Momento-Rotação 30

2.3.1. Mecanismo de Amolecimento do Concreto 32

2.3.2. Relações de Aderência - Curvas Bond-Slip 35

2.3.3. Mecanismo de Enrijecimento à Tração 39

2.4. Método de Newton-Raphson 50

3 Algoritmos Implementados 53

3.1. Capacidade Resistente da Seção - Interação Completa 53

3.1.1. Parcelas Referentes ao Concreto 55

3.1.2. Parcelas Referentes à Armadura $\quad 57$

3.2. Perfil de Deformação na Seção 57

3.3. Diagramas Momento-Curvatura (M-1/r) 61

3.4. Análise Não Linear de Vigas de Concreto 63

3.5. Diagrama Momento-Rotação (M-ө) 66

4 Validação e Resultados $\quad 79$

4.1. Ensaios em Vigas de Concreto Armado (Sá, 2018) 79

4.2. Avaliação dos Resultados 81 
5 Considerações Finais 90

5.1. Conclusões 90

5.2. Sugestões para Trabalhos Futuros 91

6 Referências Bibliográficas 93 


\section{Lista de Figuras}

Figura 1. a) Rótula plástica formada (Haskett et al., 2009.a); b) Fissura em elemento de concreto armado (Murray et al., 2007) 19

Figura 2. Formação de cunha de concreto 25

Figura 3.Diagrama tensão-deformação do concreto à compressão (Adaptado - NBR 6118:2014) 27

Figura 4. Diagrama tensão-deformação do aço à tração (Adaptado - NBR

6118:2014)

Figura 5. Diagrama tensão $\times$ deformação à tração para as principais barras de FRP (Adaptado - FIB Bulletin 40, 2007)

Figura 6. Mecanismo idealizado da rotação de corpo rígido do prisma de concreto

Figura 7. Trecho ascendente e descendente do concreto sob compressão.

Figura 8. Elemento de concreto sob compressão e as forças atuantes no plano deslizante.

Figura 9. Relação bond-slip aço-concreto (Adaptado - Model Code, 2010)

Figura 10. Modelo bond-slip linear ascendente idealizado (Adaptado Taheri e Barros, 2012)

Figura 11. Curva bond-slip típica para sistemas de NSM-FRP (Adaptado De Lorenzis, Rizzo e La Tegola, 2002)

Figura 12 Relação tensão $x$ deformação para o concreto até o limite de resistência à tração

Figura 13. Tensão de tração $\times$ abertura de fissuras no concreto (Adaptado - FIB Bulletin 42, 2008)

Figura 14. a) Prisma infinitamente longo; b) Seção transversal do prisma;

c) Equilíbrio na interface do concreto; d) Equilíbrio na interface da barra (Adaptada - Muhamad et al., 2012) 
Figura 15. Condições de contorno (Adaptada - Muhamad et al., 2012) 46

Figura 16. Aplicação do método de Newton-Raphson

Figura 17. Perfil de tensões e deformações ao longo da seção e resultantes de forças no concreto e na armadura.

Figura 18. Fluxograma - perfil de deformações 61

Figura 19. Fluxograma - momento-curvatura 63

Figura 20 Fluxograma - análise de vigas $\quad 66$

Figura 21. Seção de concreto discretizada com a força resultante atuando no CG

Figura 22. Faixa de concreto discretizada dentro de uma região de fissura (Adaptada - Taheri e Barros, 2012) 70

Figura 23. Faixa de concreto sob tensões de tração inferior à resistência (Adaptada - Taheri e Barros, 2012)

Figura 24. Armadura fora da região de fissura (Adaptada - Taheri e Barros, 2012)

Figura 25. Armadura dentro da região de fissura (Adaptada - Taheri e Barros, 2012) 75

Figura 26. Fluxograma - momento-rotação 78

Figura 27. Viga de concreto ensaiada (Adaptada - Sá, 2018) 79

Figura 28. Curva bond-slip idealizada - concreto-aço 81

Figura 29. Curva bond-slip idealizada - concreto-GFRP 81

Figura 30. Carga-deslocamento - viga VA-12 82

Figura 31. Carga-deslocamento - Viga VA-5 83

Figura 32. Carga-deslocamento - viga VP-12 83

Figura 33. Diagrama momento - curvatura - Viga VA - 12

Figura 34. Diagrama momento - curvatura - Viga VA - 5

Figura 35. Diagrama momento - curvatura - Viga VP - 12

Figura 36. Contribuição das parcelas resistentes - viga VA-12 87

Figura 37. Contribuição das parcelas resistentes - viga VA-5 87

Figura 38. Contribuição das parcelas resistentes - viga VP-12 88

Figura 39. Momento - abertura de fissuras 89 


\section{Lista de Tabelas}

Tabela 1. Propriedades mecânicas à tração de barras de FRP -

(Adaptada - Reis, 2009) 29

Tabela 2. Conversões de condições de contorno para o sistema fictício (Martha, 2017) 65

Tabela 3. Propriedades dos materiais (Sá, 2018) 


\section{Lista de Símbolos}

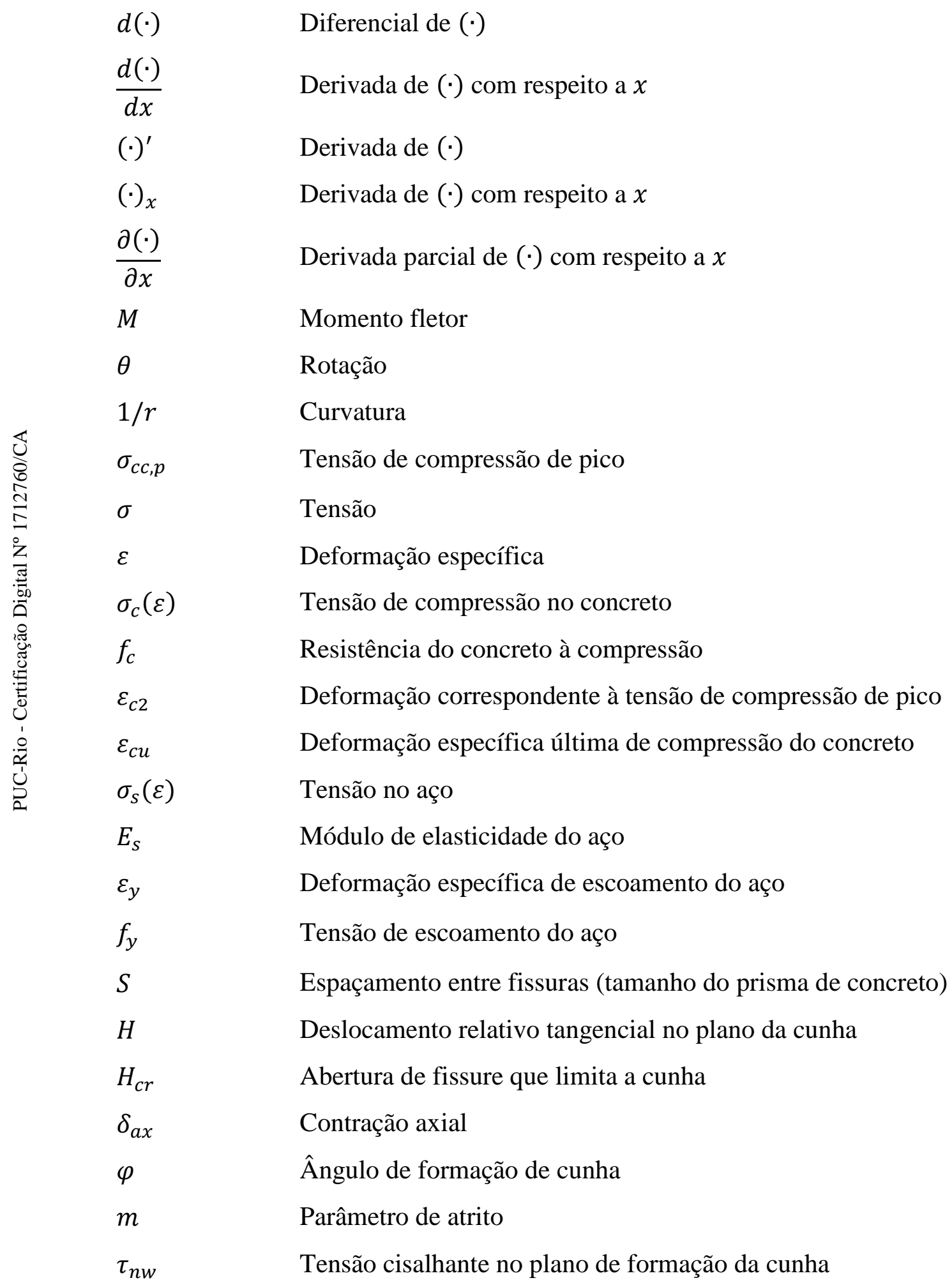




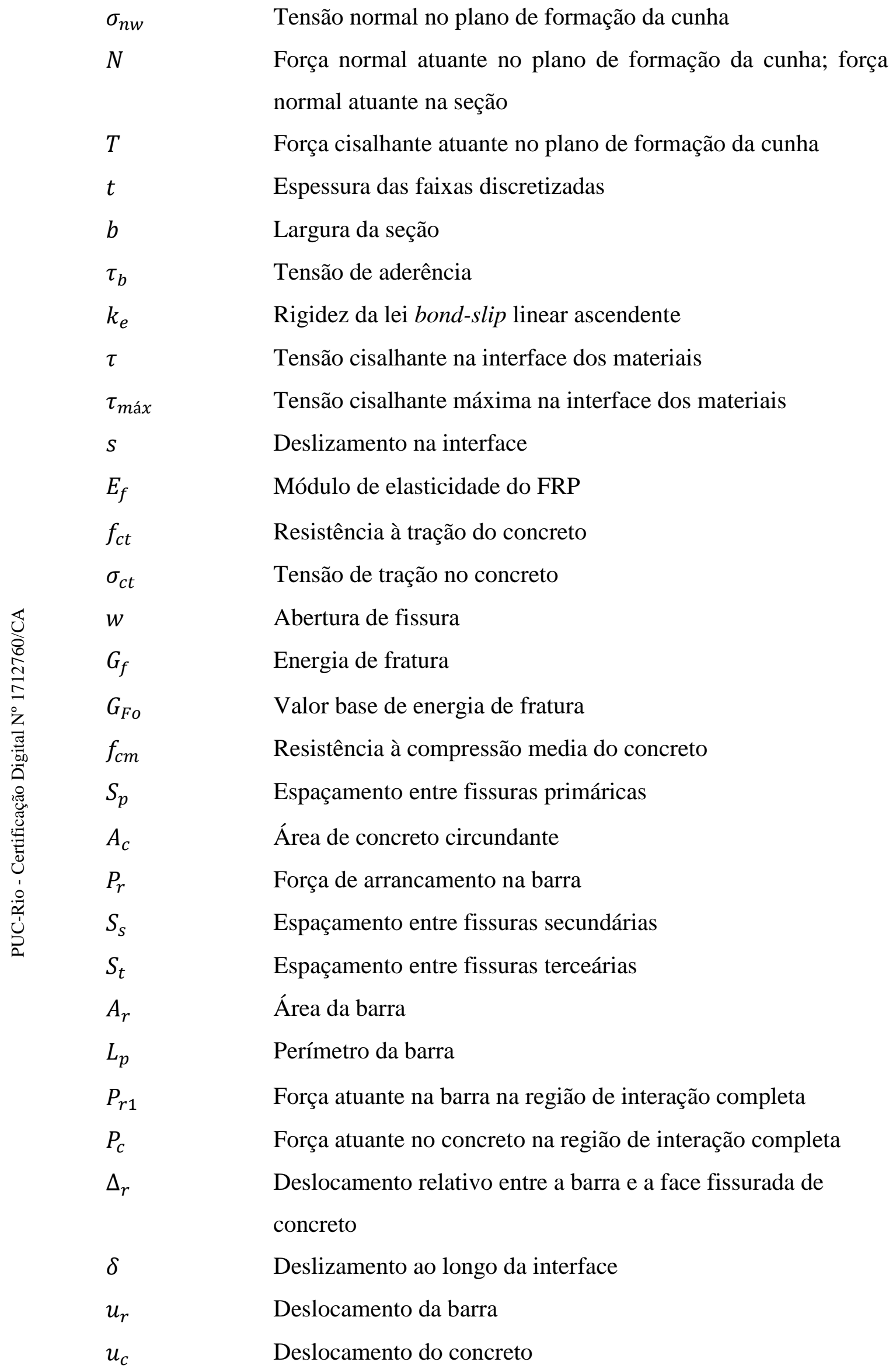


$\sigma_{r}$

$E_{r}$

$E_{C}$

$\varepsilon_{r}$

$\varepsilon_{c}$

$P_{\text {fis }}^{\text {pri }}$

$P_{\text {fis }}^{\text {sec }}$

$P_{\text {fis }}^{\text {ter }}$

$P_{\text {cont }}$

$\sigma_{c t}(w)$

$P_{\text {cont }, 1}$

$P_{\text {cont }, 2}$

$P_{\text {cont }, 3}$

$x$

$f\left(x_{i}\right)$

$J\left(x_{i}\right)$

$\varepsilon_{0}$

$k$

$y$

$h$

$\varepsilon_{\text {sup }}$

$\varepsilon_{\text {inf }}$

$\varepsilon_{c i}$

$N_{R}$

$N_{c}$

$N_{r}$

$M_{R}$

$M_{C}$
Tensão na barra

Módulo de elasticidade da barra

Módulo de elasticidade do concreto

Deformação específica na barra

Deformação específica no concreto

Força necessária para abertura de fissuras primárias

Força necessária para abertura de fissuras secundárias

Força necessária para abertura de fissuras terceárias

Força de contribuição do concreto à tração entre fissuras

Tensão de tração no concreto em função da abertura de fissura

Força de contribuição do concreto à tração considerando o

surgimento de fissuras primárias

Força de contribuição do concreto à tração considerando o

surgimento de fissuras secundárias

Força de contribuição do concreto à tração considerando o

surgimento de fissuras terceárias

Vetor de incógnitas

Função vetorial

Matriz Jacobiana

Deformação específica no centro geométrico da seção

Curvatura da seção

Distância de uma fibra qualquer até o centro geométrico da seção

Altura da seção

Deformação específica no topo da seção

Deformação específica na base da seção

Deformação específica em uma faixa $i$ discretizada de concreto

Esforço normal resistente da seção

Esforço normal resistente referente à parcela do concreto

Esforço normal resistente referente à parcela da armadura

Momento fletor resistente da seção

Momento fletor resistente referente à parcela do concreto 
$M_{r} \quad$ Momento fletor resistente referente à parcela da armadura

$\sigma_{r i} \quad$ Tensão da armadura na camada analisada

$A_{r i} \quad$ Área da armadura na camada analisada

$y_{r i} \quad$ Altura de cada camada analisada em relação à origem dos eixos cartesianos

$\overline{E A} \quad$ Rigidez axial não linear da seção

$\overline{E S} \quad$ Rigidez transversal não linear da seção

$\overline{E I} \quad$ Rigidez flexional não linear da seção

$E A_{c} \quad$ Rigidez axial referente à parcela do concreto

$E S_{c} \quad$ Rigidez transversal referente à parcela do concreto

$E I_{c} \quad$ Rigidez flexional referente à parcela do concreto

$E A_{r} \quad$ Rigidez axial referente à parcela da armadura

$E S_{r} \quad$ Rigidez transversal referente à parcela da armadura

$E I_{r} \quad$ Rigidez flexional referente à parcela da armadura

p Tolerância

$\Delta x \quad$ Tamanho da discretização do elemento

$n \quad$ Quantidade de trechos da discretização

$L \quad$ Comprimento da viga

$w_{i} \quad$ Peso elástico

$\varepsilon_{r i}$

Deformação específica na camada da armadura analisada

$\varepsilon_{c r}$

Deformação específica necessária para abertura de fissura

Incremento de rotação

$d_{L N}$

Distância do topo da seção até a linha neutra

$q$

Número de faixas discretizadas na seção

$d_{s i} \quad$ Distância do topo da seção até a camada de armadura

$w_{c} \quad$ Abertura de fissura na posição da faixa de concreto discretizada

$\Delta_{c} \quad$ Deslizamento na posição da faixa de concreto discretizada

$d_{i} \quad$ Distância do topo da seção até à faixa discretizada

$d_{c r} \quad$ Distância do topo da seção até a ponta da fissura

$\varepsilon_{f i c} \quad$ Deformação específica fictícia na faixa pertencente à cunha

$z_{c} \quad$ Braço de alavanca para o esforço normal referente ao concreto

$z_{r} \quad$ Braço de alavanca para o esforço normal referente à armadura 


\section{Introdução}

A análise comportamental das estruturas de concreto armado tem sido objeto de estudo a partir de diversas abordagens. Algumas destas podem se tornar não triviais, principalmente devido à complexidade dos materiais constituintes, sobretudo do comportamento não linear do concreto. A correta análise desses elementos demanda cautela para representar da forma mais realística um modelo analítico ou numérico. Isso se deve a fenômenos complexos de serem tratados, por vezes sendo negligenciados nas análises corriqueiras de projeto.

Dois importantes fenômenos, geralmente ignorados, são a contribuição do concreto entre fissuras na rigidez global de um elemento estrutural e da formação de cunhas de concreto na capacidade de deformação residual de um elemento.

Neste trabalho, uma abordagem baseada em deslocamentos, chamada momento-rotação $(M-\theta)$, é estudada. A mesma incorpora os dois fenômenos supracitados, possibilitando desenvolver a implementação de um modelo mecânico para análise estrutural de vigas de concreto. Essa incorporação é permitida graças às formulações de dois mecanismos de interação parcial: o mecanismo de enrijecimento à tração e o mecanismo de amolecimento do concreto.

\section{1. \\ Motivação}

A engenharia estrutural vem evoluindo ao longo dos anos e adaptando-se ao surgimento de novos materiais, a fim de atender às mais diferentes demandas como maior durabilidade, redução de peso e consumo de materiais, transparência eletromagnética etc. Dentre as inovações disponíveis em estruturas de concreto armado, é possível citar a incorporação de fibras metálicas, sintéticas ou naturais ao concreto, a substituição de armaduras convencionais de aço por armaduras não metálicas de polímero reforçado com fibras - PRF (do inglês, Fiber Reinforced Polymer, FRP) ou por tecidos, além do uso de concretos de alto e ultra-alto desempenho. Um dos maiores desafios nesse avanço da indústria está associado 
com a necessidade do desenvolvimento de modelos mecânicos que permitam incorporar os diversos mecanismos observados e explicar de forma fiel o comportamento de elementos estruturais feitos com esses novos materiais, dando suporte ao desenvolvimento de prescrições normativas seguras.

Desenvolver tais modelos pode não ser uma tarefa tão simples, visto que esses novos materiais podem apresentar, além de um comportamento não linear, diagramas tensão-deformação com trechos de amolecimento, podendo ainda apresentar fraca aderência entre as interfaces dos materiais constituintes, levando em conta mecanismos não antes retratados em um modelo mecânico habitual.

Alguns importantes mecanismos presentes em estruturas de concreto armado são os mecanismos de interação parcial, que permitem retratar os deslizamentos relativos entre as faces do concreto separadas por uma fissura ou entre o concreto e a barra. Esses dois fatores podem influenciar no comportamento global de um elemento estrutural.

É possível observar efeitos da interação parcial em elementos de concreto fissurados ou sujeitos à formação de rótula plástica, por exemplo, como mostra a Figura 1. Esses efeitos da interação parcial podem afetar a avaliação do comportamento à flexão, ao cisalhamento e axial de elementos de concreto, sendo seu estudo de grande relevância para um entendimento mais amplo sobre o comportamento estrutural. A representação desses mecanismos pode ser feita por meio de diversos modelos, variando de acordo com o grau de refinamento desejado, o que leva a diferentes níveis de eficiência e confiabilidade.

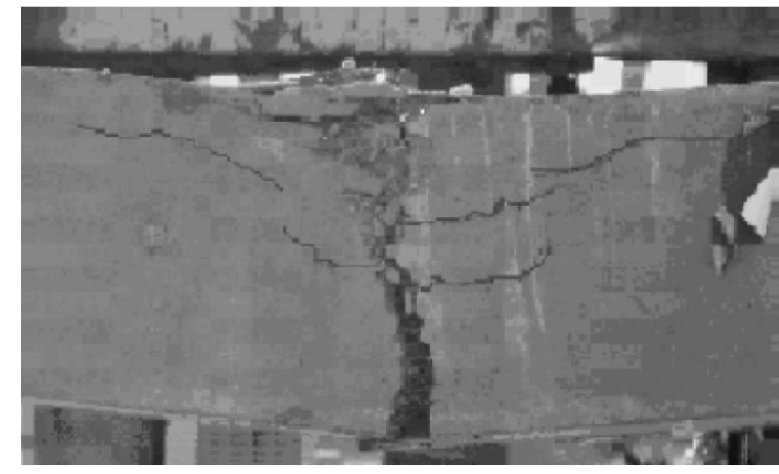

a)

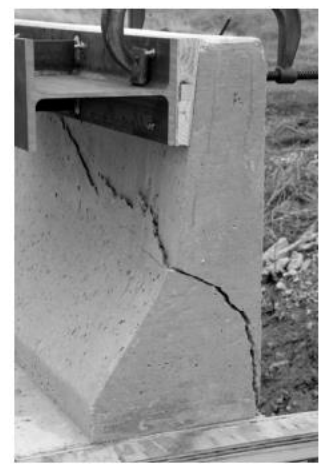

b)

Figura 1. a) Rótula plástica formada (Haskett et al., 2009.a); b) Fissura em elemento de concreto armado (Murray et al., 2007) 
De acordo com Oehlers et al. (2017), existem modelos empíricos, semiempíricos, mecânicos numéricos e mecânicos de fórmula fechada. Nos modelos empíricos ou semi-empíricos, são necessários ensaios para avaliar a resistência do elemento ou parâmetros de grande influência no mesmo, ficando todo estudo e desenvolvimento de normas vinculados às condições fixadas nesses ensaios. Já os modelos mecânicos são aqueles que representam o comportamento das estruturas tal como na realidade mediante o uso de formulações e independente de fatores empíricos, sendo necessário apenas ensaios para determinação das relações constitutivas dos materiais.

Para a avaliação da rigidez de elementos de concreto armado, o modelo mecânico numérico comumente utilizado é expresso em termos da relação momento-curvatura $(M-1 / r)$ em uma dada seção transversal. Esse modelo é baseado em uma interação completa, ou seja, leva em consideração a perfeita aderência entre os materiais constituintes e é amplamente utilizado para previsão do comportamento de uma dada seção fissurada em elemento de concreto armado. No entanto, esse modelo não leva em consideração a influência do concreto entre fissuras na rigidez à flexão de um elemento estrutural e o deslizamento na interface concreto-barra, sendo incapaz de fornecer resultados confiáveis acerca de deflexão e aberturas de fissuras. Além disso, esse modelo não incorpora, de maneira adequada, o comportamento de concretos com fibra, cuja relação constitutiva à tração é definida em termos de resistência residual versus abertura de fissura (MODEL CODE, 2010; RILEM TC 162-TDF, 2002).

Alguns modelos semi-empíricos foram formulados para levar em conta a fissuração, como por exemplo, a proposta de uma rigidez efetiva à flexão de Branson (1977). Porém, de acordo com Oehlers et al. (2017), esses modelos semiempíricos, por estarem vinculados a pelo menos um parâmetro oriundo de ensaio experimental, possuem aplicações limitadas, que em geral são contornadas com o uso de coeficientes e fatores adicionais de segurança.

A simulação adequada desses mecanismos só pode ser feita por meio de modelos mecânicos numérico ou de fórmula fechada. Mecanismos de interação parcial como o enrijecimento à tração (do inglês, tension-stiffening), o descolamento junto à fissura intermediária (do inglês, intermediate crack debonding), o deslizamento por cisalhamento (do inglês, shear-sliding) e o amolecimento do concreto (do inglês, concrete softening) vêm sendo base de 
desenvolvimento de diversos estudos, como os realizados em Muhamad et al. (2012), Seracino, Raizal e Oehlers (2007), Lucas et al. (2012), Visintin (2012), Oehlers et al. (2012b) e Oehlers et al. (2014a). Retratar esses mecanismos pode levar a um modelo mecânico completo que seja capaz de reproduzir o comportamento estrutural de forma mais realista.

O modelo mecânico baseado em uma abordagem momento-rotação surge, portanto, como uma alternativa ao modelo momento-curvatura, já que consegue representar os mecanismos de enrijecimento à tração e de amolecimento do concreto.

\section{2.}

\section{Objetivos}

Objetiva-se, neste trabalho, o estudo e a implementação de um modelo para análise de vigas de concreto armado por meio da abordagem momento-rotação, que é capaz de representar diferentes materiais e interfaces, seguindo principalmente as propostas de Haskett et al. (2009a), Ali et al. (2012) e Taheri e Barros (2012).

Para uma implementação consistente, são necessários definir alguns objetivos específicos:

- Apresentar os conceitos básicos necessários para fundamentar a abordagem momento-rotação;

- Apresentar uma implementação do modelo de interação completa, momentocurvatura, de modo a possibilitar uma comparação com o modelo momentorotação implementado;

- Apresentar a implementação do modelo baseado na abordagem momentorotação;

- Implementação de um algoritmo para análise estrutural de vigas;

- Validação dos resultados oriundos da análise baseada na abordagem momento-rotação mediante a comparação com os resultados experimentais;

- Avaliação da rigidez, da capacidade resistente e da flexibilidade devido a incorporação dos mecanismos de interação parcial. 


\section{3.}

\section{Estrutura da dissertação}

O presente trabalho está estruturado em seis capítulos, a fim de apresentar a abordagem momento-rotação e sua devida implementação. O capítulo 1 é constituído dessa introdução.

No capítulo 2, é apresentada uma breve revisão da literatura a respeito dos mecanismos de interação parcial e das relações bond-slip, além das relações constitutivas dos materiais e do método numérico utilizado neste trabalho.

No capítulo 3, são apresentadas as implementações dos modelos de interação parcial e completa, além de uma implementação para análise não linear de vigas.

No capítulo 4, os resultados obtidos do modelo principal são apresentados, analisados e comparados com os resultados dos modelos baseados em interação completa e com os obtidos dos ensaios experimentais.

No capítulo 5, são apresentadas as principais conclusões obtidas desta pesquisa, além das sugestões para trabalhos futuros. 


\section{2 \\ Revisão da Literatura e Conceitos Fundamentais}

Nesse capítulo são abordados conceitos fundamentais para avaliação do comportamento de vigas, com ênfase em concreto armado com barras de aço e FRP, fazendo uma breve referência aos modelos tradicionais e descrição das relações constitutivas básicas e características relevantes dos materiais. Apresenta-se também uma revisão dos trabalhos anteriores a respeito deste tema e abordam-se os mecanismos a serem considerados no modelo mecânico apresentado no presente trabalho.

\section{1.}

\section{Considerações Iniciais}

A avaliação do comportamento não linear de elementos de concreto armado com barras de aço estrutural submetidos à flexão simples ou composta vem sendo tradicionalmente realizada a partir de diagramas momento-curvatura, que permitem avaliar a degradação da rigidez seccional com o aumento da curvatura. A utilização desses diagramas é normalmente suficiente para a análise das seções mais solicitadas quando a aderência entre os constituintes é elevada, sendo possível assumir uma aderência perfeita, ou seja, realizar uma análise considerando interação completa entre materiais.

Com o crescente emprego de materiais de reforço, como as barras de FRP, estudos sobre tratamento e conformação superficial, as leis de aderência na interface concreto-FRP têm sido o foco de diversas pesquisas, visando uma melhor compreensão acerca dessa interface e, consequentemente, o uso adequado do material. Assim, há a necessidade de adoção de modelos mecânicos que possam incorporar esses efeitos de deslizamento na interface entre materiais, ou seja, um modelo que se fundamentasse em mecanismos de interação parcial.

A avaliação da rigidez e da ductilidade em elementos de concreto armado está relacionada às mudanças que podem ocorrer na seção do elemento, como a introdução de um novo elemento de reforço, perda da seção bruta de concreto e 
efeitos de fluência e retração. Devido à baixa resistência do concreto à tração e por ser um material altamente não linear, os elementos de concreto armado apresentam formação de fissuras para níveis baixos de solicitações. Essa formação de fissuras e o espaçamento entre elas altera a rigidez global da estrutura.

De acordo com Muhamad et al. (2012), o espaçamento, a formação e o alargamento dessas fissuras, além dos deslocamentos em elementos fissurados, podem ser determinados por meio do mecanismo de interação parcial de enrijecimento à tração. Esse mecanismo é estabelecido a partir da simulação de um ensaio de tração em prismas, no qual um conjunto de considerações são feitas de modo a determinar o espaçamento entre fissuras, a abertura de fissuras, o deslizamento relativo na face fissurada, e, sobretudo, a principal informação do mecanismo que é a contribuição da porção do concreto entre as fissuras. Tal mecanismo é apresentado com maiores detalhes na seção 2.3.3.

Enquanto que, para um elemento fletido, na região tracionada ocorre formação de fissuras, na região comprimida existe a possibilidade de surgir outro fenômeno de interação parcial que impacta na rigidez do elemento, que é a formação de cunhas de concreto. Na da Figura 2, é possível visualizar que a formação da cunha é formada em situações de compressão, quando o concreto atinge sua tensão de pico $\left(\sigma_{c c, p}\right)$, ou seja, no trecho descendente da relação tensãodeformação do concreto à compressão. Uma vez formada, passa a ocorrer um deslizamento no plano de formação dessa cunha, que resulta na redução das forças internas atuantes nesse plano de deslizamento, dando origem ao amolecimento do concreto (Taheri e Barros, 2012). A atuação dessas forças internas na cunha de concreto pode ser explicada por meio da teoria atrito-cisalhamento, como será visto mais a diante. 


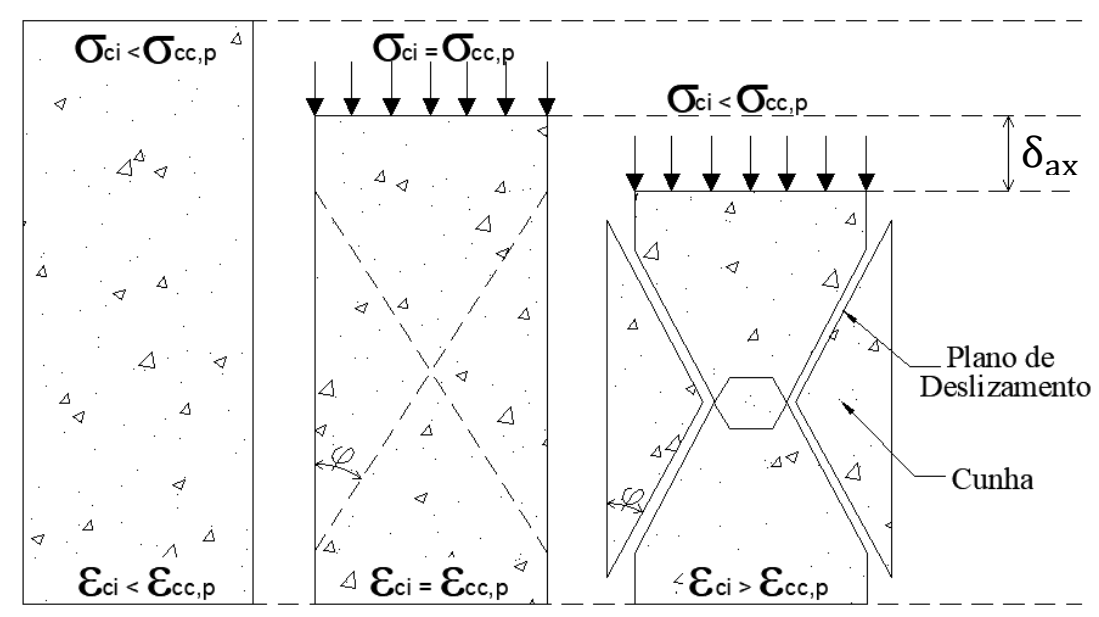

Figura 2. Formação de cunha de concreto

Portanto, para abordar esses mecanismos de deslizamentos, tanto na face fissurada quanto no plano de formação de cunha, diversos modelos empíricos e mecânicos vêm sendo analisados. Estudos como os de Oehlers, Liu e Seracino (2005) e Visintin et al. (2012) foram realizados para compreender o comportamento global de um elemento de concreto armado após a formação de múltiplas fissuras, e além disso, apresentaram conclusões relevantes a respeito da formação de fissuras, e da subsequente formação de rótulas plásticas. No estudo de Oehlers et al (2011b), é apresentado como alguns autores empregam a abordagem bidimensional de momento-curvatura, integrada num comprimento de rótula obtido empiricamente, para realizar uma análise tridimensional de elementos de concreto armado e avaliar a capacidade de rotação de rótulas e de sua interferência no comportamento global de tais elementos.

Já no estudo de Muhamad et al. (2012), os mecanismos de deslizamento e de enrijecimento à tração são descritos em detalhes, sendo propostas expressões para a força necessária para formações de fissuras primárias, secundárias e terciárias, além de relações para deslizamento e abertura de fissuras para diferentes leis bondslip. Já no trabalho de Muhamad et al. (2011) apresenta-se um modelo mecânico de fórmulas fechadas e um modelo numérico para simular a relação entre a força transferida para o barra e o deslizamento entre a barra e o concreto na face fissurada. Na pesquisa de Haskett et al. (2009b) foi estudada a influência da tensão de escoamento no comportamento global da relação. Por fim, Visintin (2012) usa a teoria atrito-cisalhamento para estudar o mecanismo de formação de cunhas que leva ao amolecimento do concreto. 
De modo a incluir os mecanismos de interação parcial em um modelo mecânico e possibilitar uma análise mais rigorosa, uma abordagem tridimensional baseada em deslocamentos, chamada momento-rotação, vem ganhando destaque em relação à abordagem bidimensional tradicional de momento-curvatura. Esse assunto foi objeto de estudo nos trabalhos de Haskett et al. (2009a), Ali et al. (2012), Taheri e Barros (2012) e Barros, Taheri e Salehian (2015), nos quais foram apresentados modelos mecânicos numéricos e de fórmula fechada, além de conceitos que fundamentam a abordagem, diferentes metodologias de aplicação e comparações com resultados experimentais. Os trabalhos supracitados ajudaram a nortear o presente estudo.

\section{2.}

\section{Relações Constitutivas dos Materiais}

A seguir são apresentadas as relações constitutivas adotadas no modelo mecânico apresentado neste trabalho.

\subsection{1.}

\section{Concreto}

A relação constitutiva tensão-deformação $(\sigma \times \varepsilon)$ para o concreto sob compressão adotada no modelo de interação completa apresentado no presente trabalho é a recomendada pela NBR 6118 (2014) conforme indica a Figura 3. Tal relação é formulada a partir de:

$$
\begin{gathered}
\sigma_{c}(\varepsilon)=\left\{\begin{array}{cc}
0, & \text { se } \varepsilon \leq 0 \\
f_{c}\left(1-\left(1-\frac{\varepsilon}{\varepsilon_{c 2}}\right)^{n}\right), & \text { se } 0<\varepsilon<\varepsilon_{c 2} \\
f_{c}, & \text { se } \varepsilon \geq \varepsilon_{c 2}
\end{array}\right. \\
\varepsilon_{c 2}=\left\{\begin{array}{cc}
2, & \text { se } f_{c} \leq 50 M P a \\
2+0,085\left(f_{c}-50\right)^{0,53}, & \text { se } 50 M P a<f_{c} \leq 90 M P a
\end{array}\right. \\
\varepsilon_{c u}=\left\{\begin{array}{cl}
3,5, & \text { se } f_{c} \leq 50 M P a \\
2,6+35\left(\frac{90-f_{c}}{100}\right)^{4}, & \text { se } 50 M P a<f_{c} \leq 90 M P a
\end{array}\right. \\
2, \quad \text { se } f_{c} \leq 50 M P a
\end{gathered}
$$


em que $\varepsilon_{c 2}$ é a deformação específica de compressão que corresponde à tensão de pico do concreto à compressão $\sigma_{c c, p}$ e início do patamar de plastificação e $\varepsilon_{c u}$ é a deformação específica última de compressão do concreto.

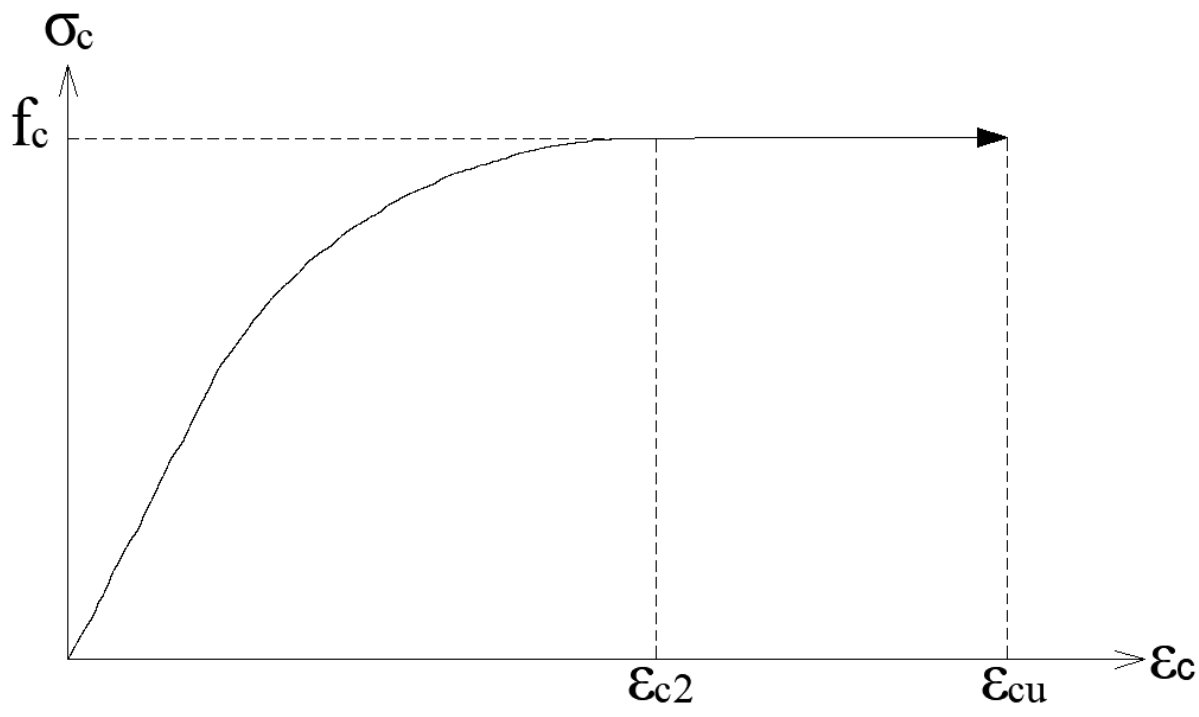

Figura 3.Diagrama tensão-deformação do concreto à compressão (Adaptado - NBR 6118:2014)

\subsection{2.}

\section{Aço Estrutural}

O modelo constitutivo idealizado para o aço estrutural é o sugerido pela norma brasileira, que é considerado bilinear com plasticidade perfeita, conforme apresentado na Figura 4.

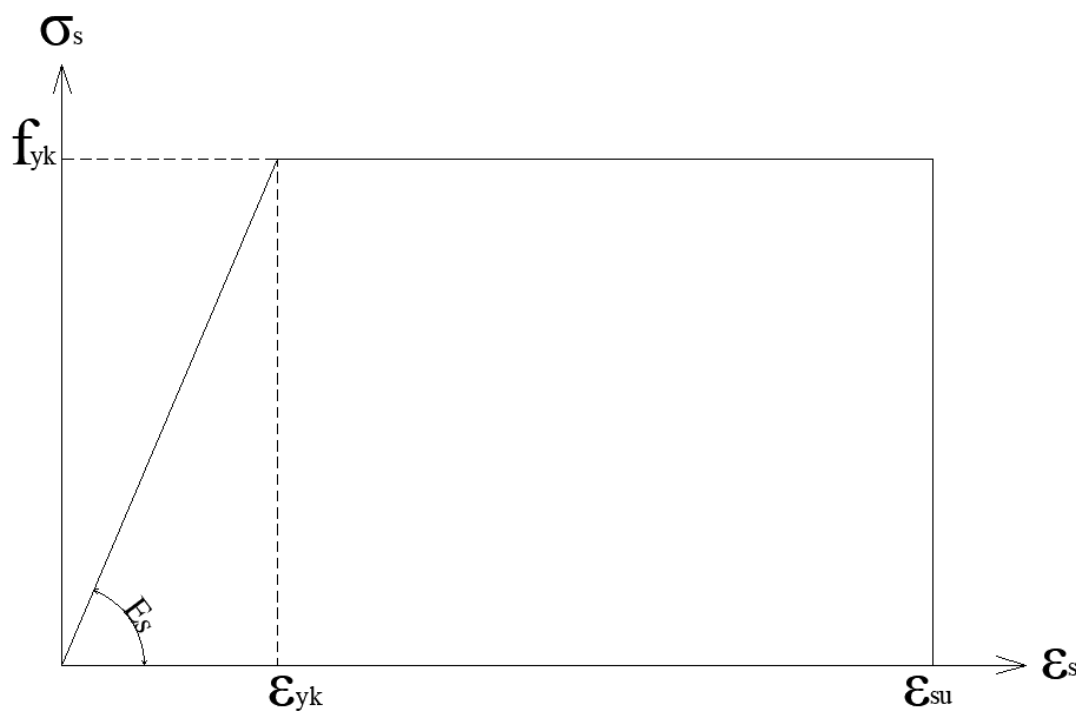

Figura 4. Diagrama tensão-deformação do aço à tração (Adaptado - NBR 6118:2014) 
As tensões atuantes na armadura $\left(\sigma_{s}\right)$ e a deformação específica de escoamento do aço $\left(\varepsilon_{y}\right)$ são dadas pelas equações (2.5) e (2.6):

$$
\begin{gathered}
\sigma_{s}(\varepsilon)=\left\{\begin{array}{l}
E_{s} \varepsilon, \quad \text { se }|\varepsilon| \leq \varepsilon_{y} \\
\frac{|\varepsilon|}{\varepsilon} f_{y}, \quad \text { se }|\varepsilon|>\varepsilon_{y}
\end{array}\right. \\
\varepsilon_{y}=\frac{f_{y}}{E_{s}}
\end{gathered}
$$

em que $f_{y}$ tensão de escoamento do aço e o módulo de elasticidade do aço, $E_{s}$.

\subsection{3.}

\section{Barras de FRP}

Os sistemas compostos de Polímero Reforçado com Fibra são formados pela união de uma matriz polimérica (fase contínua), geralmente resina epóxi, com a adição de fibras (fase dispersa) de alta resistência de um único material ou de dois ou mais materiais (FRP híbrido). São constituídos por uma determinada disposição e variação de volume de fibra, que governa diretamente propriedades como resistência e módulo de elasticidade, formando assim um material compósito não convencional, mas que vem ganhando interesse cada vez mais entre pesquisadores e adquirindo destaques em aplicações correntes na engenharia.

$\mathrm{Na}$ construção civil os sistemas compostos de FRP surgiram como uma alternativa de substituição ao aço, podendo ser usados no lugar de perfis metálicos, chapas metálicas e barras convencionais para armadura. As principais vantagens desses materiais podem incluir sua elevada relação resistência-peso, desempenho superior em ambientes agressivos, e transparência eletromagnética.

Dentre os FRPs mais utilizados na indústria da construção civil estão os compostos com fibras de Vidro (GFRP), Aramida (AFRP), Carbono (CFRP) e Basalto (BFRP). O CFRP possui as melhores propriedades mecânicas, porém é pouco acessível, pois seu processo de fabricação demanda maior custo. Nesse aspecto, o GFRP é o mais difundido, já que consegue reunir boas propriedades mecânicas e um custo acessível, constituindo a melhor relação custo-benefício dentre os materiais citados. O GFRP tem se destacado, pois consegue atingir resistências elevadas, cerca de 1,5 a 2 vezes maior que o aço, apesar de possuir um 
módulo de elasticidade inferior (cerca de 1/4 a 1/3), além de estar mais suscetível ao fenômeno de fluência e de perda de resistência para carregamentos de longa duração (GUDONIS et al., 2014).

O FRP é um material anisotrópico e possui característica de um material frágil, ou seja, seu comportamento é elástico-linear até a ruptura, não possuindo em sua lei constitutiva um patamar de plasticidade. Devido a isso, diversos estudos, como os de De Lorenzis, Galati e La Tegola (2004), Oehlers (2006) e Wang e Belarbi (2011) foram desenvolvidos acerca de alternativas para ductilidade de elementos de FRP.

A resistência à compressão das barras de FRP, quando imersa em matriz de concreto, também tem sido objeto de estudos. Deitz, Harik e Gesund (2003), realizaram uma campanha experimental para investigar a resistência à compressão e os modos de falha de barras de GFRP. No estudo, foi possível concluir que, para barras não esbeltas, a resistência à compressão é cerca de $50 \%$ da de tração, enquanto que os módulos de elasticidade para ambos são praticamente de mesmo valor. No estudo analítico de Choo, Harik e Gesund (2006) sobre colunas armadas com FRP, as propriedades à compressão das barras de FRP foram consideradas como sendo igual ao módulo de elasticidade e resistência à tração, sendo a metade destes, e por fim, sendo desconsiderada qualquer contribuição. Ao eliminar completamente essa contribuição, o autor afirma que é uma decisão muito conservadora na análise de elementos armados com FRP, porém por ausência de valores normativos, códigos internacionais têm recomendado desconsiderar tais propriedades à compressão. A Tabela 1 identifica valores de propriedades mecânicas para os tipos mais comuns de FRP e a Figura 5 apresenta o comportamento desses FRP à tração.

Tabela 1. Propriedades mecânicas à tração de barras de FRP - (Adaptada - Reis, 2009)

\begin{tabular}{lccc}
\hline \multirow{2}{*}{\multicolumn{1}{c}{ Propriedade }} & \multicolumn{3}{c}{ Material } \\
\cline { 2 - 4 } & CFRP & AFRP & GFRP \\
\hline Tensão tração (MPa) & 600 a 3690 & 1000 a 2540 & 450 a 1600 \\
\hline Módulo de elasticidade (GPa) & 100 a 580 & 40 a 125 & 35 a 60 \\
\hline Deformação última (\%) & 0.5 a 1.7 & 1.9 a 4.4 & 1.2 a 3.7 \\
\hline
\end{tabular}




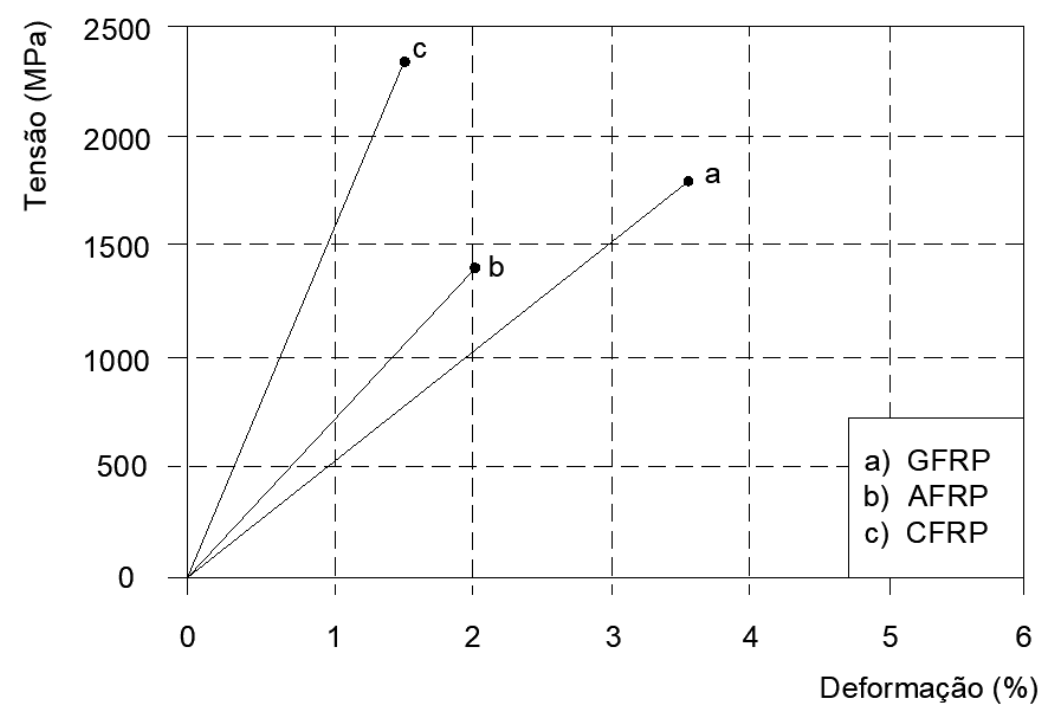

Figura 5. Diagrama tensão $\times$ deformação à tração para as principais barras de FRP (Adaptado FIB Bulletin 40, 2007)

Portanto, apesar de existir uma contribuição considerável à compressão do FRP, neste trabalho, optou-se em considerar apenas a lei constitutiva à tração, negligenciando assim qualquer contribuição vinda de propriedades compressivas.

\section{3.}

Abordagem Momento-Rotação

A abordagem momento-rotação trata-se de um modelo mecânico tridimensional baseado em deslocamentos, ou seja, considera que a seção transversal (face) fissurada está sujeita a rotações, fazendo o prisma idealizado (Figura 6), de comprimento $S$, deslocar-se de corpo rígido (deslocamento que envolve as três dimensões do prisma). Tal abordagem, diferentemente da análise bidimensional (deslocamentos no plano) de momento-curvatura, baseada em interação completa, permite a representação dos mecanismos de interação parcial. 


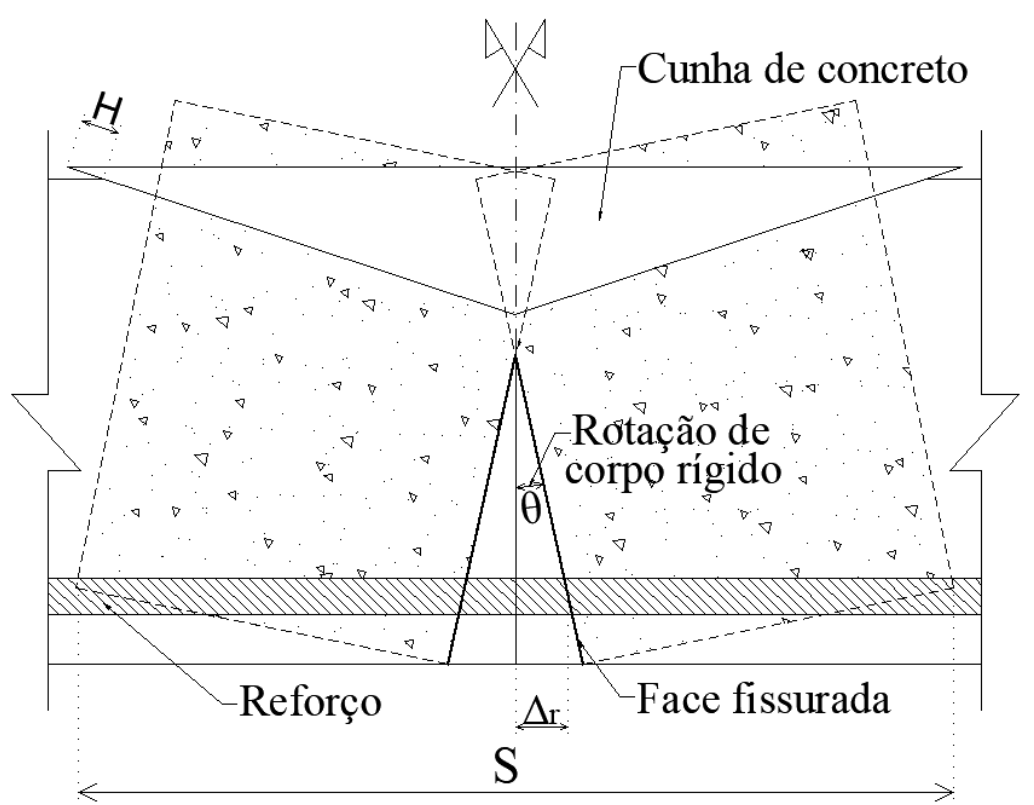

Figura 6. Mecanismo idealizado da rotação de corpo rígido do prisma de concreto

Com o surgimento das primeiras fissuras, o elemento de concreto passa a ter uma região perturbada delimitada pelo tamanho do prisma $(S)$ (Figura 6), sendo esse tamanho de prisma equivalente ao espaçamento entre fissuras. Na seção média desse comprimento de prisma está localizada uma fissura, na qual a face fissurada sofrerá incrementos de rotações, fazendo essa face deslocar-se de corpo rígido, sendo esses deslocamentos permitidos devido a possibilidade de deslizamento entre barra e concreto. Esses deslocamentos de corpo-rígido sofridos pela face fissurada governarão toda evolução de rotações incrementadas na abordagem.

Assim como na região de tração, há o deslocamento de corpo rígido da face fissurada na região de compressão, como já comentado, na qual pode haver o esmagamento do concreto e a formação de cunhas. Forma-se então um perfil linear constante de deformações na zona da cunha e um perfil linear para o trecho ascendente da curva tensão-deformação. Essas deformações são traçadas a partir de expressões baseadas em rotações sofrida pela face da fissura.

Segundo Oehlers et al. (2011b), antes de iniciar os mecanismos de interação parcial, a abordagem momento-rotação fornece exatamente os mesmos resultados de uma análise momento-curvatura, e que uma vez traçado um diagrama momentorotação, sua conversão em momento-curvatura equivalente pode ser facilmente realizada. 
A fundamentação do modelo mecânico de momento-rotação é idealizada na Figura 6 e é discutida por Haskett et al. (2009a); Ali et al. (2012); Haskett et al. (2009b); Muhamad et al. (2011); Taheri e Barros (2012); Visintin et al. (2012); Haskett et al. (2009c). Ela pode ser baseada em três princípios fundamentais: no deslocamento de corpo rígido da cunha em relação ao prisma de concreto e da face fissurada, e nos dois mecanismos de interação parcial: enrijecimento à tração e amolecimento do concreto (OEHLERS et al., 2011b).

Para que os mecanismos de interação parcial citados acima sejam bem retratados, os mesmos necessitam de propriedades adicionais de materiais, que são: a lei característica de aderência entre materiais na interface concreto-barra e as propriedades que regem o deslizamento de cunhas de concreto, obtidas por meio da teoria atrito-cisalhamento.

\subsection{1. Mecanismo de Amolecimento do Concreto}

A relação constitutiva do concreto à compressão é uma das propriedades mais importantes para qualquer modelagem estrutural, seja ela empírica ou mecânica. As propriedades do trecho ascendente $(\mathrm{O}-\mathrm{A})$ já estão bem definidas na literatura. Porém, para determinar as propriedades do trecho descendente, ou seja, do trecho de amolecimento do concreto, apresentado no trecho A-B da Figura 7, algumas pesquisas têm focado nesse assunto ao longo dos últimos anos.

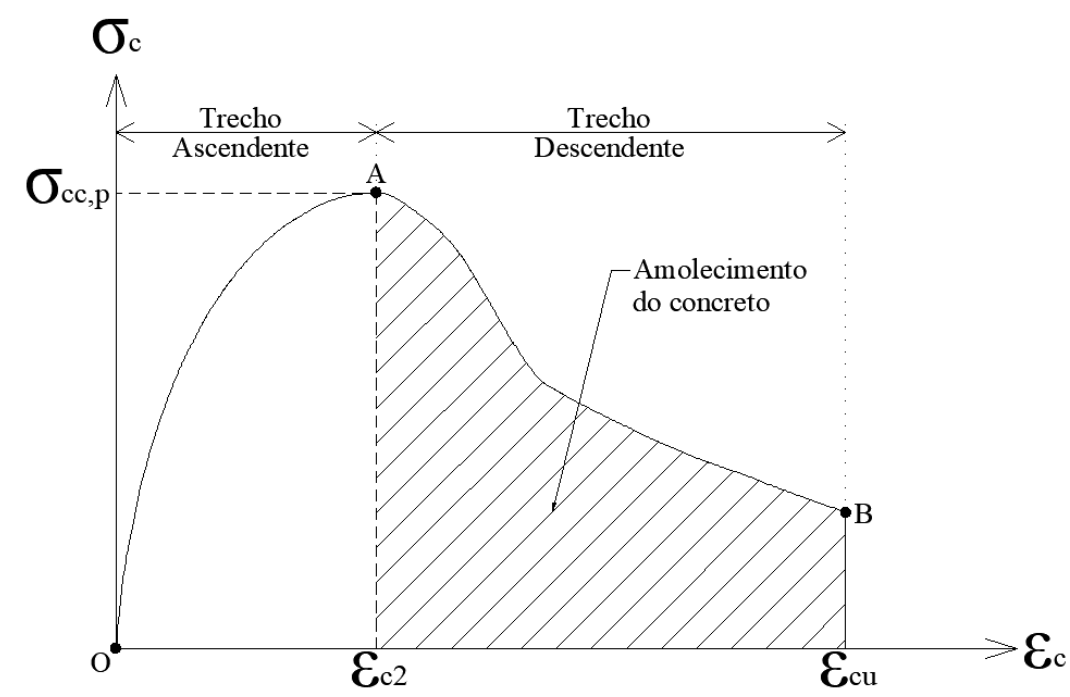

Figura 7. Trecho ascendente e descendente do concreto sob compressão. 
De acordo com Visintin (2012), essas propriedades do amolecimento do concreto podem ser obtidas com base na teoria atrito-cisalhamento, que é uma teoria já bem consolidada, em que formam-se cunhas de concreto delimitadas pela formação e alargamento de uma fissura localizada à uma inclinação de ângulo $\varphi$ formado com a vertical (Figura 8), determinado a partir da propriedade de atrito ( $m$ ) do critério de falha de Mohr-Coulomb no plano.

Devido a formação do plano da cunha de concreto, tem-se o surgimento de propriedades do amolecimento do concreto, como o deslizamento no plano deslizante, que corresponde ao deslocamento relativo tangencial $(H)$ no plano da cunha, e a abertura dessa fissura que delimita a cunha, que é dada como $H_{c r}$. Visintin (2012) afirma ainda que esses deslizamentos gradativos levam à redução da tensão axial do trecho descendente, devido a diminuição na capacidade de transferência de forças cisalhantes no plano deslizante. Com o aumento desses deslocamentos tangenciais, como é possível observar pela Figura 8, há o aumento também da contração axial $\left(\delta_{a x}\right)$, que por sua vez, é responsável pelo aumento da deformação axial no trecho de amolecimento do concreto. Sendo assim, Visintin (2012) afirma que essa deformação axial no trecho descendente é uma deformação efetiva dependente da contração axial sofrida por conta do surgimento de deslocamentos relativos no plano deslizante da cunha de concreto.

A determinação do deslocamento relativo tangencial $H$ pode ser feita conforme procedimento descrito por Taheri e Barros (2012). Esta depende da contração axial $\delta_{a x}$, do ângulo $\varphi$ e da abertura $H_{c r}$. Porém, devido ao insignificante valor de $H_{c r}$, a mesmo acaba sendo desconsiderado, como são apresentados nas expressões seguintes.

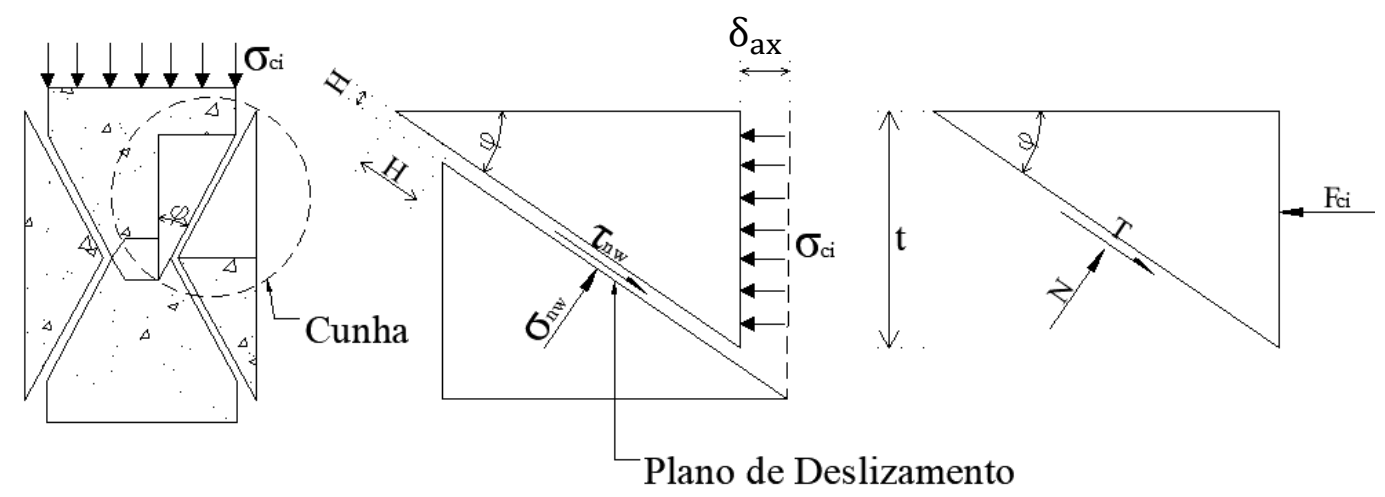

Figura 8. Elemento de concreto sob compressão e as forças atuantes no plano deslizante. 


$$
\begin{gathered}
H=\frac{\delta_{a x}}{\cos \varphi}+H_{c r} \tan \varphi \\
H=\frac{\delta_{a x}}{\cos \varphi}
\end{gathered}
$$

O ângulo $\varphi$ é determinado por intermédio da expressão (2.9), que depende do parâmetro de atrito $m$, determinado no estudo de Mattock (2001).

$$
\varphi=\arctan \left(-\mathrm{m}+\sqrt{\mathrm{m}^{2}}+1\right)
$$

O parâmetro $m$, segundo Haskett et al. (2011), varia entre 0,29 e 0,8; resultando em um ângulo $\varphi$ entre $26^{\circ}$ e $38^{\circ}$, sendo $37^{\circ}$ o valor para um concreto comum assumido nos trabalhos de Taheri e Barros (2012).

A Figura 8 mostra ainda outras propriedades do amolecimento do concreto além das já citadas $\left(H_{c r}\right.$ e $H$ ), que são a tensão cisalhante $\tau_{n w}$ e a tensão normal $\sigma_{n w}$ atuantes no plano da cunha. O estudo de Visintin (2012) desenvolveu expressões matemática para determinar essas propriedades em função da tensão de pico $\sigma_{c c, p}$ da relação $\sigma \times \varepsilon$ do concreto à compressão. Calcula-se a tensão de cisalhamento conforme apresentado por Haskett et al. (2011), considerando as unidades MPa e mm, respectivamente, para as tensões e comprimento:

$$
\tau_{n w}=\left[\left(-30,142+51,623 \frac{\sigma_{n w}}{\sigma_{c c, p}}\right) H\right]\left(\frac{\sigma_{c c, p}}{30}\right)^{0,91}+0,497 \sigma_{c c, p}
$$

De modo a garantir o equilíbrio de forças verticais atuantes no plano da cunha, como visto na Figura 8, tem-se:

$$
N=T \tan \varphi
$$

em que:

$$
\begin{aligned}
T & =\frac{\tau_{n w} t b}{\sin \varphi} \\
N & =\frac{\sigma_{n w} t b}{\sin \varphi}
\end{aligned}
$$


Portanto, substituindo (2.12) e (2.13) em (2.11) tem-se:

$$
\sigma_{n w}=\tau_{n w} \tan \varphi
$$

em que $T$ e $N$ são, respectivamente, as componentes de forças cisalhante e normal que atuam no plano da cunha, e $t$ e $b$ são a espessura e a largura, respectivamente, da parte da seção do elemento de concreto localizada dentro da região de uma cunha, ou seja, sujeita ao amolecimento do concreto.

Substituindo (2.14) em (2.10) é possível obter a expressão (2.15), que será utilizada neste trabalho.

$$
\tau_{n w}=\frac{\left(\frac{0,497 \sigma_{c c, p}}{H\left(\frac{\sigma_{c c, p}}{30}\right)^{0,91}}-30,142\right)}{H\left(\frac{\sigma_{c c, p}}{30}\right)^{0,91}-\frac{51,623 \tan \varphi}{\sigma_{c c, p}}}
$$

Portanto, de posse das forças internas atuantes na cunha, $T$ e $N$, como pode ser apresentado por Taheri e Barros (2012), é possível obter a força compressiva $F_{c i}$ (Figura 8), e consequentemente, a tensão compressiva $\sigma_{c i}$ pertencente ao trecho descendente da curva $\sigma \times \varepsilon$, inserindo desta forma, o mecanismo de interação parcial de amolecimento do concreto no modelo mecânico que será apresentado no capítulo 3.

\subsection{2.}

\section{Relações de Aderência - Curvas Bond-Slip}

O mecanismo de aderência entre dois materiais está atrelado à tensão cisalhante atuante nas superfícies de contato entre eles, ou seja, na interface entre esses materiais. Essa tensão cisalhante então, passa a ser chamada de tensão de aderência $\left(\tau_{b}\right)$, e a sua relação com os deslizamentos que ocorrem na interface pode ser influenciada por diversos parâmetros.

Modelos constitutivos para a relação entre tensão de aderência e deslizamento (bond-slip) são normalmente baseados nos resultados de ensaios de arrancamento (do termo inglês, pullout). O objetivo desse ensaio é registrar as forças mobilizadas 
ao longo do arrancamento de uma barra imersa em um bloco de concreto. No decorrer do ensaio, os deslizamentos relativos entre o bloco e a barra são medidos, sendo possível construir uma relação força-deslizamento. É importante mencionar que o ensaio de arrancamento permite obter uma tensão cisalhante média ao longo do comprimento, daí a necessidade de se utilizar barras de pequeno comprimento, evitando variações que possam influenciar na lei constitutiva.

Inúmeros estudos também se dedicaram a propor modelos analíticos ou numéricos de curvas bond-slip, como o estudo de Yankelevsky (1985), que propôs uma relação bond-slip composta por trechos lineares para estudar o arrancamento de uma barra de aço do concreto. No estudo, a barra de aço é dividida em trechos, nos quais cada um destes está sujeito a um nível diferente de carregamento e obedece a uma equação diferencial específica.

Estudos como o de Yankelevsky (1985) proporcionaram o desenvolvimento de inúmeros outros modelos e avaliação dos parâmetros de influência. Em Lin e Zhang (2014) é possível encontrar uma revisão dos principais modelos desenvolvidos. O modelo BPE, proposto por Bertero, Popov e Eligehausen (1983), é um dos principais estudos realizados e é base para o modelo atualmente recomendado pelo Model Code (2010). Tal modelo é ilustrado na Figura 9.

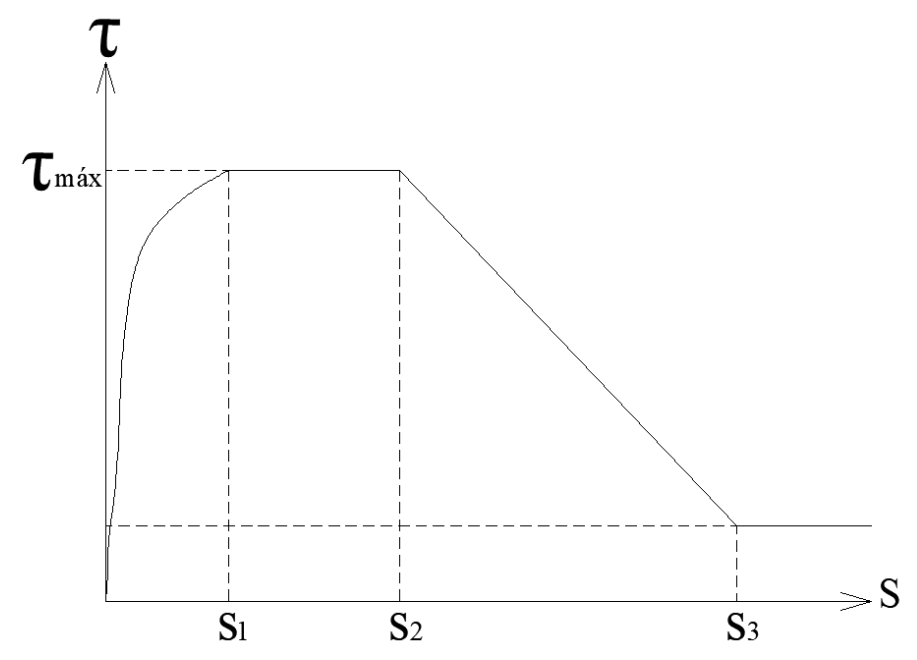

Figura 9. Relação bond-slip aço-concreto (Adaptado - Model Code, 2010)

Considerando situações em serviço, Taheri e Barros (2012) afirmam que é comum adaptar a curva bond-slip não linear e utilizar um modelo bond-slip idealizado linear ascendente, como mostra a Figura 10. 


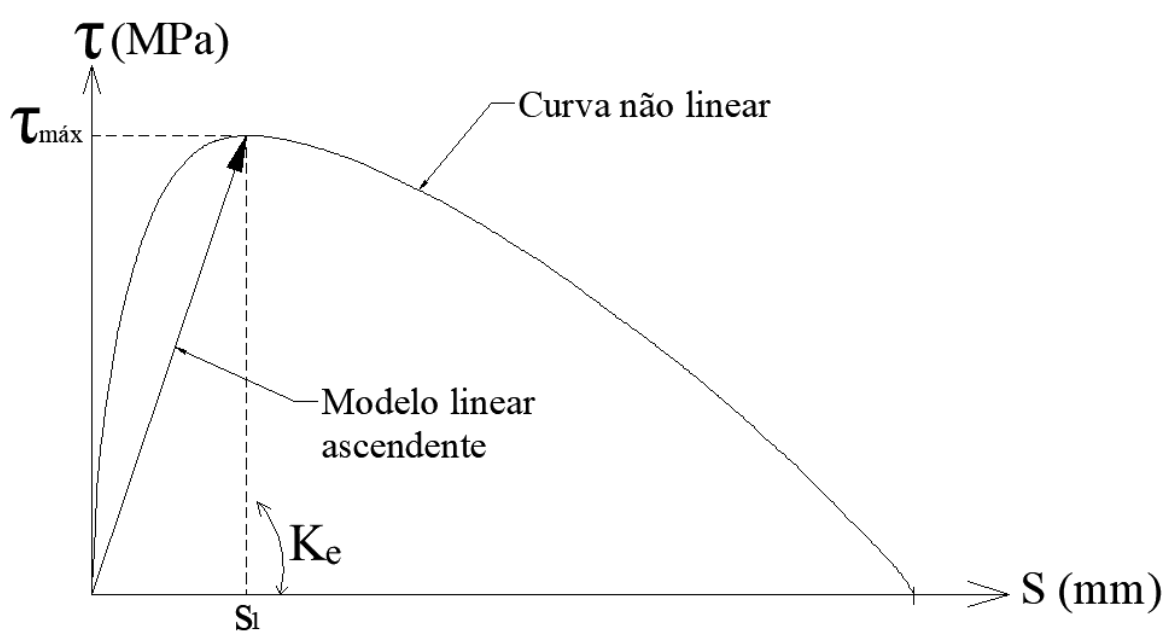

Figura 10. Modelo bond-slip linear ascendente idealizado (Adaptado - Taheri e Barros, 2012)

Esse modelo linear idealizado é definido por (2.16), cujo principal parâmetro é chamado de $k_{e}$.

$$
\tau=k_{e} s
$$

Com o surgimento e o desenvolvimento de diversas pesquisas com armaduras não-metálicas de FRP, surgiu a necessidade de estudos também buscando elaborar modelos bond-slip para a interface concreto-FRP que representassem bem o comportamento de aderência entre esses dois materiais.

Um dos primeiros modelos proposto para representar uma lei bond-slip para a interface concreto-FRP foi proposto por Malvar (1994). O modelo foi elaborado com base em dados de ensaios experimentais, em que algumas constantes do modelo foram avaliadas apenas para barras de GFRP.

Outro modelo proposto foi o $\mathrm{mBPE}$, que surgiu de uma modificação do modelo BPE original. Essa adaptação foi proposta por Cosenza, Manfredi e Realfonzo (1997), em que foi feita a calibração dos parâmetros, a partir de dados experimentais de elementos de concreto com barra de FRP. Os autores apresentam ainda um estudo sobre a influência de parâmetros, como tipo de fibra, resistência do concreto à compressão, conformação superficial e diâmetro da barra de FRP na lei bond-slip e identificam como atuam os mecanismos de aderência em cada tipo de barra de FRP. 
Um parâmetro importante para estudar a aderência concreto-FRP é o tratamento dado à superfície da barra. Barras retas lisas ou jateadas de areia tem seu mecanismo de aderência controlado por adesão no início do carregamento e depois pelo atrito entre materiais, que depende principalmente da rugosidade e do tipo de resina do FRP. Já as barras deformadas, com nervuras, por exemplo, tem sua aderência também influenciada pelo intertravamento mecânico, sendo então o módulo de elasticidade longitudinal da barra de FRP $\left(E_{f}\right)$ um parâmetro constitutivo de influência nesses casos (COSENZA; MANFREDI; REALFONZO, 1997).

Existe ainda o modelo CMR cujo trecho ascendente da curva bond-slip proposta, representa muito bem o comportamento real, sendo bem próximo do observado em ensaios experimentais, conforme é apresentado em Cosenza et al. (1995). Portanto, esse modelo pode ser também uma possibilidade interessante para situações em serviço.

Além dos estudos citados acima para barras de FRP embebidas no concreto, há ainda aqueles para representar a aderência para tiras ou barras de FRP inseridos no cobrimento do concreto (técnica Near Surface Mounted - NSM), como os de De Lorenzis, Rizzo e La Tegola (2002); Cruz e Barros (2004) e Ceroni et al. (2012).

De Lorenzis, Rizzo e La Tegola (2002) desenvolveram um vasto estudo experimental, variando comprimento de aderência, tamanho da ranhura, material de preenchimento e superfície da barra de FRP, para melhor entender a forma como eles afetam na aderência. Do seu estudo é possível obter uma curva típica bond-slip para sistemas NSM-FRP, como mostra a Figura 11. Já no estudo de Cruz e Barros (2004) variou-se o comprimento de aderência e a resistência do concreto à compressão e percebeu-se que, para baixas resistências do concreto à compressão, a resistência de aderência não sofre interferência. 


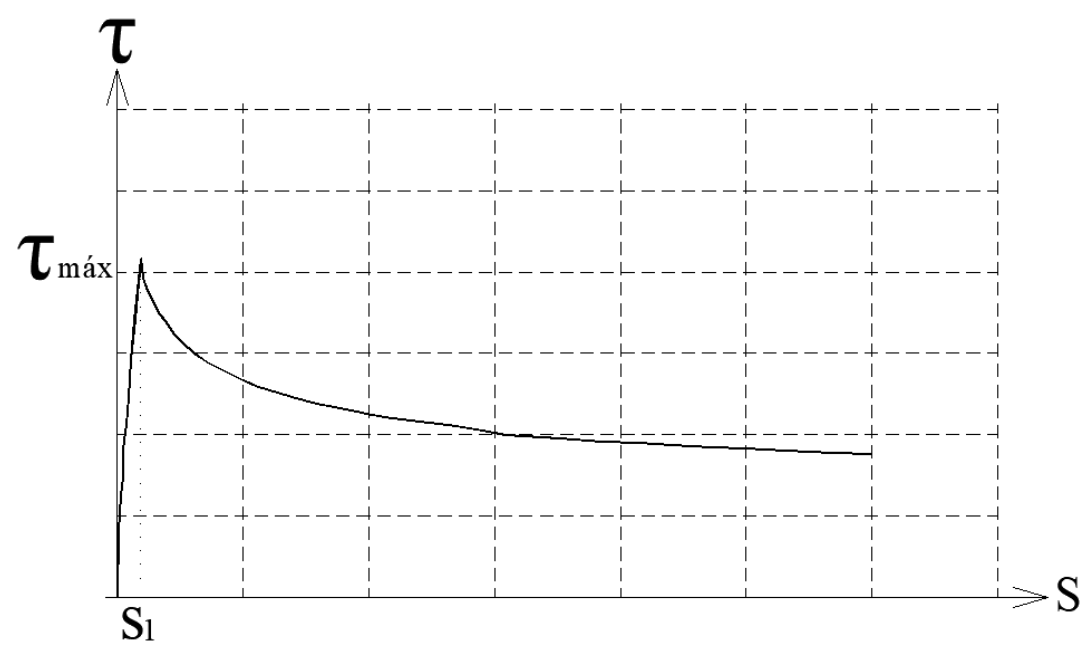

Figura 11. Curva bond-slip típica para sistemas de NSM-FRP (Adaptado - De Lorenzis, Rizzo e La Tegola, 2002)

Os trabalhos de De Lorenzis, Rizzo e La Tegola (2002) e Cruz e Barros (2004) concluíram que, para o trecho ascendente, os sistemas NSM-FRP são bem representados com a relação bond-slip da interface aço-concreto. Sendo assim, em situações de serviço, também é possível utilizar a aproximação para uma curva linear ascendente, tal como para a interface aço-concreto, desde que o parâmetro $k_{e}$ seja ajustado corretamente com base nos dados de ensaios.

\subsection{3. \\ Mecanismo de Enrijecimento à Tração}

O mecanismo de enrijecimento à tração, por meio de sua formulação baseada em um ensaio de tração em prisma de concreto, consegue avaliar de forma quantitativa a contribuição do concreto entre fissuras e, consequentemente, possibilita determinar o acréscimo de rigidez conferido a um elemento de concreto. Além disso, o mecanismo permite obter a abertura e espaçamento entre fissuras, e a identificar o estágio de formação e estabilização das mesmas.

Devido ao fato de ser um material altamente não linear, o concreto possui formação de fissuras para baixos níveis de carregamento, ou seja, possui uma fase de pré-fissuração (linear) muito curta, estando um elemento sujeito ao acréscimo de rigidez ainda em solicitações de serviço.

Esse mecanismo está diretamente associado com o deslizamento entre a barra e o concreto e à consequente abertura de fissuras. E como visto na seção anterior, 
esse deslizamento é considerado por meio da relação bond-slip da interface entre materiais.

Inúmeros estudos vêm sendo desenvolvidos acerca do mecanismo de enrijecimento à tração, com foco no comportamento de estruturas de concreto. Estudos baseados em modelos empíricos têm mostrado a importante contribuição deste efeito no comportamento de elementos de concreto armado com barras de aço convencional e com barras de FRP, como é o caso dos trabalhos de Abdalla (2002) e Sá (2018). Outros trabalhos como os de Gupta e Maestrini (1990), Russo e Romano (1992), Chan, Cheung e Huang (1993), Wu e Gilbert (2009) e Muhamad et al. (2012) apresentam a solução de equações diferenciais, sejam elas analíticas ou numéricas, para leis bond-slip específicas, sendo possível obter informações como espaçamento e abertura de fissuras e a influência do efeito enrijecimento à tração no comportamento global da estrutura.

Durante anos, esse mecanismo deixou de ser retratado em análises mecânicas de estruturas de concreto armado, levando a modelos nem sempre totalmente fiéis quanto a previsão de rigidez. Porém, pesquisas importantes emergiram acerca do assunto, como as de Chan, Cheung e Huang (1993), em que foi proposto um modelo mecânico de fissura incluindo o efeito enrijecimento à tração para estruturas de concreto. Já no trabalho de Wu e Gilbert (2009), os autores realizam uma modelagem numérica, baseada em elementos finitos, para incorporar leis bond-slip na interface concreto-aço e, então, avaliar a influência desse efeito nas deformações e tensões obtidas, além de apresentar os valores de abertura e espaçamento de fissuras que foram observados. No estudo de Gupta e Maestrini (1990), os autores apresentam o desenvolvimento das expressões necessárias com base em uma lei bond-slip com trecho bilinear e trecho constante para tratar o mecanismo. Enquanto que, no trabalho de Muhamad et al. (2012), são apresentadas as equações para leis bond-slip linear ascendente, ideal para retratar situações em serviço, linear descendente, não linear e para o modelo BPE. No Model Code (2010) é possível encontrar expressões que determinam o espaçamento e a abertura de fissuras a partir do uso de parâmetros empíricos.

Devido à baixa resistência à tração do concreto, os modelos mecânicos normalmente desprezam totalmente sua contribuição ou ignoram qualquer contribuição após o limite de resistência à tração $\left(f_{c t}\right)$, considerando apenas o trecho ascendente da lei constitutiva do concreto à tração, como mostra a Figura 12. 


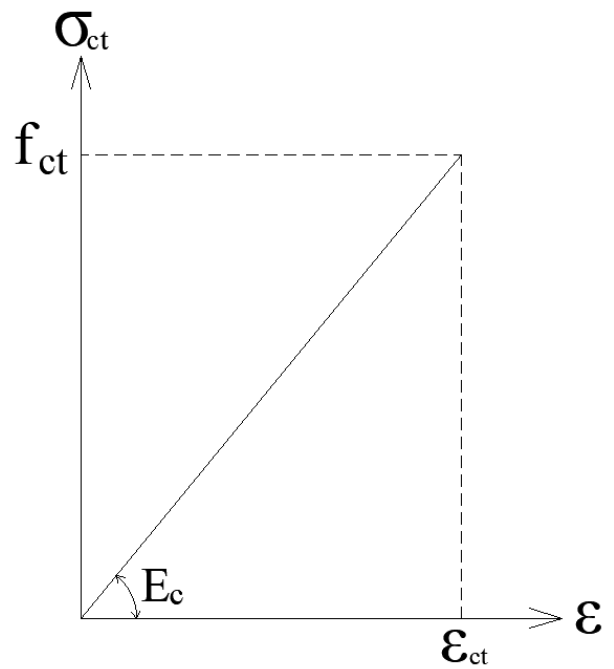

Figura 12 Relação tensão $x$ deformação para o concreto até o limite de resistência à tração

Como é possível encontrar em Gupta e Maestrini (1990), alguns modelos para o trecho descendente foram propostos para representar esse comportamento póspico, entretanto um modelo mais recente do FIB Bulletin 42 (2008) pode representar bem tal comportamento. Esse modelo é baseado no conceito de energia de fratura $\left(G_{f}\right)$ que, de acordo com o FIB Bulletin 42 (2008), é a energia necessária para propagar uma fissura de tração por unidade de área e é dada como uma propriedade do material para descrever as tensões de tração residuais a serem transferidas do concreto para a barra por intermédio da fissura. A equação retirada de FIB Bulletin 42 (2008) é apresentada a seguir.

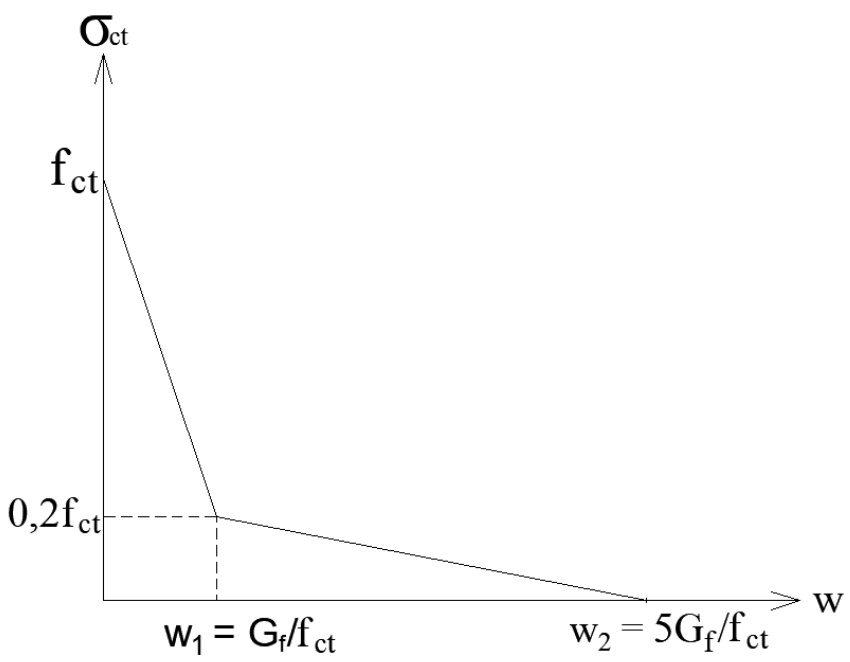

Figura 13. Tensão de tração $\times$ abertura de fissuras no concreto (Adaptado - FIB Bulletin 42, 2008) 


$$
G_{f}=G_{F o}\left(\frac{f_{c m}}{f_{c m o}}\right)^{0,18}
$$

em que $G_{F o}$ é o valor base de energia de fratura baseado no diâmetro máximo do agregado, segundo a tabela 3.2 do Model Code 1990 (1993), $f_{c m}$ é a resistência à compressão média do concreto e $f_{c m o}=10 \mathrm{MPa}$.

Sendo assim, para uma representação completa do comportamento à tração do concreto, o ideal e adotado nesse trabalho, é a utilização do trecho linear ascendente até que o concreto atinja seu limite de resistência. A partir desse limite, é considerada uma lei descendente, como a lei bilinear em função da abertura de fissura, como mostra a Figura 13.

A lei bond-slip linear ascendente (Figura 10), como já comentado anteriormente, pode ser utilizada no mecanismo de enrijecimento à tração. Tal mecanismo será apresentado a seguir baseando-se principalmente nos trabalhos de Muhamad et al. (2012), Taheri e Barros (2012) e Gupta e Maestrini (1990) para uma barra de qualquer material.

A Figura 14-a apresenta um prisma de concreto armado carregado axialmente sob tração uniforme; a Figura 14-b mostra a seção transversal do prisma evidenciando a área de concreto circundante $A_{c}$.

A barra está sujeita a uma força de arrancamento $P_{r}$, que induzirá um deslizamento regido pela lei bond-slip característica da interface concreto-barra. 

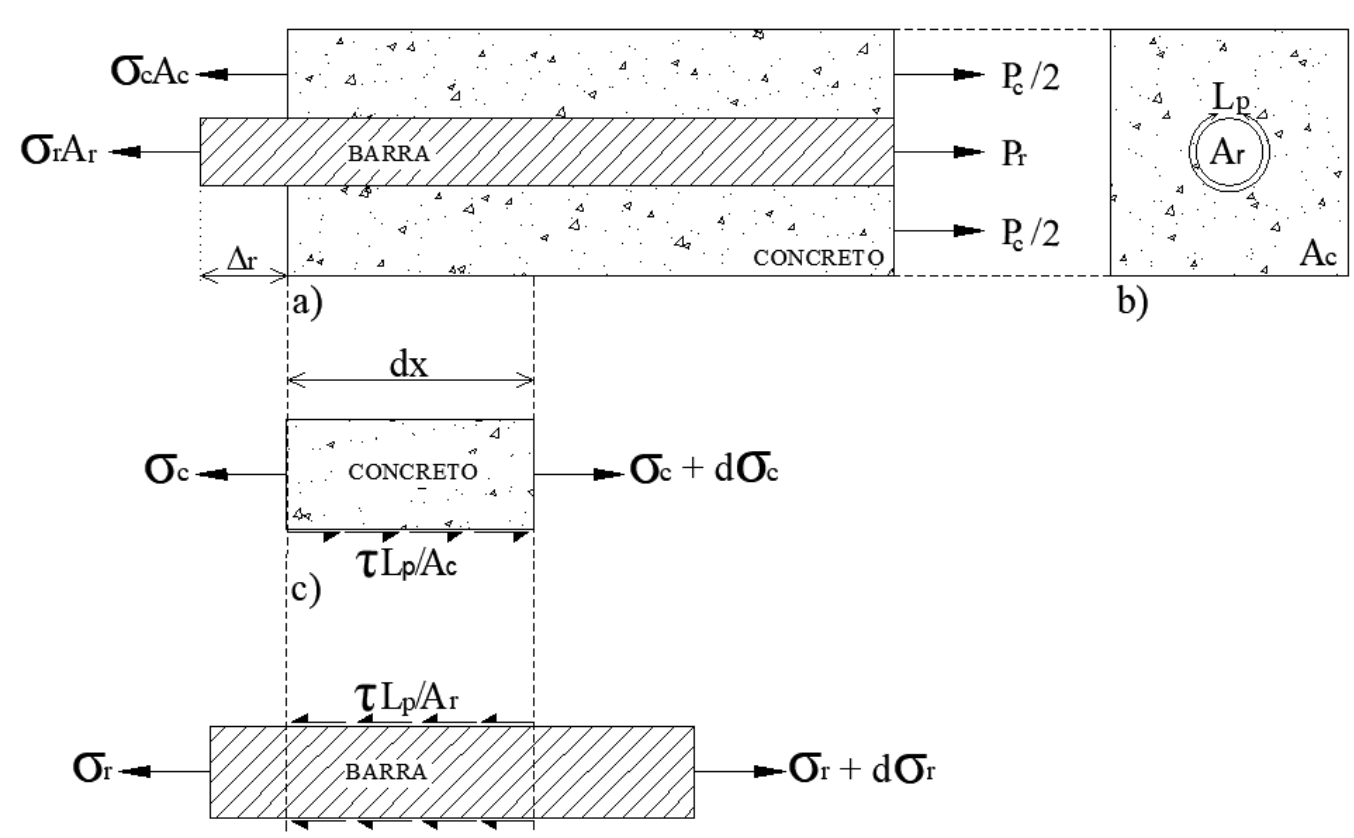

b)

d)

Figura 14. a) Prisma infinitamente longo; b) Seção transversal do prisma; c) Equilíbrio na interface do concreto; d) Equilíbrio na interface da barra (Adaptada - Muhamad et al., 2012)

De acordo com a Figura 14 o equilíbrio entre as forças atuantes no prisma e o equilíbrio nas interfaces da barra e do concreto são dados pelas expressões:

$$
\begin{gathered}
\sigma_{c} A_{c}+\sigma_{r} A_{r}=P_{r}+P_{c} \\
\frac{d \sigma_{r}}{d x}=\frac{\tau L_{p}}{A_{r}} \\
\frac{d \sigma_{c}}{d x}=-\frac{\tau L_{p}}{A_{c}}
\end{gathered}
$$

em que $A_{r}, A_{c}$ e $L_{p}$ são, respectivamente, a área da barra, a área do concreto circundante e o perímetro da barra. $P_{r}$ e $P_{c}$ representam as forças atuantes no prisma referente a barra e ao concreto, respectivamente.

O deslizamento $\Delta_{r}$ na Figura 14-a, é dado pelo deslocamento relativo entre a barra e a face fissurada de concreto.

$$
\Delta_{r}=\delta=u_{r}+u_{c}
$$

Diferenciando a expressão (2.21) com relação a $x$ : 


$$
\frac{d \delta}{d x}=\frac{d u_{r}}{d x}+\frac{d u_{c}}{d x}
$$

Do equilíbrio de uma barra carregada axialmente, tem-se que $\varepsilon=\frac{d u}{d x}$. Então, mediante a relação constitutiva para material linear, tem-se para a barra e o concreto:

$$
\begin{aligned}
& \sigma_{r}=E_{r} \frac{d u_{r}}{d x} \\
& \sigma_{c}=E_{c} \frac{d u_{c}}{d x}
\end{aligned}
$$

em que $E_{r}$ e $E_{c}$ são, respectivamente, os módulos de elasticidade da barra e do concreto. Substituindo as equações (2.23) e (2.24) em (2.22) e derivando mais uma vez com relação a $x$, tem-se:

$$
\frac{d^{2} \delta}{d x^{2}}=\frac{1}{E_{r}}\left(\frac{d \sigma_{r}}{d x}\right)-\frac{1}{E_{c}}\left(\frac{d \sigma_{c}}{d x}\right)
$$

E substituindo as expressões (2.19) e (2.20) em (2.25), tem-se:

$$
\frac{d^{2} \delta}{d x^{2}}=\frac{1}{E_{r}}\left(\frac{\tau L_{p}}{A_{r}}\right)+\frac{1}{E_{c}}\left(\frac{\tau L_{p}}{A_{c}}\right)
$$

Reorganizando a expressão (2.26) tem-se:

$$
\frac{d^{2} \delta}{d x^{2}}-\left[\frac{L_{p}}{A_{r}}\left(\frac{1}{E_{r}}+\frac{A_{r}}{E_{c} A_{c}}\right)\right] \tau=0
$$

Pode-se, portanto, introduzir um parâmetro $\beta$ dependente apenas das propriedades dos dois materiais, como:

$$
\beta=\frac{L_{p}}{A_{r}}\left(\frac{1}{E_{r}}+\frac{A_{r}}{E_{c} A_{c}}\right)
$$




$$
\frac{d^{2} \delta}{d x^{2}}-\beta \tau=0
$$

Com isso, tem-se a equação diferencial homogênea (2.29) que relaciona tensão de aderência e deslizamento. Esta é válida para qualquer relação bond-slip, desde que seja resolvida obedecendo às condições de contorno.

Para o caso particular de uma relação bond-slip linear ascendente (Figura 10) e expressão (2.16)), a EDO (2.29) pode ser reescrita da seguinte forma:

$$
\frac{d^{2} \delta}{d x^{2}}-\beta k_{e} \delta=0
$$

A solução da EDO é dada pela expressão (2.31) que representa o deslizamento relativo em função da posição:

$$
\delta(x)=A \cosh \left(\lambda_{1} x\right)+B \sinh \left(\lambda_{1} x\right)
$$

em que $A$ e $B$ são constantes de integração e $\lambda$ um parâmetro dependente apenas das propriedades dos materiais e do formato da lei bond-slip, definido como:

$$
\lambda^{2}=\beta k_{e}
$$

Substituindo a expressão (2.31) na expressão linear de bond-slip tem-se:

$$
\tau(x)=k_{e}[A \cosh (\lambda x)+B \sinh (\lambda x)]
$$

Diferenciando a equação de variação de deslizamento, tem-se:

$$
\frac{d \delta(x)}{d x}=\lambda A \sinh (\lambda x)+\lambda B \cosh (\lambda x)
$$

Para a solução das EDOs, deve-se definir as condições as condições de contorno, como mostra a figura a seguir: 


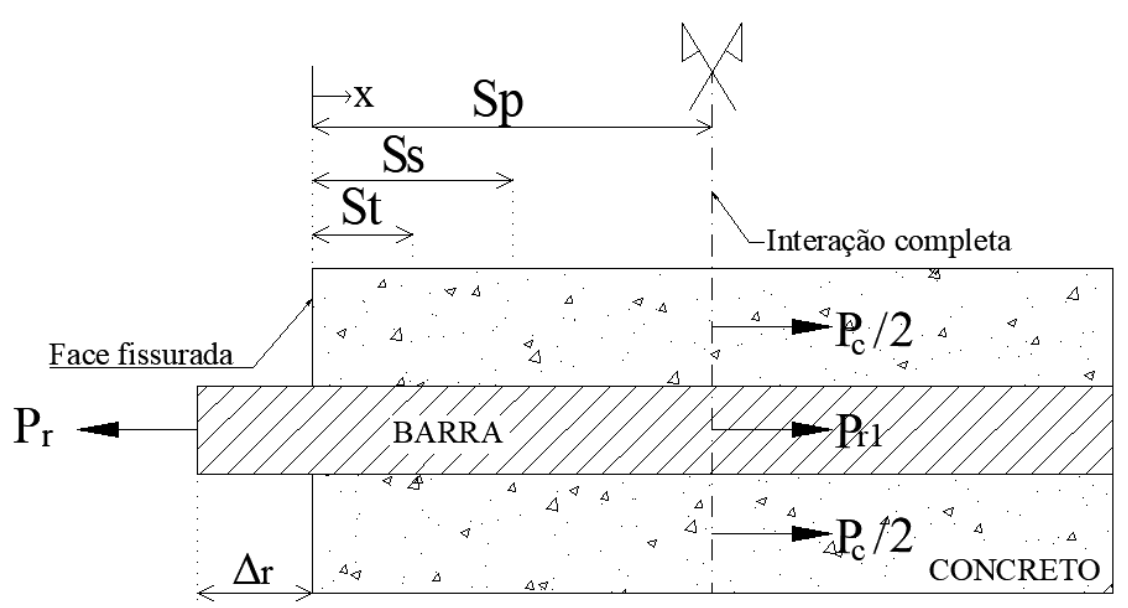

Figura 15. Condições de contorno (Adaptada - Muhamad et al., 2012)

Na Figura 15 é possível observar o comprimento $S_{p}$ (comprimento do prisma ou espaçamento entre fissuras primárias formadas) e também inferir duas condições de contorno. A primeira corresponde ao fato das deformações no concreto serem tão pequenas a ponto de serem negligenciadas junto à face fissurada $(x=0)$, de modo que:

$$
\frac{d u_{c}}{d x}=0
$$

Portanto, aplicando essa condição às expressões (2.22) e (2.23), tem-se:

$$
\frac{d \delta(0)}{d x}=\frac{d u_{r}}{d x}=\frac{\sigma_{r}}{E_{r}}=\frac{P_{r}}{A_{r} E_{r}}
$$

Substituindo (2.36) em (2.34), tem-se que a constante $B$ vale:

$$
B=\frac{P_{r}}{A_{r} E_{r} \lambda}
$$

A segunda condição está associado com o deslizamento e a diferença entre deformação nulos no centro do prisma $\left(x=S_{p}\right)$, de modo que: 


$$
\begin{aligned}
& \delta\left(S_{p}\right)=0 \\
& \frac{d \delta\left(S_{p}\right)}{d x}=0
\end{aligned}
$$

Considerando as condições de contorno citadas e substituindo o valor de $B$ em (2.31) e (2.34), tem-se:

$$
\begin{aligned}
& 0=A \cosh \left(\lambda S_{p}\right)+\frac{P_{r}}{A_{r} E_{r} \lambda} \sinh \left(\lambda S_{p}\right) \\
& 0=\lambda A \sinh \left(\lambda S_{p}\right)+\frac{P_{r}}{A_{r} E_{r}} \cosh \left(\lambda S_{p}\right)
\end{aligned}
$$

Resolvendo (2.40) e (2.41), obtêm-se os valores de $S_{p}$ e da constante $A$ :

$$
\begin{gathered}
S_{p}=\frac{2}{\lambda} \\
A=A_{p r}=-\frac{P_{r}}{A_{r} E_{r} \lambda \tanh 2}
\end{gathered}
$$

Com base na Figura 14-a, é possível concluir que na face fissurada atua a força $P_{r}$, enquanto que na posição de interação completa age $P_{r 1}$ e $P_{c}$, resultando na seguinte relação entre forças:

$$
P_{r}=P_{r 1}+P_{c}
$$

Por meio da Figura 14-c, é possível concluir que $P_{c}$ é igual à força de aderência ao longo do comprimento $S_{p}$, como mostra a expressão abaixo:

$$
P_{c}=\int_{x=0}^{x=S_{p}} \tau L_{p} d x=\sigma_{c t} A_{c}
$$

Considerando que $\sigma_{c t}=f_{c t}$, tem-se que $P_{c}$ seria a força necessária para abrir uma nova fissura no centro do prisma. Sendo assim: 


$$
P_{c}=P_{r}-P_{r 1}
$$

Tem-se ainda que, na posição de interação completa (centro do prisma), os materiais estão em aderência perfeita e, portanto, $\varepsilon_{r}=\varepsilon_{c}$, logo $P_{r 1}$ pode ser dado como:

$$
P_{r 1}=\frac{\sigma_{c}}{E_{c}} A_{r} E_{r}
$$

Em um prisma continuamente carregado, as fissuras continuam a surgir (estágio de formação de fissuras) até o momento em que não aparecem fissuras novas e as existentes se estabilizam (estágio de estabilização de fissuras) e passam apenas a apresentar aumento de sua abertura $(w)$. Portanto, considerando o prisma de tamanho $S_{p}$ (delimitação pelas fissuras primárias), submetido a um carregamento ainda no estágio de formação de fissuras, surgirá então a formação de uma fissura secundária $\left(S_{s}\right)$ localizada em $S_{s}=S_{p} / 2$, sendo portanto:

$$
S_{s}=\frac{1}{\lambda}
$$

Considerando as mesmas condições de contorno, porém com o surgimento dessa fissura secundária em uma posição intermediária do comprimento de prisma $S_{p}$, tem-se um novo valor para constate $A$, nomeada de $A_{\text {sec }}$.

$$
A_{\text {sec }}=-\frac{P_{r}}{A_{r} E_{r} \lambda} \tanh 1
$$

Estendendo a mesma ideia para a formação de uma fissura terciária localizada no ponto intermediário do comprimento de prisma $S_{S}$, tem-se então um novo prisma de tamanho $S_{t}=S_{s} / 2$, e também portanto, uma nova constante $A$, nomeada de $A_{\text {ter. }}$

$$
\begin{gathered}
S_{t}=\frac{1}{2 \lambda} \\
A_{\text {ter }}=-\frac{P_{r}}{A_{r} E_{r} \lambda} \tanh 0,5
\end{gathered}
$$


Substituindo a constante $A$ (levando em conta cada nível de formação de fissura, ou seja, considerando adequadamente $A_{p r}, A_{s e c}$ e $A_{t e r}$ ) e a constante $B$ nas expressões (2.33) e depois em (2.44), e considerando que o limite inferior da integral é $(x=0)$ e o limite superior é $\left(x=S_{p}\right),\left(x=S_{s}\right)$ e $\left(x=S_{t}\right)$, dependendo do nível de formação de fissura analisado, tem-se a partir da equação (2.46), as forças necessárias para formar fissuras primárias, secundárias e terciárias:

$$
\begin{gathered}
P_{f i s}^{p r i}=\frac{A_{r} E_{r} \lambda^{2} f_{c t} A_{c}}{k_{e} L_{p}} \\
P_{f i s}^{s e c}=\frac{A_{r} E_{r} \lambda^{2} f_{c t} A_{c}}{0,35 k_{e} L_{p}} \\
P_{f i s}^{t e r}=\frac{A_{r} E_{r} \lambda^{2} f_{c t} A_{c}}{0,113 k_{e} L_{p}}
\end{gathered}
$$

Para finalizar, avaliando a Figura 14-a, é possível concluir que:

$$
\Delta_{r}=\frac{w}{2}
$$

em que $w$ é a abertura de fissura.

Porém, é necessário que se obtenha o valor de $\Delta_{r}$. Nos trabalhos de Muhamad et al. (2012) e Taheri e Barros (2012), $\Delta_{r}$ pode ser obtido, respectivamente, por uma expressão deduzida com a solução e as condições de contorno apresentadas acima ou por meio de um processo iterativo. Neste estudo, como será mostrado no capítulo 3, optou-se por utilizar a metodologia apresentada em Haskett et al. (2009a), em que $\Delta_{r}$ é facilmente obtido geometricamente de posse de rotações impostas na abordagem momento-rotação.

Sendo assim, de posse do valor de deslizamento entre concreto-barra, e consequentemente, da abertura de fissura na face fissurada, é possível encontrar a contribuição do concreto entre fissuras com ajuda das expressões (2.44), (2.45) e (2.47):

$$
P_{\text {cont }}=P_{c}=P_{r}-\frac{\sigma_{c}}{E_{c}} A_{r} E_{r}
$$


Define-se $\sigma_{c}=\sigma_{c t}(w)$, ou seja, uma lei de tensão $\mathrm{x}$ abertura de fissuras, como apresentado na Figura 13, e $P_{r}$ sendo encontrada substituindo as constantes de integração em (2.31) para $x=0$ (face fissurada). O que leva a três forças de contribuição, (2.57), (2.58) e (2.59), a depender do nível de carregamento que está agindo no prisma e do tamanho em que ele se encontra, ou seja, em qual nível de fissuração o prisma está sujeito (entre fissuras primárias, secundárias ou terciárias), temos que $P_{\text {cont }}$ pode ser:

$$
\begin{aligned}
P_{\text {cont }, 1}= & \frac{\left(\Delta_{r} \lambda E_{c}+0,96 \sigma_{c t}(w)\right) A_{r} E_{r}}{0,96 E_{c}} \\
P_{\text {cont }, 2} & =\frac{\left(\Delta_{r} \lambda E_{c}+0,76 \sigma_{c t}(w)\right) A_{r} E_{r}}{0,76 E_{c}} \\
P_{\text {cont }, 3} & =\frac{\left(\Delta_{r} \lambda E_{c}+0,46 \sigma_{c t}(w)\right) A_{r} E_{r}}{0,46 E_{c}}
\end{aligned}
$$

Haskett et al., (2009a) afirma que os resultados obtidos para um único estágio de formação de fissura não diferem substancialmente daqueles obtidos quando são considerados múltiplos estágios de fissuração, pois o que controla a abordagem do modelo mecânico, é principalmente, a evolução da abertura de uma única fissura.

\subsection{Método de Newton-Raphson}

O método de Newton-Raphson (NR) consiste em um método utilizado para determinar raízes de equações e solucionar sistemas de equações não lineares. O método precisa de uma estimativa inicial para a solução do problema. A interpretação geométrica do método é apresentada na Figura 16, em que se deseja obter a raiz da função $f(x)$. 


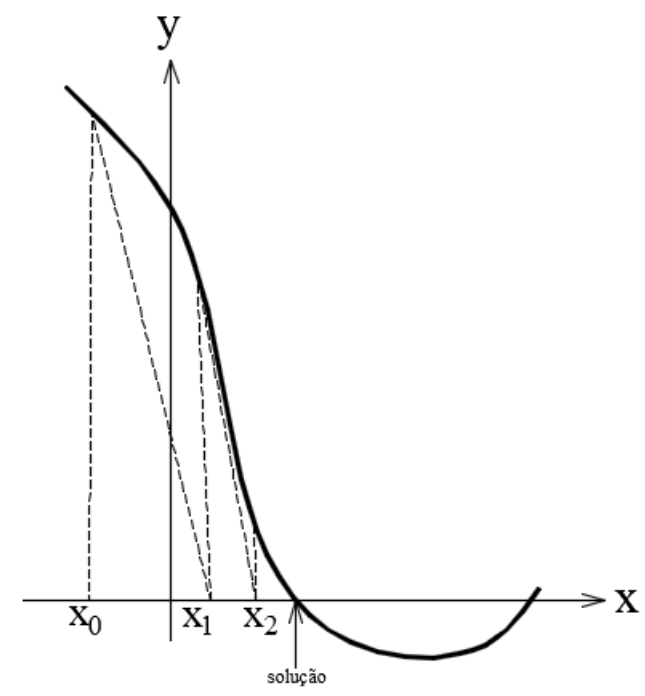

Figura 16. Aplicação do método de Newton-Raphson

Determinar a raiz desta equação significa solucionar $f(x)=0$. Para que o valor de $x$ seja determinado, estima-se uma solução inicial $x_{i}$. Partindo-se daí, busca-se uma nova solução, $x_{i+1}$, a partir da fórmula de recorrência descrita na expressão a seguir.

$$
x_{i+1}=x_{i}-\frac{f\left(x_{i}\right)}{f^{\prime}\left(x_{i}\right)}
$$

Generalizando para um problema com duas variáveis, ou seja, quando se têm duas equações não lineares e duas incógnitas a serem encontradas, tem-se a seguinte fórmula de recorrência do método de Newton-Raphson:

$$
\left\{\begin{array}{l}
x_{i+1} \\
y_{i+1}
\end{array}\right\}=\left\{\begin{array}{l}
x_{i} \\
y_{i}
\end{array}\right\}-\left[\begin{array}{ll}
g_{x}\left(x_{i}, y_{i}\right) & g_{y}\left(x_{i}, y_{i}\right) \\
h_{x}\left(x_{i}, y_{i}\right) & h_{y}\left(x_{i}, y_{i}\right)
\end{array}\right]^{-1}\left\{\begin{array}{l}
g\left(x_{i}, y_{i}\right) \\
h\left(x_{i}, y_{i}\right)
\end{array}\right\}
$$

Define-se que $g$ e $h$ são funções cujas variáveis independentes são $x$ e $y$, e $\boldsymbol{x}$ é o vetor das incógnitas, $\boldsymbol{f}\left(\boldsymbol{x}_{\boldsymbol{i}}\right)$ é a função vetorial e $\boldsymbol{J}\left(\boldsymbol{x}_{\boldsymbol{i}}\right)$ é a Matriz Jacobiana:

$$
\begin{gathered}
\boldsymbol{x}_{\boldsymbol{i}}=\left\{\begin{array}{l}
x_{i} \\
y_{i}
\end{array}\right\} \\
\boldsymbol{f}\left(\boldsymbol{x}_{\boldsymbol{i}}\right)=\left\{\begin{array}{l}
g\left(x_{i}, y_{i}\right) \\
h\left(x_{i}, y_{i}\right)
\end{array}\right\}
\end{gathered}
$$




$$
\boldsymbol{J}\left(\boldsymbol{x}_{\boldsymbol{i}}\right)=\left[\begin{array}{ll}
g_{x}\left(x_{i}, y_{i}\right) & g_{y}\left(x_{i}, y_{i}\right) \\
h_{x}\left(x_{i}, y_{i}\right) & h_{y}\left(x_{i}, y_{i}\right)
\end{array}\right]
$$

Sendo a fórmula de recorrência para um problema n-dimensional:

$$
x_{i+1}=x_{i}-\left[J\left(x_{i}\right)\right]^{-1} f\left(x_{i}\right)
$$




\section{3 Algoritmos Implementados}

Neste capítulo são apresentados algoritmos utilizados para a implementação de modelos mecânicos de análise de vigas de concreto armado. A priori, considerase uma interação completa entre materiais. Posteriormente, é realizada uma implementação considerando a interação parcial entre materiais, para que então, seja feita uma comparação entre as metodologias e uma avaliação da influência dos mecanismos locais no comportamento global das vigas abordadas nesse trabalho.

As implementações foram desenvolvidas na plataforma MATLAB, sendo que os algoritmos de momento-curvatura e momento-rotação foram desenvolvidos para seções retangulares e para flexão composta normal, visto que estes permitem a avaliação da rigidez e da capacidade resistente seccional, além do comportamento em termos de abertura de fissuras, por meio dos resultados de momento-normalcurvatura. Todavia, destaca-se que as aplicações nesse trabalho foram realizadas para flexão simples.

\section{1. Capacidade Resistente da Seção - Interação Completa}

A determinação da capacidade resistente de uma seção retangular constituída de concreto armado com barras de aço e/ou com FRP submetida à flexão simples ou composta normal é feita mediante o uso de expressões analíticas provenientes da integração das funções elásticas não lineares das relações constitutivas do concreto, como será apresentada nesta seção.

As hipóteses básicas a seguir são assumidas no algoritmo para seções de concreto armado com armadura de aço e FRP:

- A seção transversal está contida no plano $x y$, cuja origem está posicionada no centro geométrico da seção bruta de concreto armado;

- O arranjo da armadura é previamente conhecido; 
- Hipótese de Bernoulli é válida, ou seja, as seções deformadas permanecem planas e, portanto, as deformações em cada fibra na altura da seção são diretamente proporcionais à sua distância à linha neutra;

- Os encurtamentos são dados como positivos e os alongamentos, negativos;

- É considerada perfeita aderência nas interfaces concreto-aço e concreto-FRP, ou seja, para esta abordagem é realizada uma análise de interação completa.

Considerando a hipótese básica de Bernoulli, que rege a abordagem momento-curvatura, tem-se que o perfil de deformações na seção pode ser dado pela equação (3.1):

$$
\begin{gathered}
\varepsilon=\varepsilon_{0}+k y \\
k=\frac{1}{r}=\frac{\varepsilon_{\text {sup }}-\varepsilon_{\text {inf }}}{h}
\end{gathered}
$$

em que $\varepsilon_{0}$ é a deformação no Centro Geométrico (CG) da seção; $y$ a distância de uma fibra qualquer até o CG e $\varepsilon_{\text {sup }}$ e $\varepsilon_{\text {inf }}$ são as deformações no topo e na base da seção, respectivamente (Figura 17).

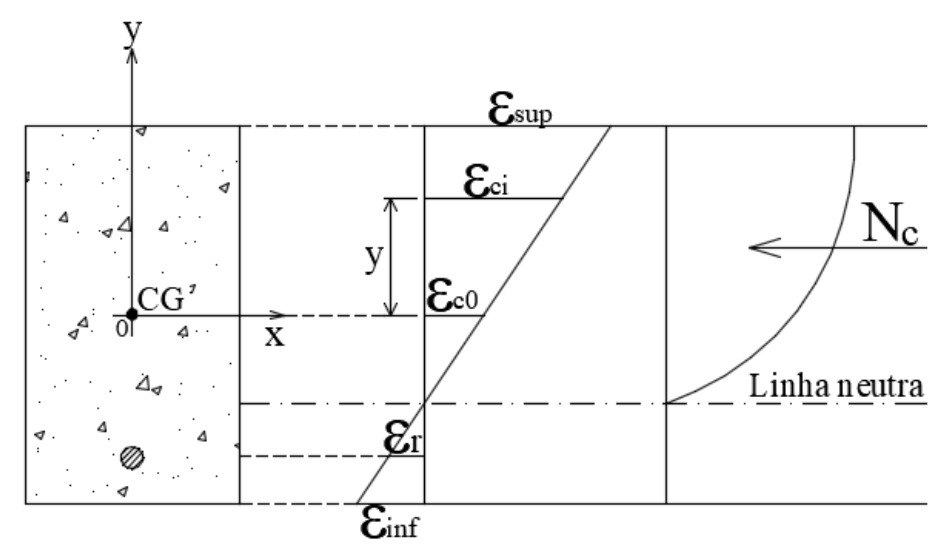

Figura 17. Perfil de tensões e deformações ao longo da seção e resultantes de forças no concreto e na armadura.

O cálculo dos esforços resistentes da seção sujeita a flexão é dado por:

$$
N_{R}=\iint_{A} \sigma(\varepsilon) d x d y
$$




$$
M_{R}=\iint_{A} \sigma(\varepsilon) y d x d y
$$

em que $N_{R}$ é o esforço normal resistente e $M_{R}$ é o momento resistente na seção. Trabalhando com as parcelas para cada material separadas, tem-se:

$$
\begin{aligned}
N_{R} & =N_{c}+N_{r} \\
M_{R} & =M_{c}+M_{r}
\end{aligned}
$$

A seguir, são apresentados os cálculos de cada uma das parcelas resistentes para o esforço normal e para o momento referente a cada material, em que o subscrito " $c$ " é referente ao concreto e o " $r$ " é referente à armadura inserida no concreto.

\subsection{1.}

\section{Parcelas Referentes ao Concreto}

Calcula-se a capacidade resistente referente ao concreto a partir de:

$$
\begin{gathered}
N_{c}=\iint_{A_{c}} \sigma_{c}(\varepsilon) d x d y \\
N_{r}=\iint_{A_{r}} \sigma_{r}(\varepsilon) d x d y \\
M_{c}=\iint_{A_{c}} \sigma_{c}(\varepsilon) y d x d y \\
M_{r}=\iint_{A_{r}} \sigma_{r}(\varepsilon) y d x d y
\end{gathered}
$$

De acordo com Mendes Neto (2009), sabendo que $\varepsilon_{\text {sup }}$ e $\varepsilon_{\text {inf }}$ podem ser calculadas por meio da equação (3.1), os esforços resistentes oriundos do concreto, obtidos das equações (3.7) e (3.9) podem ser calculados por intermédio de: 


$$
\begin{gathered}
N_{c}=\left\{\begin{array}{cc}
\frac{b}{k} \Delta I_{0}, & \text { se } \varepsilon_{\text {sup }} \neq \varepsilon_{\text {inf }} \\
\sigma_{c}\left(\varepsilon_{0}\right) b h, & \text { se } \varepsilon_{\text {sup }}=\varepsilon_{\text {inf }}
\end{array}\right. \\
M_{c}=\left\{\begin{array}{cl}
\frac{b}{k^{2}}\left(\Delta I_{1}-\varepsilon_{0} \Delta I_{0}\right), & \text { se } \varepsilon_{\text {sup }} \neq \varepsilon_{\text {inf }} \\
0, & \text { se } \varepsilon_{\text {sup }}=\varepsilon_{\text {inf }}
\end{array}\right.
\end{gathered}
$$

em que os termos $\Delta I_{0}$ e $\Delta I_{1}$ dados por:

$$
\begin{aligned}
& \Delta I_{0}=I_{0}\left(\varepsilon_{\text {sup }}\right)-I_{0}\left(\varepsilon_{\text {inf }}\right) \\
& \Delta I_{1}=I_{1}\left(\varepsilon_{\text {sup }}\right)-I_{1}\left(\varepsilon_{\text {inf }}\right)
\end{aligned}
$$

Mendes Neto (2009) apresenta as funções $I_{0}$ e $I_{1}$ oriundas da integração analítica do diagrama $\sigma \times \varepsilon$, dado por (2.1). No seu trabalho as mesmas foram obtidas para o modelo constitutivo da norma brasileira e para concretos de resistência à compressão até 50MPa. Essas funções foram ajustadas por Abreu, Costa e Aguiar (2017) para uma faixa que varia até 90MPa, chegando-se às seguintes expressões:

$$
\begin{gathered}
I_{0}(\varepsilon)=\int_{0}^{\varepsilon} \sigma_{c} \varepsilon d \varepsilon=\left\{\begin{array}{cc}
0, & \text { se } \varepsilon \leq 0 \\
f_{c}\left(\varepsilon-\frac{E_{0}(\varepsilon)}{n+1}\right), & \text { se } 0<\varepsilon<\varepsilon_{c 2} \\
f_{c}\left(\varepsilon-\frac{\varepsilon_{c 2}}{n+1}\right), & \text { se } \varepsilon \geq \varepsilon_{c 2}
\end{array}\right. \\
I_{1}(\varepsilon)=\int_{0}^{\varepsilon} \varepsilon \sigma_{c} \varepsilon d \varepsilon= \begin{cases}f_{c}\left(\frac{\varepsilon^{2}}{2}-\frac{E_{1}(\varepsilon)}{(n+1)(n+2)}\right), & \text { se } \varepsilon \leq 0<\varepsilon<\varepsilon_{c 2} \\
f_{c}\left(\frac{\varepsilon^{2}}{2}-\frac{\varepsilon_{c 2}}{(n+1)(n+2)}\right), & \text { se } \varepsilon \geq \varepsilon_{c 2}\end{cases} \\
E_{0}(\varepsilon)=\varepsilon_{c 2}-\left(1-\frac{\varepsilon}{\varepsilon_{c 2}}\right)^{n}\left(\varepsilon_{c 2}-\varepsilon\right) \\
E_{1}(\varepsilon)=\left(1-\frac{\varepsilon}{\varepsilon_{c 2}}\right)^{n}\left(\varepsilon-\varepsilon_{c 2}\right)\left(\varepsilon+\varepsilon_{c 2}+n \varepsilon\right)+\varepsilon_{c 2}^{2}
\end{gathered}
$$




\subsection{2.}

\section{Parcelas Referentes à Armadura}

As parcelas resistentes referentes à armadura são consideradas discretas na seção de concreto. Assim, tem-se:

$$
\begin{gathered}
N_{r}=\sum_{i=1}^{n} \sigma_{r i} A_{r i} \\
M_{r}=\sum_{i=1}^{n} \sigma_{r i} A_{r i} y_{r i}
\end{gathered}
$$

em que que $A_{r i}$ é a área da armadura na camada analisada e $y_{r i}$ é a altura de cada camada analisada em relação à origem dos eixos cartesianos.

\section{2.}

\section{Perfil de Deformação na Seção}

A partir de valores pré-estabelecidos de $N$ e $M$ atuantes na seção, é possível determinar a distribuição de deformações na mesma, determinando $\varepsilon_{0}$ e $k$. Além disso, é possível verificar se algum Estado Limite Último (ELU) é atingido. Tal distribuição será necessária na seção 3.4, que trata do algoritmo para a implementação de análise de vigas considerando interação completa. Para realizar esse processo utilizou-se o método de Newton-Raphson descrito na seção 2.4. As equações de equilíbrio na seção determinam o sistema (3.21) a ser solucionado e formam a função vetorial $\boldsymbol{f}(\boldsymbol{x})$ do problema (3.22):

$$
\begin{gathered}
\left\{\begin{array}{l}
N=N_{R} \\
M=M_{R}
\end{array}\right. \\
\boldsymbol{f}(\boldsymbol{x})=\left\{\begin{array}{l}
N-N_{R} \\
M-M_{R}
\end{array}\right.
\end{gathered}
$$

em que o vetor das incógnitas $\boldsymbol{x}$ e a matriz Jacobiana $\boldsymbol{J}$ são dados por (3.23) e (3.24):

$$
\boldsymbol{x}=\left\{\begin{array}{l}
\varepsilon_{0} \\
k
\end{array}\right\}
$$




$$
\boldsymbol{J}=-\boldsymbol{R}=-\left[\begin{array}{ll}
\frac{\partial N_{r}}{\partial \varepsilon_{0}} & \frac{\partial N_{r}}{\partial k} \\
\frac{\partial M_{r}}{\partial \varepsilon_{0}} & \frac{\partial M_{r}}{\partial k}
\end{array}\right]
$$

Tem-se que a matriz Jacobiana é composta pelas rigidezes axial $(\overline{E A})$, transversal $(\overline{E S})$ e flexional $(\overline{E I})$ não lineares da seção:

$$
\boldsymbol{R}=\left[\begin{array}{ll}
E A & \overline{E S} \\
\overline{E S} & \overline{E I}
\end{array}\right]
$$

em que as rigidezes são dadas por:

$$
\begin{aligned}
& \overline{E A}=E A_{c}+E A_{r} \\
& \overline{E S}=E S_{c}+E S_{r} \\
& \overline{E I}=E I_{c}+E I_{r}
\end{aligned}
$$

considerando que as parcelas das rigidezes para o concreto e a armadura valem:

$$
\begin{gathered}
\overline{E A}_{c}=\left\{\begin{array}{cc}
\frac{b}{k} \Delta J_{0}, & \text { se } \varepsilon_{\text {sup }} \neq \varepsilon_{\text {inf }} \\
\sigma_{c}{ }^{\prime}\left(\varepsilon_{0}\right) b h, & \text { se } \varepsilon_{\text {sup }}=\varepsilon_{\text {inf }}
\end{array}\right. \\
\overline{E S}_{c}=\left\{\begin{array}{cc}
\frac{b}{k^{2}}\left(\Delta J_{1}-\Delta I_{0}\right), & \text { se } \varepsilon_{\text {sup }} \neq \varepsilon_{\text {inf }} \\
0, & \text { se } \varepsilon_{\text {sup }}=\varepsilon_{\text {inf }}
\end{array}\right. \\
\overline{E I}_{c}=\left\{\begin{array}{c}
\frac{b}{k^{3}}\left(\Delta J_{2}-2\left(\Delta I_{1}-\varepsilon_{0} \Delta I_{0}\right)\right), \quad \text { se } \varepsilon_{\text {sup }} \neq \varepsilon_{\text {sup }}=\varepsilon_{\text {inf }} \\
\sigma_{c}{ }^{\prime}\left(\varepsilon_{0}\right) \frac{b h^{3}}{12}, \\
E A_{r}=\sum_{i=1}^{n} \sigma^{\prime}\left(\varepsilon_{r i}\right) A_{r i} \\
E S_{r}=\sum_{i=1}^{n} \sigma^{\prime}\left(\varepsilon_{r i}\right) A_{r i} y_{r i} \\
E I_{r}=\sum_{i=1}^{n} \sigma^{\prime}\left(\varepsilon_{r i}\right) A_{r i} y_{r i}{ }^{2}
\end{array}\right.
\end{gathered}
$$


As expressões (3.29) a (3.31) dependem do parâmetro $\Delta J_{n}$, dado por:

$$
\begin{gathered}
J_{n}(\varepsilon)=\sigma_{c}(\varepsilon)\left(\varepsilon-\varepsilon_{0}\right)^{2} \\
\Delta J_{n}(\varepsilon)=J_{n}\left(\varepsilon_{\text {sup }}\right)-J_{n}\left(\varepsilon_{\text {inf }}\right)
\end{gathered}
$$

As expressões (3.29) a (3.34) requerem o cálculo das derivadas das curvas tensão-deformação do concreto e do aço. Assim, estas derivadas são apresentadas a seguir:

$$
\begin{gathered}
\sigma_{c}^{\prime}(\varepsilon)=\left\{\begin{array}{c}
0, \quad \text { se } \varepsilon<0 \text { ou } \varepsilon \geq \varepsilon_{c 2} \\
\frac{f_{c}^{n}}{\varepsilon_{c 2}}\left(1-\frac{\varepsilon}{\varepsilon_{c 2}}\right)^{n-1}, \quad \text { se } 0 \leq \varepsilon<\varepsilon_{c 2}
\end{array}\right. \\
\sigma_{r}{ }^{\prime}(\varepsilon)= \begin{cases}E_{r}, & \text { se }|\varepsilon| \leq \varepsilon_{y} \\
0, & \text { se }|\varepsilon|>\varepsilon_{y}\end{cases}
\end{gathered}
$$

Assim sendo, para empregar o método de Newton-Raphson, deve-se aplicar a equação (2.65) iterativamente, a partir de uma estimativa inicial dos valores de $\varepsilon_{0}$ e $k$. Manipulando esta equação, chega-se às formulas de recorrência utilizadas para esta aplicação:

$$
\begin{aligned}
& \varepsilon_{0} \leftarrow \varepsilon_{0}+\frac{\overline{E I}\left(N-N_{R}\right)-\overline{E S}\left(M-M_{R}\right)}{R} \\
& k \leftarrow k+\frac{\overline{E A}\left(M-M_{R}\right)-\overline{E S}\left(N-N_{R}\right)}{R}
\end{aligned}
$$

em que $R$ é o determinante da matriz $\boldsymbol{R}$ oriundo da sua inversão, dado por:

$$
R=\overline{E A E I}-\overline{E S}^{2}
$$

Uma boa estimativa inicial dos valores de $\varepsilon_{0}$ e $k$, segundo Mendes Neto (2009), é $\varepsilon_{0}=k=0$, pois essa estimativa impede $R=0$, já que isso indica que a matriz Jacobiana não pode ser invertida. O processo iterativo deve continuar até que os esforços resistentes sejam aproximadamente iguais aos esforços solicitantes. Sugere-se avaliar a qualidade da solução por meio de (3.42): 


$$
f=\sqrt{\left(\frac{N_{R}-N}{f_{c} b h}\right)^{2}-\left(\frac{M_{R}-M}{f_{c} b h^{2}}\right)^{2}} \leq p
$$

Sendo $p$ uma constante preestabelecida e próxima de zero. Os termos $f_{c} b h \mathrm{e}$ $f_{c} b h^{2}$ foram introduzidos para adimensionalizar os termos dentro da raiz. É importante ressaltar que, segundo Mendes Neto (2009), se o processo iterativo resultar em um valor de R muito próximo de zero, isso indica que a seção transversal não resiste ao par de esforços aplicados.

Sabendo que $\varepsilon_{m a ́ x}$ é o maior valor entre $\varepsilon_{\text {sup }}$ e $\varepsilon_{i n f}$, e $\varepsilon_{\text {mín }}$ é a menor deformação específica das camadas de armadura, avalia-se as equações (3.43), (3.44) e (3.45) para determinar se a seção atinge o ELU. Caso qualquer uma destas seja falsa, o ELU foi atingido.

$$
\begin{gathered}
\varepsilon_{m a ́ x} \leq \varepsilon_{c u} \\
\varepsilon_{\text {mín }} \geq \varepsilon_{r u} \\
\varepsilon_{0}+k h\left(\frac{\varepsilon_{c 2}}{\varepsilon_{c u}}-0.5\right) \leq \varepsilon_{c 2}
\end{gathered}
$$

O fluxograma a seguir resume o algoritmo implementado. 


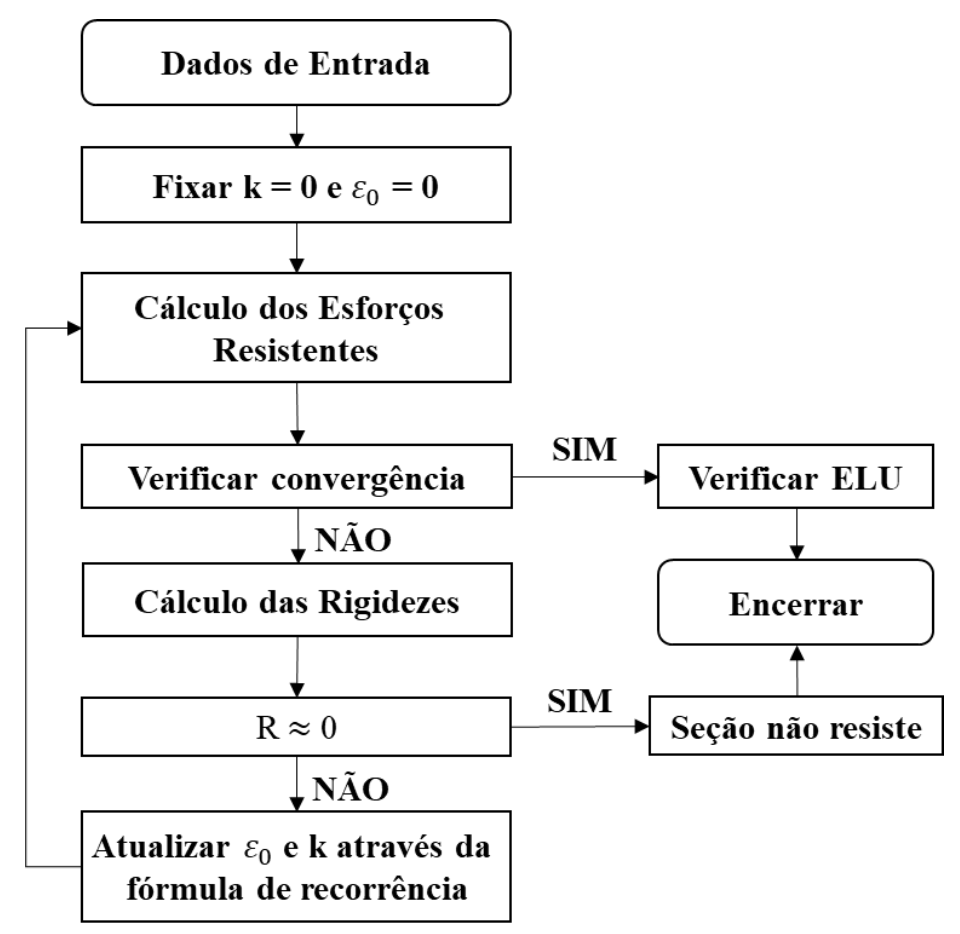

Figura 18. Fluxograma - perfil de deformações

\section{3. \\ Diagramas Momento-Curvatura (M-1/r)}

A análise da seção transversal de um elemento fletido consiste em estudar a evolução da degradação da rigidez flexional $(E I)$ à medida que há incrementos de curvaturas na seção estudada. Para realizar esse estudo são elaborados diagramas de momento-curvatura para elementos submetidos à flexão simples (ou momentonormal-curvatura, para flexão composta).

Segundo Oehlers et al. (2011b), para o traçado desses diagramas faz-se uso de uma abordagem bidimensional, baseada em um perfil linear de deformações, apoiada na Hipótese de Bernoulli. Isso porque, à medida que a seção vai sendo solicitada, tem-se uma evolução de curvaturas, que leva o elemento a deformar-se continuamente.

Este diagrama, portanto, relaciona a curvatura $1 / r$ e o momento fletor resistente $M_{R}$ correspondente, para um dado valor de força normal $N$, em que o $M_{R}$ é avaliado para diversos valores de $1 / r$, variando de 0 até a seção atingir o ELU. Sendo assim, $N$ e $1 / r$ são os dados inicialmente conhecidos; $M_{R}$ e $\varepsilon_{0}$ incógnitas do problema. 
No modelo implementado nesse estudo, para a determinação dos diagramas momento-curvatura utilizou-se o método de Newton-Raphson, comentado na seção 2.4, em que a função vetorial definida $\boldsymbol{f}(\boldsymbol{x})$, o vetor das incógnitas $\boldsymbol{x}$ e a matriz Jacobiana $\boldsymbol{R}$ são dados por (3.46), (3.47) e (3.48), respectivamente:

$$
\begin{gathered}
f(x)=\left\{\begin{array}{l}
N-N_{R} \\
M-M_{R}
\end{array}\right\} \\
\boldsymbol{x}=\left\{\begin{array}{c}
M_{R} \\
\varepsilon_{0}
\end{array}\right\} \\
\boldsymbol{R}=\left[\begin{array}{ll}
0 & E A \\
1 & E S
\end{array}\right]
\end{gathered}
$$

Sendo que para tal problema, a fórmula de recorrência é dada pela expressão:

$$
\left\{\begin{array}{c}
M_{R} \\
\varepsilon_{0}
\end{array}\right\} \leftarrow\left\{\begin{array}{c}
M_{R} \\
\varepsilon_{0}
\end{array}\right\}+\boldsymbol{R}^{-1}\left\{\begin{array}{c}
N-N_{R} \\
M-M_{R}
\end{array}\right\}
$$

A fórmula de recorrência dada pela equação (3.49) é simplificada por meio das duas equações a seguir:

$$
\begin{gathered}
M_{R d} \leftarrow M-\frac{E S}{E A}\left(N-N_{R}\right) \\
\varepsilon_{0} \leftarrow \varepsilon_{0}+\frac{1}{E A}\left(N-N_{R}\right)
\end{gathered}
$$

Das equações separadas acima, é interessante aplicar apenas a equação (3.51), encerrando-se o processo quando $N-N_{R} \approx 0$. Para isso, a curvatura $k$ é fixada e são atribuídos valores de $\varepsilon_{0}$, formando perfis de deformações diferentes, até que para um determinado perfil de deformação, haja a convergência para o par $\left(k, M_{R}\right)$, sendo $M_{R}$ calculado por (3.6).

Sugere-se como estimativa inicial $\varepsilon_{0}=0$. Além disso, é sugerido que se determine o término do processo iterativo por meio da expressão (3.52) para uma constante $p$ preestabelecida e com valor próximo de zero.

$$
f=\left|N-N_{R}\right| \leq p
$$


Um fluxograma pode melhor resumir o algoritmo implementado.

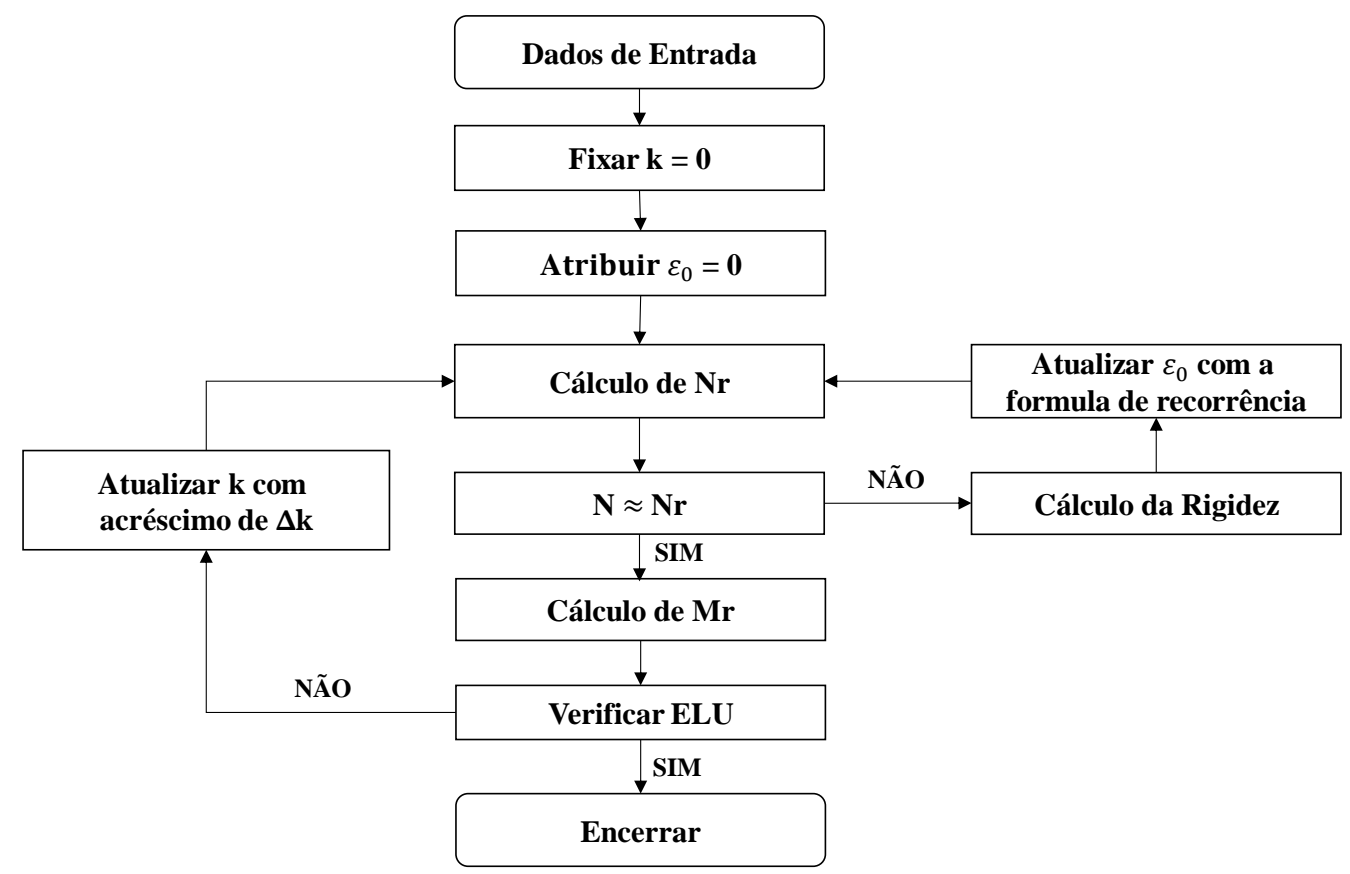

Figura 19. Fluxograma - momento-curvatura

\section{4 . \\ Análise Não Linear de Vigas de Concreto}

As vigas, em um sistema estrutural, podem ser representadas como elementos lineares, ou seja, que possuem uma dimensão muito maior que as outras duas. As vigas, por estarem sujeitas a flexão simples, não estão sujeitas aos efeitos de segunda ordem.

A determinação dos deslocamentos ao longo das vigas, e consequentemente, da configuração deformada das mesmas, é realizada nesse trabalho por intermédio de uma metodologia baseada na analogia de Mohr.

A analogia de Mohr é um método iterativo baseado, assim como o Princípio dos Trabalhos Virtuais (PTV), na ideia de carga fictícia equivalente. A analogia foi determinada com base no observado a seguir:

- Analogia 1: observando as expressões a seguir, em que a equação da linha elástica, que relaciona deslocamento e curvatura, e a equação diferencial da estática, que mostra a relação entre momento e carregamento atuante no 
elemento, é permitido obter por analogia que a curvatura em um sistema real pode ser dada como o carregamento atuante em um elemento fictício.

$$
\begin{aligned}
& \frac{d^{2} y}{d x^{2}}=\frac{M(x)}{E I} \\
& \frac{d^{2} M}{d x^{2}}=q(x)
\end{aligned}
$$

- Analogia 2: observando as expressões a seguir, em que a primeira, também oriunda do estudo de deflexões, que relaciona momento e esforço cortante, e a segunda, que relaciona deslocamento e rotação, é permitido obter por analogia que os deslocamentos atuantes em um sistema real podem ser obtidos por meio dos momentos calculados em um sistema fictício.

$$
\begin{aligned}
& \frac{d M}{d x}=Q(x) \\
& \frac{d y}{d x}=\phi(x)
\end{aligned}
$$

Portanto, a partir do entendimento da analogia de Mohr, é possível considerar que o carregamento aplicado na viga em um sistema fictício é equivalente à curvatura obtida das relações momento-curvatura em um sistema real, permitindo inserir desta forma, a não linearidade física do material. Com este carregamento fictício, obtêm-se os momentos fletores realizando uma análise estática usual, obtendo os deslocamentos no sistema real.

É importante ressaltar ainda que as condições de contorno devem ser ajustadas no sistema equivalente, segundo a tabela a seguir. 
Tabela 2. Conversões de condições de contorno para o sistema fictício (Martha, 2017)

\begin{tabular}{|c|c|c|c|}
\hline \multicolumn{2}{|c|}{ VIGA REAL } & \multicolumn{2}{|c|}{ VIGA CONJUGADA } \\
\hline apoio simples & $\Delta$ & $\Delta$ & apoio simples \\
\hline$v=0 \quad \theta \neq 0$ & $\Delta$ & $\Delta$ & $M^{C}=0 \quad Q^{C} \neq 0$ \\
\hline engaste & & & extremidade livre \\
\hline$v=0 \quad \theta=0$ & $\longleftarrow$ & - & $M^{C}=0 \quad Q^{C}=0$ \\
\hline extremidade livre & - & & engaste \\
\hline$v \neq 0 \quad \theta \neq 0$ & & - & $M^{C} \neq 0 \quad Q^{C} \neq 0$ \\
\hline engaste deslizante & $\$ d$ & \$a & engaste deslizante \\
\hline$v \neq 0 \quad \theta=0$ & $-\frac{\alpha}{\alpha}$ & of & $M^{C} \neq 0 \quad Q^{C}=0$ \\
\hline
\end{tabular}

Sendo assim, apresenta-se o algoritmo implementado:

1. O processo inicia-se com a discretização da viga de comprimento $L$ na quantidade $(n)$ de trechos desejada, sendo que o comprimento do trecho é $\Delta x$ :

$$
\Delta x=\frac{L}{n}
$$

2. Calcular o momento fletor para cada ponto de discretização.

3. De posse do momento fletor que solicita a seção discretizada, utilizar o algoritmo implementado em (3.3) para obter a curvatura.

4. Aplicação da Analogia de Mohr:

De posse da curvatura, obter o carregamento fictício, formando assim um sistema equivalente a um sistema real. Dependendo do diagrama de momento fletor, esse carregamento fictício pode assumir uma distribuição linear constante ou uma variação parabólica. Esse carregamento pode então ser substituído por cargas pontuais equivalentes que atuam nos nós de discretização, chamadas de pesos elásticos. Esses pesos elásticos são dados em função da curvatura e, segundo Santos (1987), podem ser expressos pelas equações a seguir:

$$
\begin{gathered}
w_{0}=\frac{\Delta x}{12}\left(3,5 \frac{1}{r_{0}}+3 \frac{1}{r_{1}}-0,5 \frac{1}{r_{2}}\right) \\
w_{i}=\frac{\Delta x}{12}\left(\frac{1}{r_{i-1}}+10 \frac{1}{r_{i}}+\frac{1}{r_{i+1}}\right)
\end{gathered}
$$




$$
w_{n}=\frac{\Delta x}{12}\left(3,5 \frac{1}{r_{n}}+3 \frac{1}{r_{n-1}}-0,5 \frac{1}{r_{n-2}}\right)
$$

5. Com o carregamento fictício definido em 4, calcular o momento fletor em cada ponto de discretização no sistema equivalente. Esse momento fletor, por analogia de Mohr, corresponderá aos deslocamentos no sistema real. Com o deslocamento em cada ponto, é possível traçar a deformada real da viga.

O fluxograma a seguir apresenta uma forma resumida do processo.

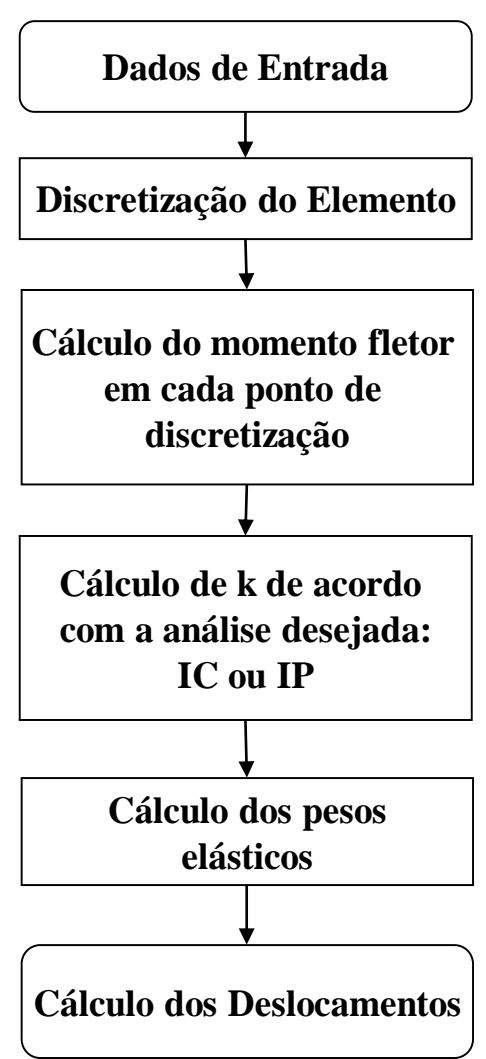

Figura 20 Fluxograma - análise de vigas

\section{5.}

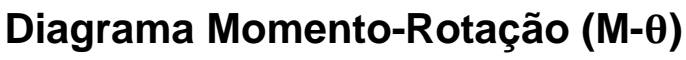

A abordagem momento-rotação corresponde a um modelo mecânico em que é possível inserir mecanismos fundamentais para avaliação da rigidez de elementos fletidos após a abertura de fissuras, permitindo uma análise mais completa de elementos de concreto. No presente trabalho, os mecanismos de enrijecimento à 
tração e de amolecimento do concreto foram inseridos na análise de vigas por meio dessa abordagem.

Para traçar o diagrama momento-rotação, assim como acontece para o diagrama momento-curvatura, é necessário realizar o cálculo das parcelas de forças resistente da seção, considerando os mecanismos supracitados. Para isso, a metodologia seguida nesse trabalho é dada por discretizar a seção de concreto em faixas e calcular a deformação em cada uma dessas faixas $\left(\varepsilon_{c i}\right)$. Sendo calculadas também, as deformações para cada camada de armadura $\left(\varepsilon_{s i}\right)$.

À medida que a rotação $\theta$ é incrementada, avaliam-se as deformações por meio de expressões de deformações baseadas nessas rotações e no tamanho do prisma $S_{p}$, seguindo com dois tipos de tratamento: deformações $\varepsilon_{i} \geq \varepsilon_{c r}$ ou $\varepsilon_{i}<$ $\varepsilon_{c r}$, inserindo assim, os mecanismos de interação parcial para a primeira hipótese.

O procedimento é melhor retratado a seguir, apresentando o algoritmo implementado e as considerações adotadas, nas quais teve-se como base os trabalhos de Barros, Taheri e Salehian, Taheri e Barros et al (2012), Ali et al. (2012) e Haskett et al. (2009a).

\section{- Descrição do Algoritmo Implementado:}

Similar a abordagem momento-curvatura, é necessário conhecer dois parâmetros para traçar um perfil de deformações. Neste caso, os parâmetros conhecidos são a rotação $\theta$ que é fixada e a profundidade da linha neutra $d_{L N}$ cuja origem localiza-se no topo da seção. Portanto:

1. Fixar uma rotação $\theta$ e um acréscimo de rotação $\Delta \theta$ que será dado, considerando que a cada nova iteração, $\theta$ é atualizado. Sugerindo-se, por exemplo, fazer $\Delta \theta=0,001$.

$$
\begin{gathered}
\theta=0 \\
\theta=\theta+\Delta \theta
\end{gathered}
$$

2. Assumir um valor inicial para a profundidade da linha neutra $d_{L N} \mathrm{e}$ proceder com sucessivas tentativas até que haja o equilíbrio da seção. Para isso, utilizou-se o método de Newton-Raphson para a solução da equação de equilíbrio 
não linear, ou seja, para encontrar a $d_{L N}$ adequada que possa minimizar a função de resíduo (3.64). O método possui a fórmula de recorrência (3.63) a seguir:

$$
\begin{gathered}
\left\{d_{L N}\right\} \leftarrow\left\{d_{L N}\right\}+R^{-1}\left\{f\left(d_{L N}\right)\right\} \\
f_{\text {res }}=f\left(d_{L N}\right)=N-N_{R}=0
\end{gathered}
$$

sendo que $R^{-1}$ é calculada por intermédio de uma derivada numérica (3.66), devido à complexidade da função de resíduo, que impossibilita o cálculo da derivada analítica.

$$
\begin{gathered}
R^{-1}=\frac{1}{\partial_{d_{L N}}(f)} \\
\partial_{d_{L N}}(f)=\frac{f\left(d_{L N}+x\right)-f\left(d_{L N}-x\right)}{2 x}
\end{gathered}
$$

em que $x$ é o valor do passo dado para obter os pontos vizinhos ao ponto que se deseja obter a derivada numérica. Para que a solução numérica esteja mais próxima possível da solução analítica, é importante que o valor de $x$ seja um valor bem pequeno, mas que respeite a capacidade de representação numérica da máquina.

Ainda é importante frisar que o valor da primeira iteração estimado para $d_{L N}$ seja zero, conforme foi sugerido em outras aplicações do método de NewtonRaphson nesse trabalho, porém a partir da segunda iteração, sugere-se que $d_{L N}$ inicial assuma o valor de $d_{L N}$ convergido do passo anterior, pois isso ajuda a acelerar o processo de convergência.

3. Cálculo do esforço normal resistente da seção: Parcela referente ao concreto.

3.1. Dividir a seção de concreto de altura $h$ em uma quantidade $q$ de faixas de espessura $t$. Sendo que, a parcela de esforço normal referente a cada uma dessas faixas de discretização $\left(F_{c i}\right)$ atua no Centro Geométrico $(\mathrm{CG})$ de cada faixa, como mostra a Figura 21.

$$
t=\frac{h}{q}
$$




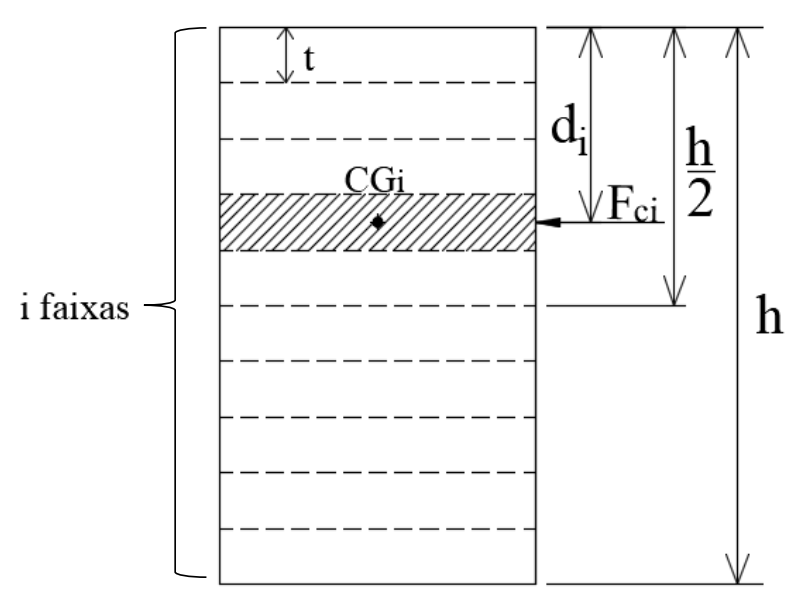

Figura 21. Seção de concreto discretizada com a força resultante atuando no CG

3.2. Calcular a deformação em cada faixa discretizada por meio da expressão (3.68) que permite obtê-la com base na rotação sofrida:

$$
\varepsilon_{c i}=\frac{2\left(\theta\left(d_{L N}-d_{i}\right)\right.}{S_{p}}
$$

em que $S_{p}$ é o espaçamento entre fissuras ou tamanho do prisma de concreto da região perturbada.

3.3. Calcular a deformação de fissuração $\left(\varepsilon_{c r}\right)$ para identificar quais faixas de concreto estão sujeitas a uma tração inferior a resistência do concreto à tração $f_{c t} \mathrm{e}$ quais aquelas com $\varepsilon_{c i}>\varepsilon_{c r}$ (concreto entre fissuras).

$$
\varepsilon_{c r}=\frac{f_{c t}}{E_{c}}
$$

3.3.1. Se $\varepsilon_{c i}<\varepsilon_{c r}$, tem-se o concreto dentro de uma região de fissura, como mostra a Figura 22. 


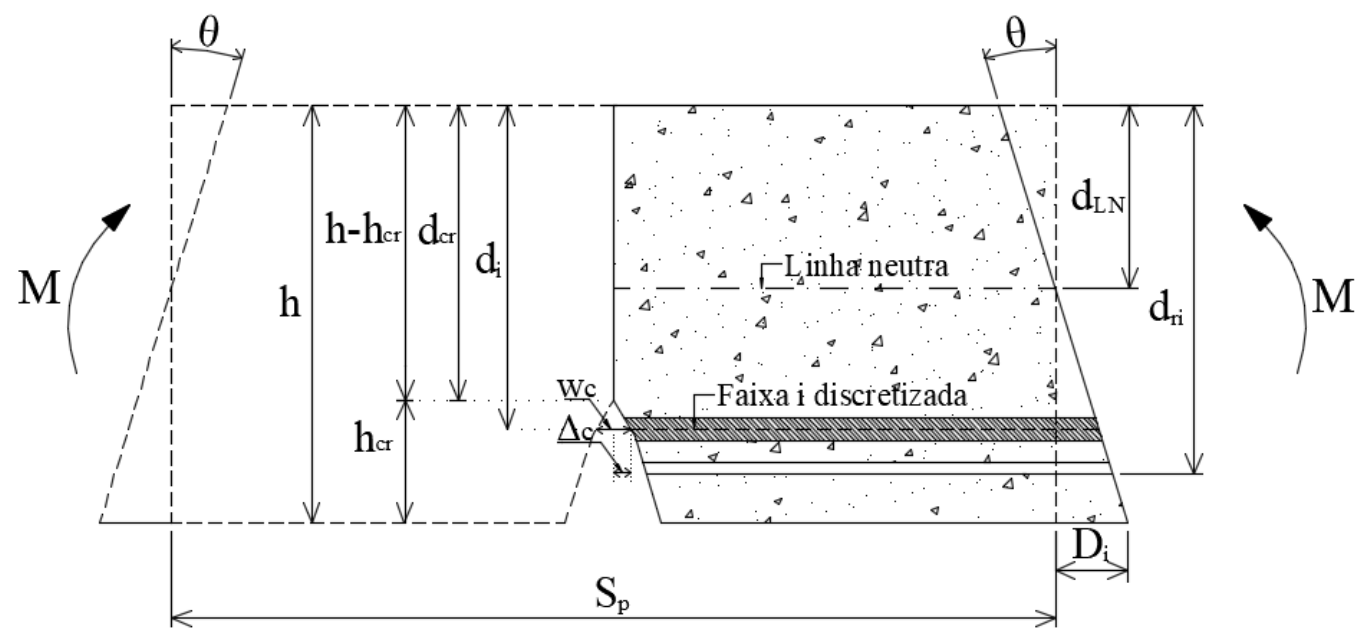

Figura 22. Faixa de concreto discretizada dentro de uma região de fissura (Adaptada - Taheri e Barros, 2012)

Para esta posição de faixa de concreto, calcula-se a abertura de fissura $\left(w_{c}\right)$ nesse nível, por meio do deslizamento $\left(\Delta_{c}\right)$ na face fissurada para esta faixa calculado geometricamente. Para isso, é necessário saber a que profundidade do topo da seção abrirá uma fissura $\left(d_{c r}\right)$. E isso é feito por meio da expressão (3.70), rearranjada da expressão (3.68).

$$
\begin{gathered}
d_{c r}=d_{L N}-\frac{\varepsilon_{c r} S_{p}}{2 \theta} \\
\Delta_{c}=\theta\left(d_{i}-d_{c r}\right) \\
w_{c}=2 \Delta_{c}
\end{gathered}
$$

Com $w_{c}$ definido é possível utilizar a lei $\sigma_{c t}-w$ (Figura 13), enunciada na seção 2.3.3, sendo $w_{c}=w$. Dessa forma obtém-se a tensão atuante no concreto correspondente a esta abertura de fissura:

$$
\sigma_{c i}=\sigma_{c t}=\left\{\begin{array}{cl}
f_{c t}\left(1-0,8 \frac{w}{w_{2}}\right), & \text { se } w \leq w_{2} \\
f_{c t}\left(0,25-0,05 \frac{w}{w_{2}}\right), & \text { se } w_{2}<w \leq w_{\text {máx }} \\
0, & \text { se } w \geq w_{\text {máx }}
\end{array}\right.
$$

3.3.2. Se $0>\varepsilon_{c i}>\varepsilon_{c r}$, tem-se o concreto sob tração, porém com tensões limitadas à sua resistência à tração (Figura 23). 


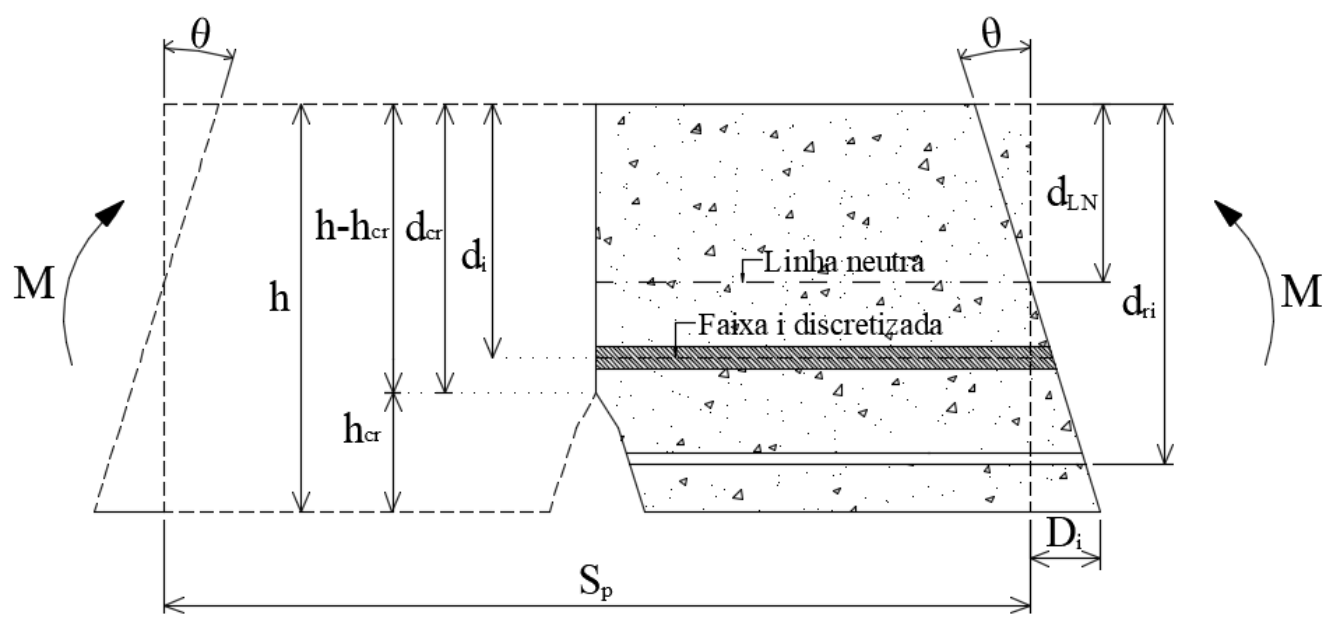

Figura 23. Faixa de concreto sob tensões de tração inferior à resistência (Adaptada - Taheri e Barros, 2012)

$$
\sigma_{c i}=\varepsilon_{c i} E_{c}
$$

3.3.3. Se $\varepsilon_{c 2} \geq \varepsilon_{c i}>0$, tem-se o concreto sob compressão, com deformações ainda no trecho ascendente da curva $\sigma \mathrm{x} \varepsilon$, ou seja, com deformações inferiores à deformação correspondente à tensão de pico $\left(\sigma_{c c, p}\right)$. Sendo assim, utiliza-se a lei constitutiva apresentada na seção 2.2.1.

3.3.4. Se $\varepsilon_{c i}>\varepsilon_{c 2}$, tem-se o concreto com deformações de compressão pertencente a região de amolecimento do concreto, ou seja, para estas faixas de concreto deve-se incluir as propriedades definidas 2.3.1.

Para encontrar a tensão atuante no concreto nesse trecho de cunha é necessário um procedimento iterativo, no qual é assumido um valor de deformação fictícia, tal que equilibre as forças internas atuantes na cunha. Foi utilizado nesse processo o método da bissecção, sendo que os limites são as deformações na qual deve estar a deformação atuante na cunha $\left(0<\varepsilon_{f i c}<\varepsilon_{c u}\right)$.

Aplicando-se o método da bissecção, tem-se os limites definidos:

$$
\begin{gathered}
A=\varepsilon_{f i c, \text { inf }}=0 \\
B=\varepsilon_{f i c, \text { sup }}=\varepsilon_{c u}
\end{gathered}
$$

3.3.4.1. Assumir um valor para a deformação no concreto para esta faixa analisada pertencente a cunha e calcular a contração axial $\left(\delta_{a x}\right)$ : 


$$
\begin{gathered}
\varepsilon_{f i c}=0 \\
\delta_{a x}=D_{i}-\varepsilon_{f i c} \frac{S_{p}}{2} \\
D_{i}=\theta\left(d_{L N}-d_{i}\right)
\end{gathered}
$$

visto que $D_{i}$ é o deslocamento da faixa analisada devido a rotação dada.

3.3.4.2. De posse de $\delta_{a x}$, calcula-se o deslocamento tangencial $(H)$ por meio da expressão (2.8).

3.3.4.3. Com $H$ definido, chega-se a um sistema dependente das tensões $\sigma_{n w}$ e $\tau_{n w}$, dadas por (2.14) e (2.15), respectivamente.

3.3.4.4. Calcular as componentes de forças internas $N$ e $T$ (normal e tangencial) que agem no plano de deslizamento de cunha por intermédio das expressões (2.12) e (2.13), respectivamente.

3.3.4.5. De posse de $N$ e $T$, calcular a força compressiva $\left(F_{c i}\right)$ :

$$
F_{c i}=T \cos \varphi+N \sin \varphi
$$

3.3.4.6. Com $F_{c c}$, calcula-se $\sigma_{c i}$ :

$$
\sigma_{c i}=\frac{F_{c i}}{b t}
$$

3.3.4.7. Para avaliar a função para o limite estipulado $A$, deve-se calcular a tensão no concreto para a deformação fictícia $\varepsilon_{f i c}=A$ :

$$
\begin{gathered}
\sigma_{f i c}\left(\varepsilon_{f i c}\right)=f_{c}\left(1-\left(1-\frac{\varepsilon_{f i c}}{\varepsilon_{c 2}}\right)^{n}\right) \\
f(A)=\sigma_{c i}-\sigma_{f i c}\left(\varepsilon_{f i c}\right)
\end{gathered}
$$

3.3.4.8. Repetir o procedimento de 3.3.4.1 a 3.3.4.7 para $\varepsilon_{f i c}=B$ e encontrar $f(B)$ e então obter o ponto médio $C$ :

$$
f(B)=\sigma_{c i}-\sigma_{f i c}\left(\varepsilon_{f i c}\right)
$$




$$
C=\frac{A+B}{2}
$$

3.3.4.9. Repetir o procedimento de 3.3.4.1 a 3.3.4.7 para $\varepsilon_{f i c}=C$ e encontrar $f(C)$, e então, avaliar as funções $f(A)$ e $f(C)$, verificando em qual intervalo se encontra a resposta procurada:

$$
\left\{\begin{array}{l}
B=C \text { e } f(B)=f(C), \text { se } f(A) f(C)<0 \\
A=C \text { e } f(A)=f(C), \text { se } f(A) f(C)>0
\end{array}\right.
$$

3.3.4.10. Repetir o processo até que haja convergência, ou seja, até que as respostas de $A$ e $B$ fiquem bem próximas:

$$
\text { dif }=|A-B| \leq \text { tol }
$$

em que tol é uma tolerância pré-definida para o processo.

3.3.4.11. Encontrando a deformação atuante na cunha:

$$
\varepsilon_{c i}=\varepsilon_{f i c}=\frac{A+B}{2}
$$

3.3.4.12. Repete-se o processo de 3.3.4.1 a 3.3.4.6, chegando ao valor real de $\sigma_{c i}$

3.4. Cálculo da parcela do esforço normal resistente para cada faixa de concreto:

De posse de $\sigma_{c i}$ para todas as possibilidades de deformações atuantes nas faixas discretizadas da seção de concreto é possível obter $F_{c i}$ :

$$
F_{c i}=\sigma_{c i} b t
$$

4. Cálculo do esforço normal resistente da seção: Parcela referente à armadura.

4.1. Calcular a deformação em cada camada de armadura por meio da expressão (3.90) que permite obter a deformação baseada na rotação sofrida: 


$$
\varepsilon_{r i}=\frac{2\left(\theta\left(d_{L N}-d_{r i}\right)\right.}{S_{p}}
$$

em que $d_{r i}$ é a posição de cada camada de armadura.

4.1.1. Se $\varepsilon_{r i} \geq-\varepsilon_{c r}$, tem-se a armadura tracionada fora de uma região de fissura, ou seja, em uma região de interação completa, como mostra a Figura 24.

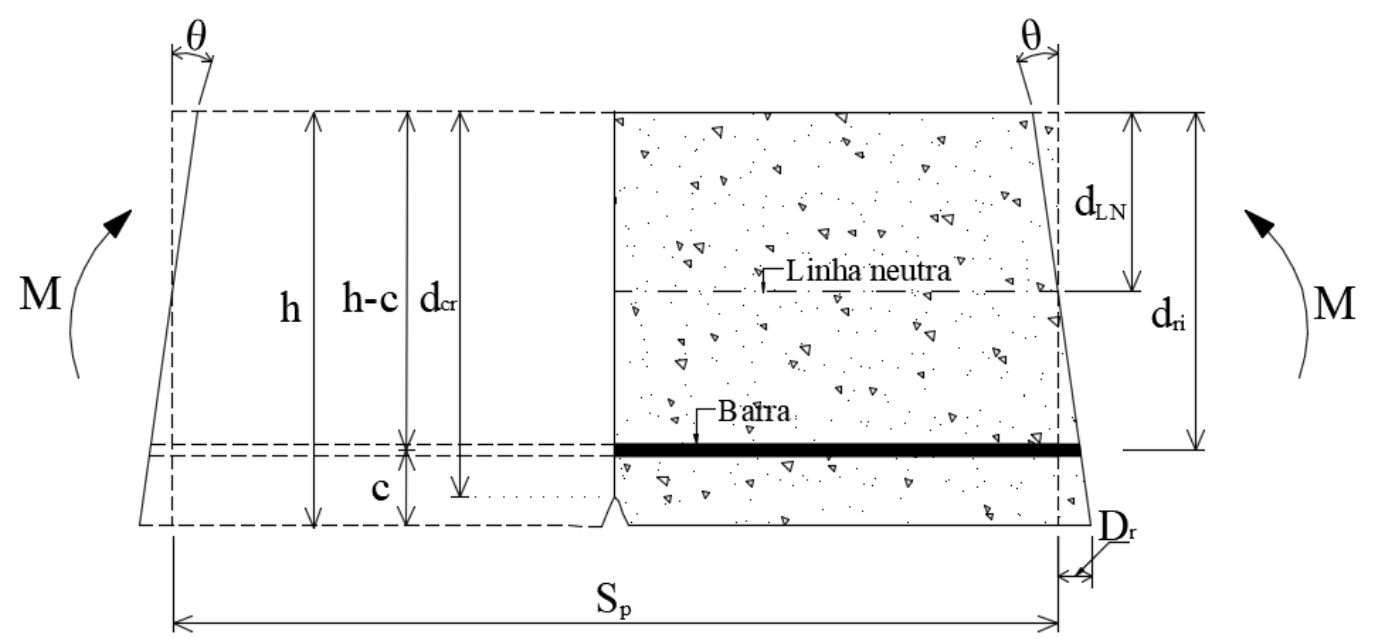

Figura 24. Armadura fora da região de fissura (Adaptada - Taheri e Barros, 2012)

Para armadura de aço:

$$
\sigma_{r i}=\sigma_{s i}= \begin{cases}\varepsilon_{r i} E_{r}, & \text { se } \varepsilon_{r i}<\varepsilon_{y} \\ \varepsilon_{r i} f_{y}, & \text { se } \varepsilon_{r i} \geq \varepsilon_{y}\end{cases}
$$

Para armadura de FRP:

$$
\sigma_{r i}=\sigma_{f i}=\varepsilon_{r i} E_{f}, \quad \text { se } \varepsilon_{r i}<\varepsilon_{f u}
$$

em que $\varepsilon_{f u}$ é a deformação última de tração do FRP.

4.1.2. Se $\varepsilon_{r i}<-\varepsilon_{c r}$, tem-se a armadura tracionada dentro de uma região de fissura, ou seja, em uma região de interação parcial, como mostra a Figura 25. 


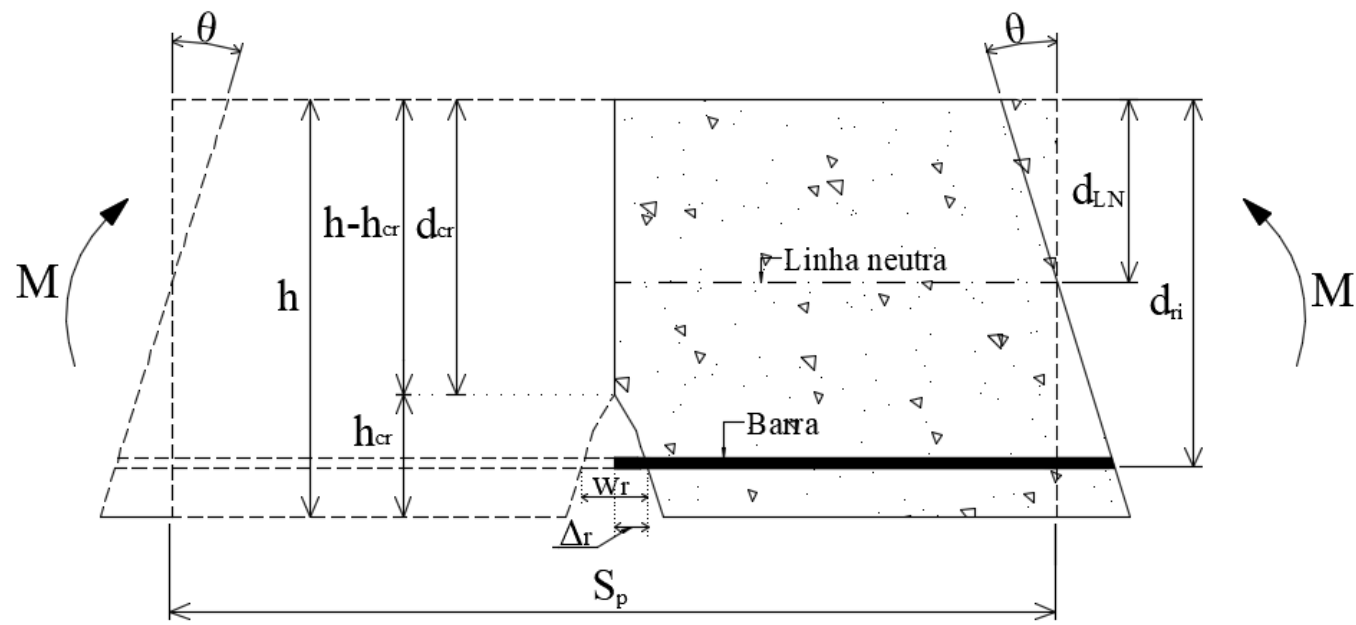

Figura 25. Armadura dentro da região de fissura (Adaptada - Taheri e Barros, 2012)

Nessa posição de camada de armadura, calcula-se o deslizamento $\Delta_{r}$ pela expressão a seguir:

$$
\Delta_{r}=\theta\left(d_{r i}-d_{c r}\right)
$$

É necessário que o $\Delta_{r}$ seja limitado ao deslizamento máximo permitido pela lei bond-slip. E assim, com $\Delta_{r}$ obtido, é possível calcular a abertura de fissura na posição da camada de armadura analisada $\left(w_{r}\right)$ :

$$
w_{r}=2 \Delta_{r}
$$

De posse do deslizamento $\left(\Delta_{r}\right)$ e da abertura de fissuras $\left(w_{r}\right)$, ambos na posição da camada de armadura e do parâmetro $\lambda$ (expressão (2.32)), é possível calcular a força de tração que leva em conta a contribuição do concreto à tração entre fissuras $\left(P_{\text {cont }}\right)$ transferida para o aço por meio da interface.

O ideal seria que a implementação identificasse qual a parcela de contribuição entre as citadas na seção 2.3.3 deveria ser adotada. Por ser uma tarefa complexa, neste trabalho, adota-se apenas uma das parcelas por análise. Assim, como já comentado na seção 2.3.3, adota-se uma das expressões entre (2.57) a (2.59). Sendo assim, com $P_{\text {cont }}$ é possível obter $\sigma_{r i}$ : 


$$
\sigma_{r i}=\frac{P_{c o n t}}{A_{r}}
$$

4.2. Cálculo da parcela do esforço normal resistente para cada camada de armadura:

Tendo obtido $\sigma_{r i}$ para todas as possibilidades de deformações atuantes nas camadas de armadura, é possível obter $F_{r}$ :

$$
F_{r i}=\sigma_{r i} A_{r}
$$

5. Cálculo da parcela total de esforço normal resistente referente ao concreto e a armadura:

$$
\begin{aligned}
& N_{c}=\sum F_{c i} \\
& N_{r}=\sum F_{r i}
\end{aligned}
$$

6. Equilíbrio dos esforços normais atuantes na seção:

$$
\begin{gathered}
N_{R}=N \\
N_{R}=N_{c}+N_{r}
\end{gathered}
$$

7. Equilíbrio dos momentos fletores atuantes na seção:

$$
M_{R}=M
$$

7.1. Cálculo do braço de alavanca para o esforço normal referente ao concreto $\left(z_{c}\right)$ e referente à armadura $\left(z_{r}\right)$ :

$$
z_{c}=\left\{\begin{array}{cc}
0, & \text { se } N_{c}=0 \\
\frac{\sum F_{c i} d_{i}}{N_{c}} & \text { se } N_{c} \neq 0
\end{array}\right.
$$




$$
z_{r}=\left\{\begin{array}{cc}
0, & \text { se } N_{r}=0 \\
\frac{\sum F_{r i} d_{r i}}{N_{r}}, & \text { se } N_{r} \neq 0
\end{array}\right.
$$

7.2. Cálculo do momento fletor resistente na seção $\left(M_{R}\right)$ :

$$
M_{R}=N_{c}\left(\frac{h}{2}-z_{c}\right)+N_{r}\left(\frac{h}{2}-z_{r}\right)
$$

8. Caso o equilíbrio em (3.99) e (3.101) seja atendido, verifica-se os ELU de deformação de cada material e finaliza-se o processo. Caso contrário, repetir o procedimento do item 2 ao 7 até que haja convergência.

Obtido o diagrama momento-rotação, transformá-lo em diagrama momentocurvatura é uma tarefa simples, utilizando as expressões (3.105), (3.106) e (3.107) a seguir:

$$
\begin{gathered}
\varepsilon_{\text {sup }}=\frac{2 \theta\left(d_{L N}-0\right)}{S_{p}} \\
\varepsilon_{\text {inf }}=\frac{2 \theta\left(d_{L N}-h\right)}{S_{p}} \\
k=\frac{\left|\varepsilon_{\text {sup }}\right|+\left|\varepsilon_{\text {inf }}\right|}{h}
\end{gathered}
$$

em que $\varepsilon_{\text {sup }}$ é a deformação no topo e $\varepsilon_{\text {inf }}$ é a deformação na base da seção de concreto.

O fluxograma a seguir apresenta de forma simplificada o processo acima: 


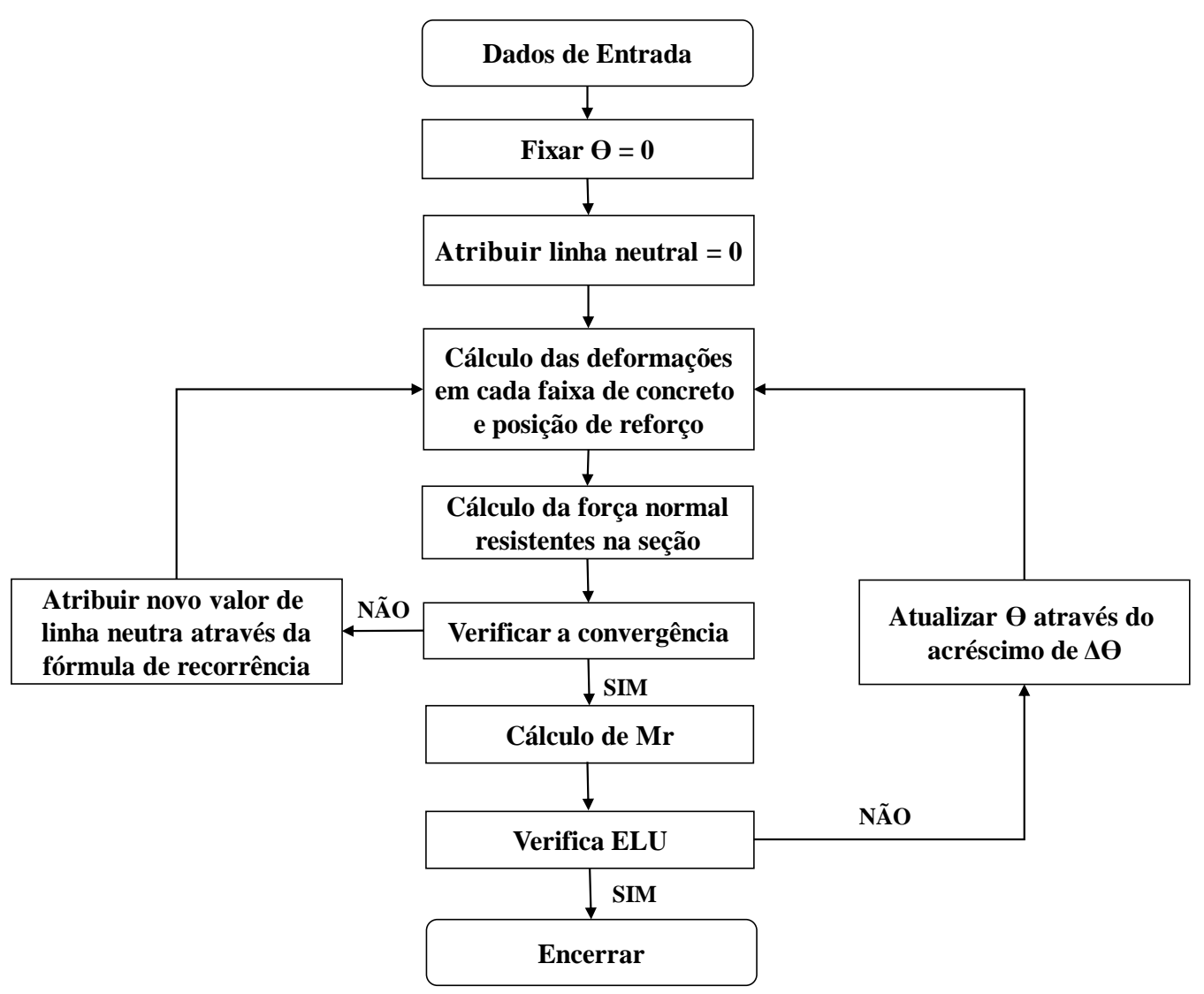

Figura 26. Fluxograma - momento-rotação 


\section{4}

\section{Validação e Resultados}

Neste capítulo são apresentadas as validações do modelo mecânico de momento-rotação apresentado no capítulo anterior. Tal validação é possível a partir da comparação dos resultados obtidos com os oriundos de ensaios experimentais realizados em vigas de concreto armado. Os resultados consistem em diagramas momento-curvatura resultantes de análises de interação completa e parcial para avaliação da rigidez nos dois casos; em curvas de carga x deslocamento que são traçadas para analisar a flexibilidade das vigas, e além disso, são expostos gráficos que apresentam a parcela de contribuição de cada mecanismo resistente na seção da viga ensaiada e gráficos que mostram a relação momento-abertura de fissuras. Os resultados dos ensaios experimentais foram obtidos por Sá (2018).

\section{1.}

\section{Ensaios em Vigas de Concreto Armado (Sá, 2018)}

Os experimentos realizados por Sá (2018) consistem em ensaios de quatro pontos em vigas de concreto armado com barras de aço e de GFRP. Em sua pesquisa foram realizados ensaios de caracterização para o concreto, o aço, o GFRP e para as interfaces. Isso foi possível por meio de ensaios de compressão e tração uniforme nos materiais constituintes e de ensaios de arrancamento das barras embebidas na matriz de concreto. As vigas ensaiadas possuem as propriedades geométricas apresentadas na Figura 27.

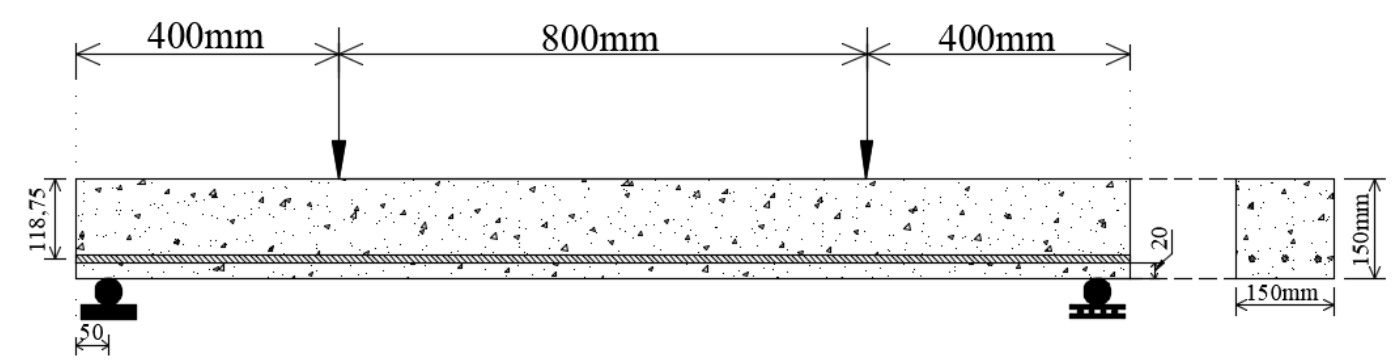

Figura 27. Viga de concreto ensaiada (Adaptada - Sá, 2018) 
A obtenção dos resultados de deslocamentos e deformações foi feita a partir da leitura de LVDTs e extensômetros, posicionados no meio da viga e nas faces do concreto, respectivamente. Utilizou-se ainda, a correlação digital de imagem para obtenção de dados de fissuração, como abertura e espaçamento entre fissuras.

Da série de vigas ensaiadas, comparou-se com os resultados numéricos as seguintes amostras: viga armada com 3 barras de aço de 12,5mm (VA-12); viga armada com 4 barras de 5mm (VA-5) e viga armada com 3 barras de GFRP de 12,5mm (VP-12). Os valores médios obtidos dos ensaios de caracterização são resumidos na Tabela 3. Maiores detalhes são apresentados no trabalho de Sá (2018).

Tabela 3. Propriedades dos materiais (Sá, 2018)

\begin{tabular}{|c|c|c|c|c|}
\hline \multicolumn{5}{|c|}{ Propriedades dos Materiais } \\
\hline & \multicolumn{2}{|c|}{ Concreto } & $\begin{array}{c}\text { Aço à } \\
\text { tração }\end{array}$ & $\begin{array}{c}\text { GFRP à } \\
\text { tração }\end{array}$ \\
\cline { 2 - 5 } & Compressão & Tração & 495,00 & 879,4 \\
\hline $\boldsymbol{f}(\mathbf{M P a})$ & 53,80 & 4,6 & 198000 & 40700 \\
\hline $\boldsymbol{E}(\mathbf{M P a})$ & 36700 & 36700 & 2,50 & 2,30 \\
\hline $\boldsymbol{\varepsilon}_{\boldsymbol{m a ́} \boldsymbol{x}(\boldsymbol{\%})}$ & 0,25 & 0,007 & 480,00 & - \\
\hline $\boldsymbol{f y} \mathbf{y P a})$ & - & - & \multicolumn{2}{c}{} \\
\hline
\end{tabular}

Define-se que $f$ é a resistência, $E$ o módulo de elasticidade, $f_{y}$ a tensão de escoamento do aço e $\varepsilon_{m a ́ x}$ as deformações máximas dos materiais. Além das propriedades básicas apresentadas na tabela, o autor realizou ainda a caracterização da interface entre os materiais. Os ensaios de arrancamento foram realizados com barras de aço e barras de GFRP embebidas na matriz de concreto para obter as características das interfaces concreto-aço e concreto-GFRP, para isso, foram utilizados três e cinco Corpos-de-Prova $(\mathrm{CP})$, respectivamente.

Como discutido na seção 2.3.2, utiliza-se aqui uma formulação baseada em um modelo bond-slip linear ascendente, que pode ser idealizado a partir das curvas não lineares de aderência como sugere Taheri e Barros (2012). Com isso, é possível obter os dois parâmetros referentes a lei de aderência: $k_{e}$ e $s_{m a ́ x}$. A seguir apresentam-se os modelos bond-slip idealizados para as interfaces concreto-aço e concreto-GFRP, ajustados a partir das amostras ensaiadas. 


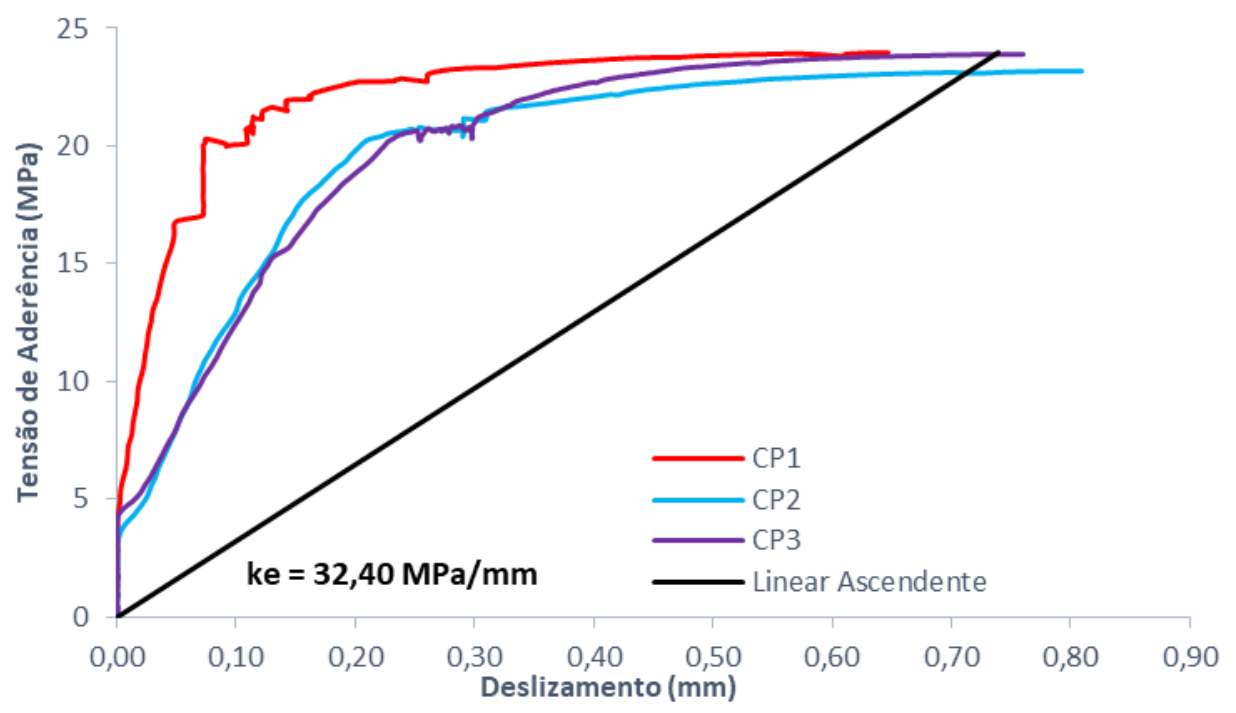

Figura 28. Curva bond-slip idealizada - concreto-aço

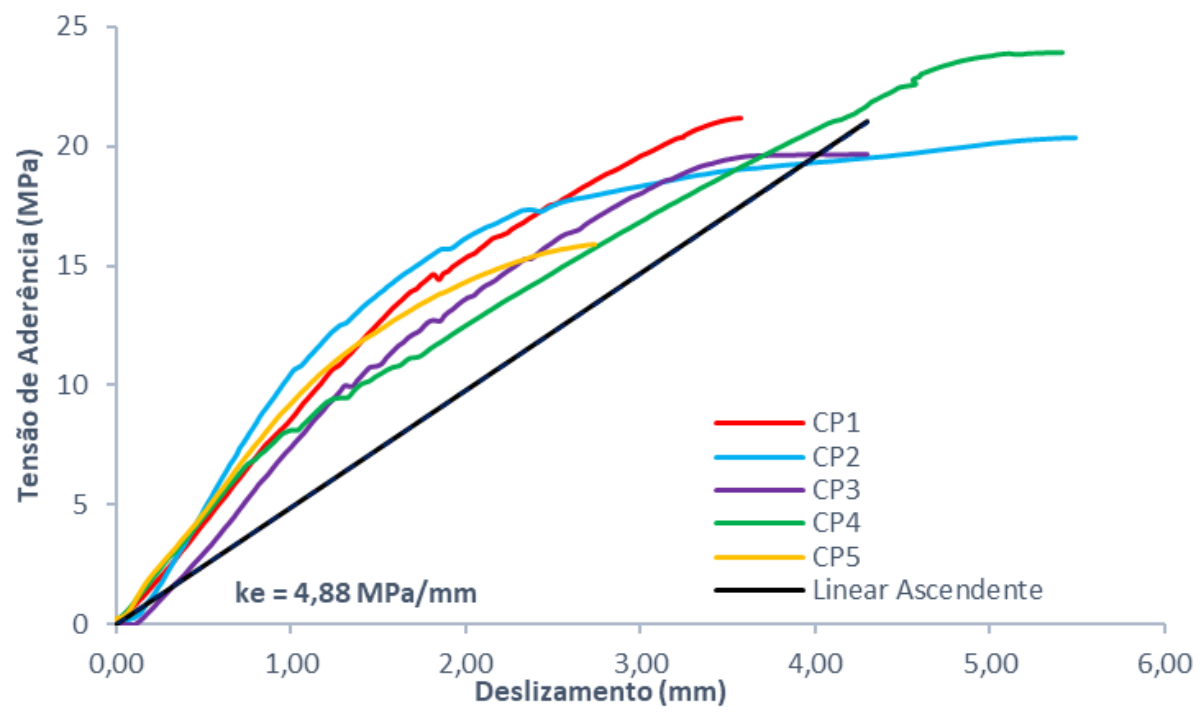

Figura 29. Curva bond-slip idealizada - concreto-GFRP

\section{2.}

\section{Avaliação dos Resultados}

A partir dos transdutores de deslocamentos posicionados no ponto central do vão das vigas foi possível obter as curvas carga-deslocamento naquele ponto. Estas são apresentadas nas Figura 30 a Figura 32, que contém também as curvas numéricas para análise de vigas considerando uma interação completa e parcial entre materiais. 
Nas curvas de interação parcial é feita uma comparação do acréscimo de rigidez entre a formulação que considera o surgimento de fissuras primárias, secundárias e terciárias. Vale ressaltar, que, conforme exposto no capítulo 2, podem ser utilizadas como contribuição do concreto entre fissuras as expressões (2.57) a (2.59). Essa contribuição é maior a partir do surgimento de mais fissuras, pois aumenta-se a quantidade de prismas de concreto enrijecidos, diminui-se o espaçamento entre fissuras, o que leva ao acréscimo de rigidez desses prismas, e consequentemente, da estrutura.

Portanto, nesse trabalho são expostos os resultados referentes às equações (2.57), (2.58) e (2.59), nomeadas contribuições C1, C2 e C3, respectivamente.

É possível observar nas curvas carga - deslocamento a seguir, que para baixos níveis de carregamento a rigidez secante das curvas analíticas para os três tipos de análise de interação parcial apresentam os mesmos valores. A rigidez começa a divergir nas análises quando ocorre o surgimento das primeiras fissuras, perceptível por meio dos pontos angulosos presentes ao ampliar a região. Essas fissuras são indicadas nas figuras ampliadas nos gráficos, como $1^{\mathrm{a}}$ e $2^{\mathrm{a}}$ fissura. Para a viga armada com GFRP esses pontos angulosos foram menos visíveis.

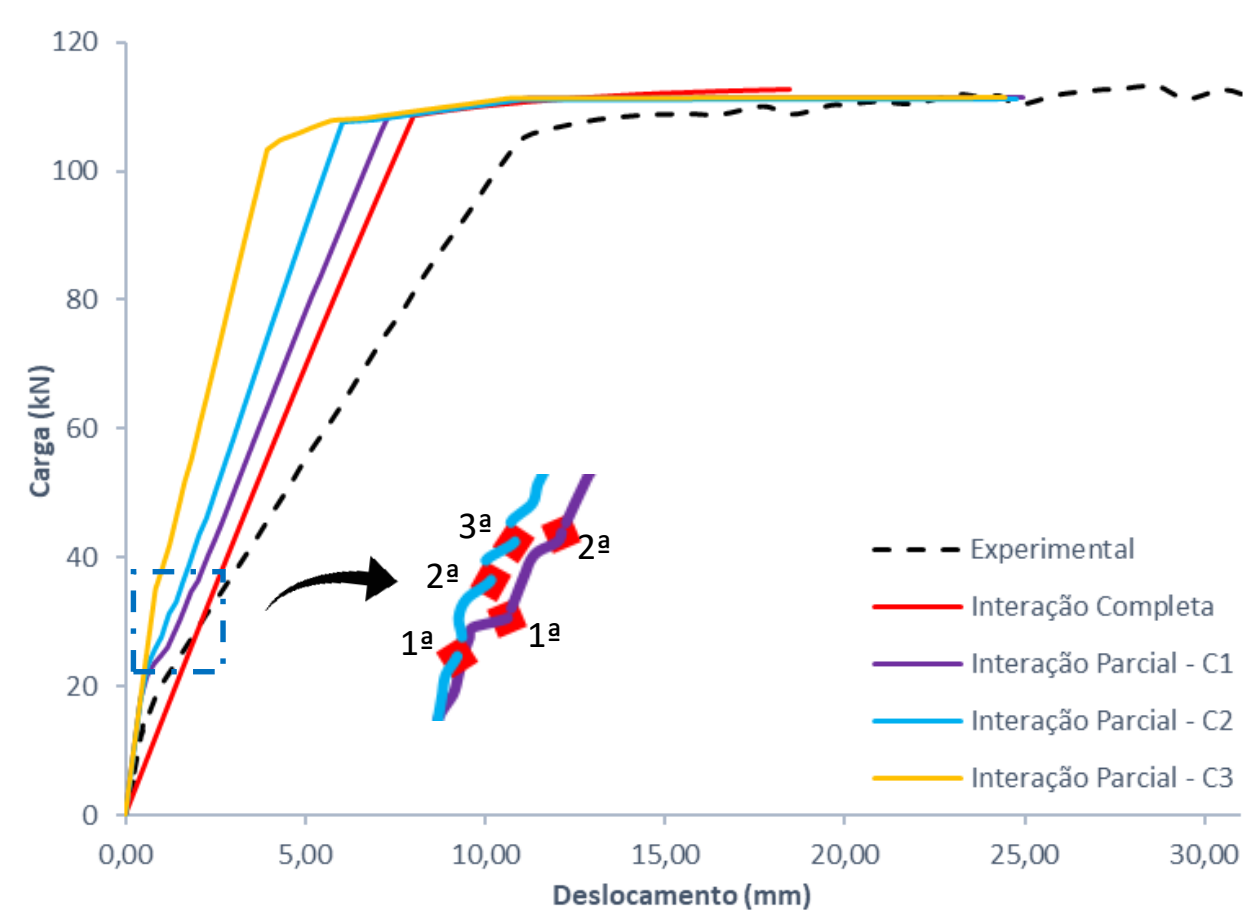

Figura 30. Carga-deslocamento - viga VA-12 


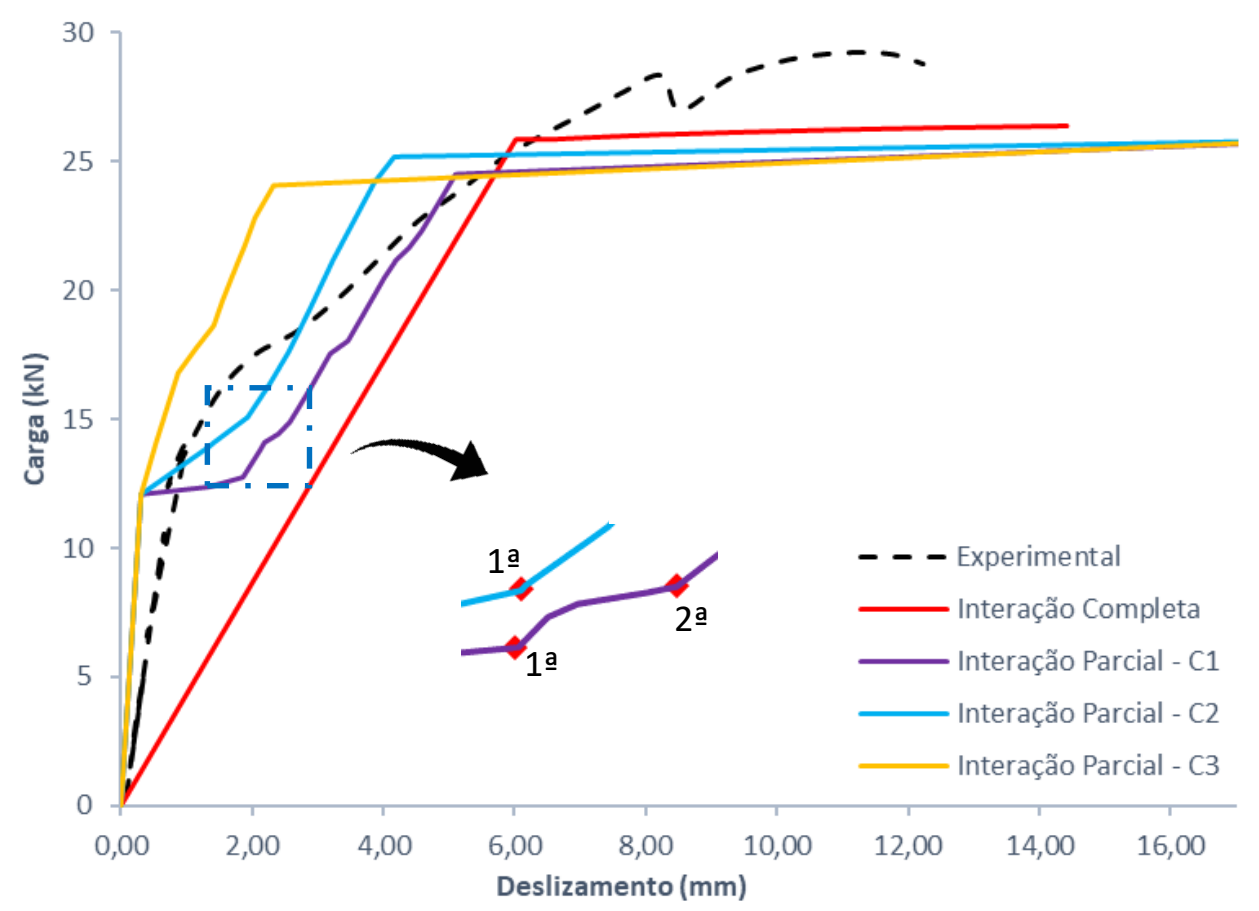

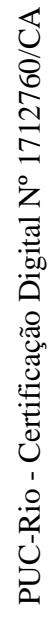

Figura 31. Carga-deslocamento - Viga VA-5

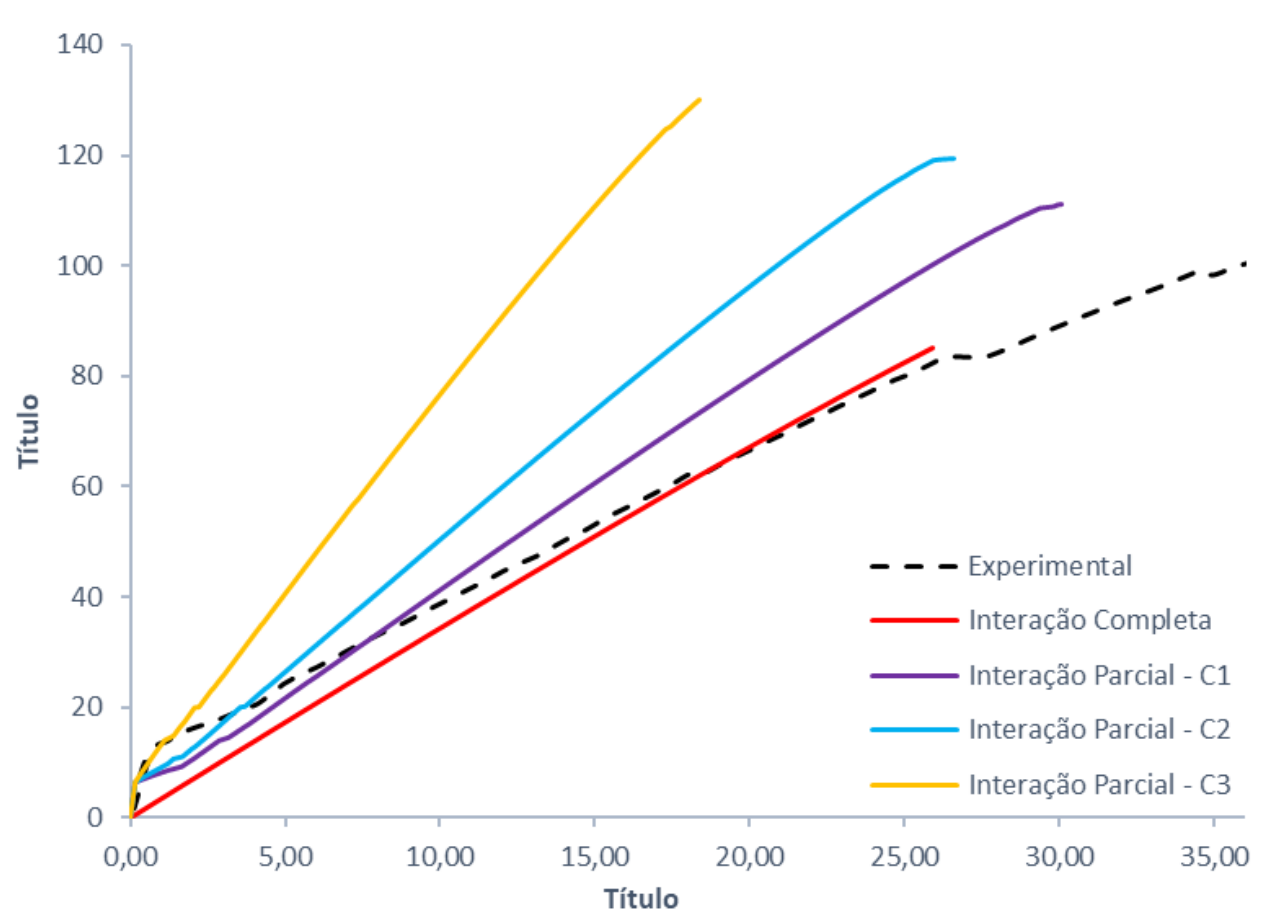

Figura 32. Carga-deslocamento - viga VP-12 
É possível observar ainda, que os resultados de carga última apresentam certa concordância com os resultados experimentais, todavia o mesmo não ocorreu com deslocamentos. Isso pode ser explicado, devido ao fato do ensaio experimental conter um pequeno vão de cisalhamento, o que leva a uma importante influência dos esforços cisalhantes.

Além dos resultados de carga - deslocamento apresentados, é possível avaliar ainda a rigidez seccional por meio dos diagramas momento - curvatura oriundos das implementações de interação completa e parcial, confrontando-os com os obtidos experimentalmente.

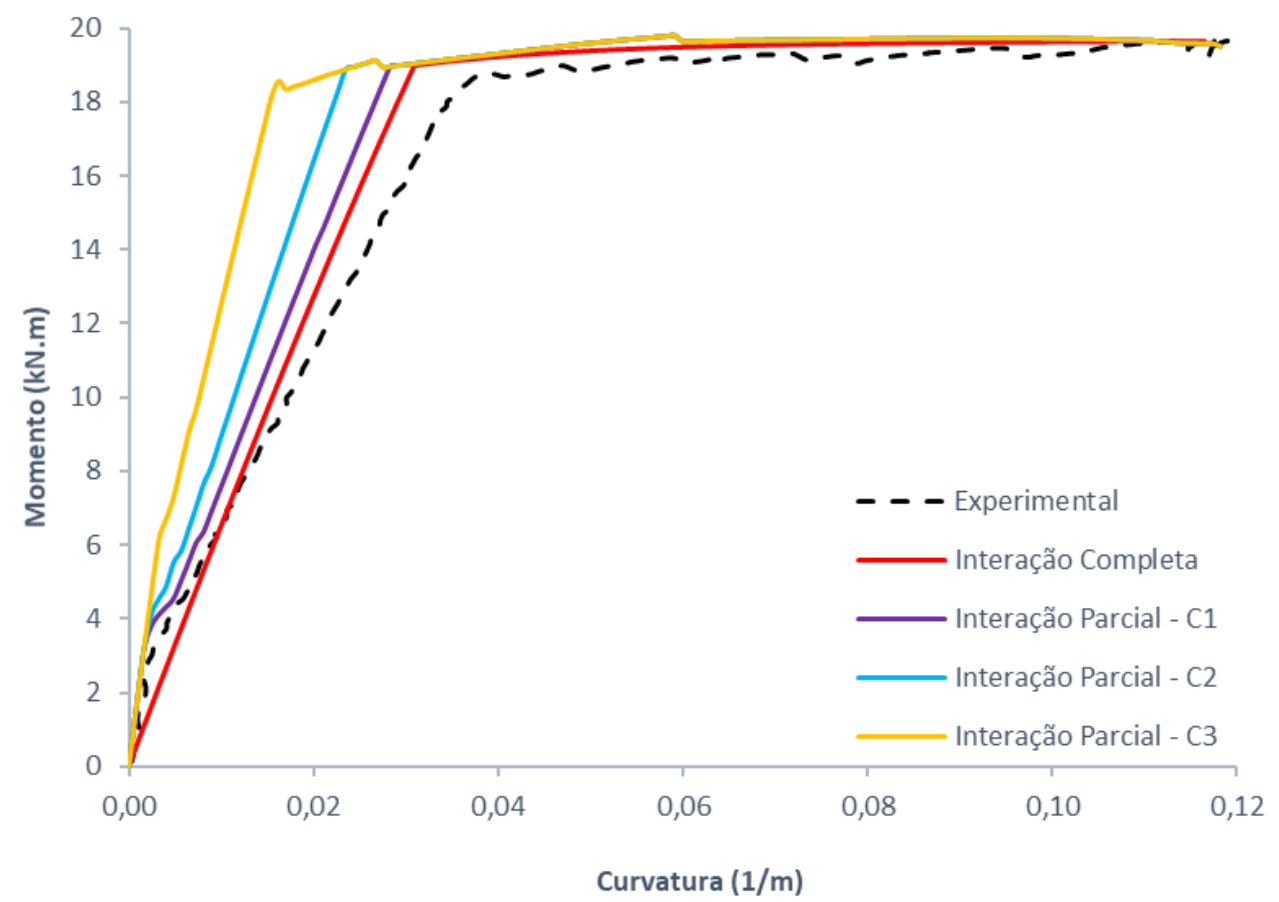

Figura 33. Diagrama momento - curvatura - Viga VA - 12 


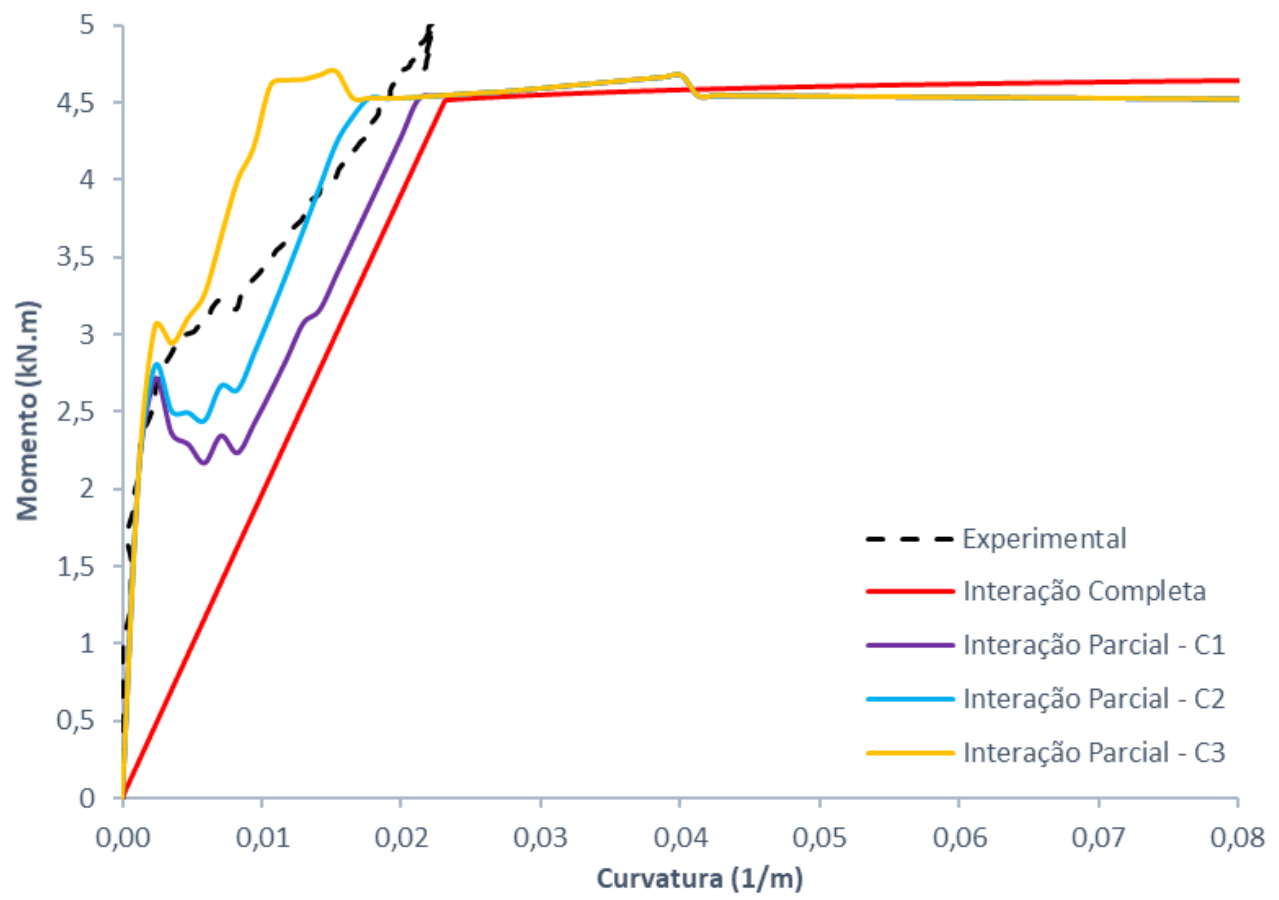

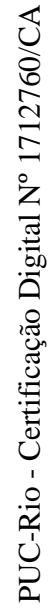

Figura 34. Diagrama momento - curvatura - Viga VA - 5

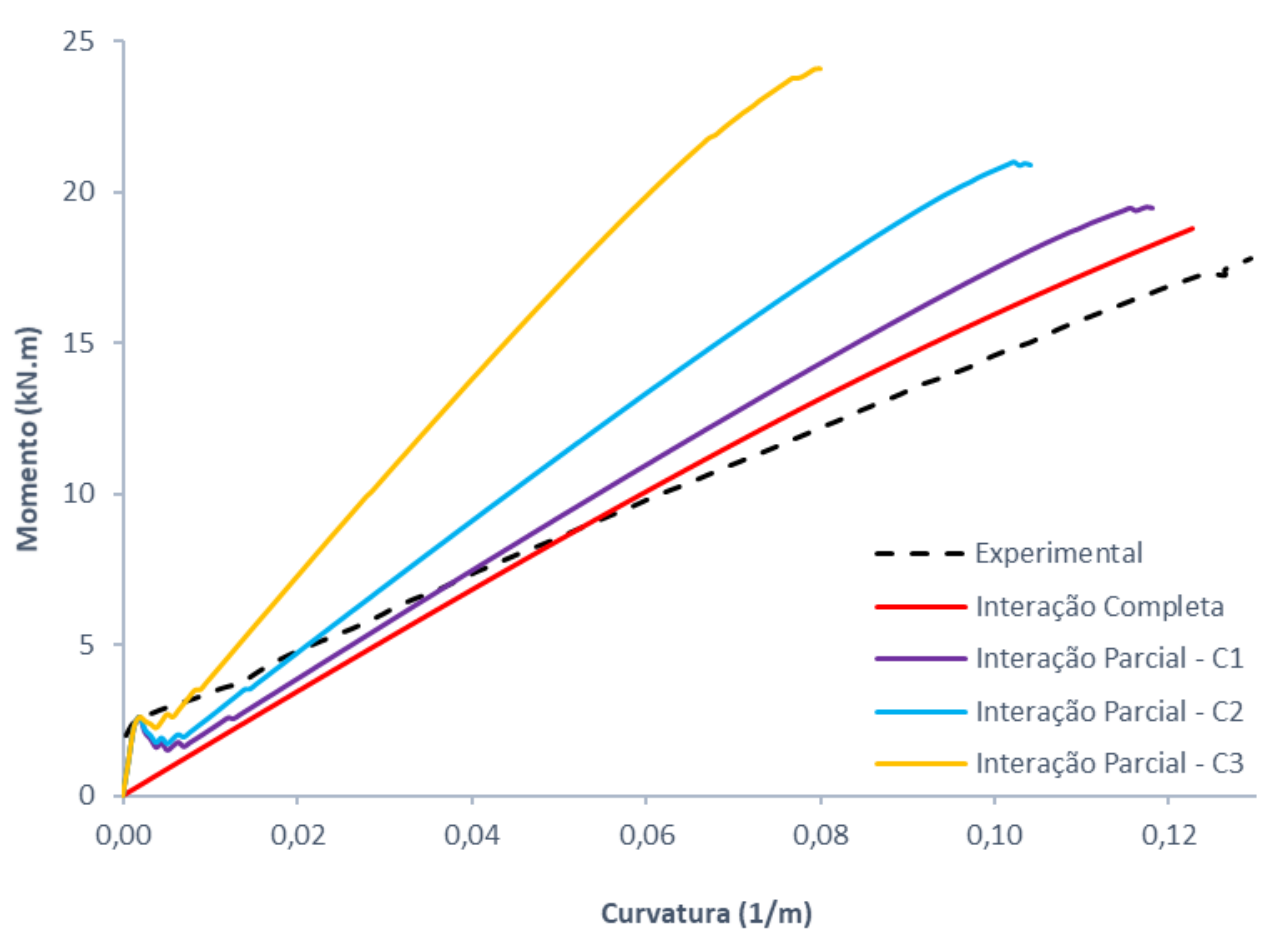

Figura 35. Diagrama momento - curvatura - Viga VP - 12 
É realizada uma comparação entre os momentos e as curvaturas obtidas para o fim do estádio I e estádio II. Conclui-se:

- Na VA-12, no estádio I, ou seja, antes da fissuração do concreto, as curvas analíticas (C1, C2 e C3) apresentaram um acréscimo no momento de 17\% e uma redução na curvatura de $18 \%$. Já para o estádio II, houve um aumento de $1 \%(\mathrm{C} 1$ e $\mathrm{C} 2)$ e redução de $1 \%(\mathrm{C} 3)$ de momento e a curvatura reduziu $28 \%$ (C1) e 39\% (C2 e C3), em relação ao experimental.

- A VA-5 apresentou no estádio I um aumento de $11 \%, 14 \%$ e $24 \%$ (C1, C2 e C3, respectivamente) de momento e aumento na curvatura de $22 \%$ para todas as análises. Enquanto que, no estádio II, tanto momento quanto curvatura sofreram reduções de $12 \%$ (C1 e C2) e $11 \%$ (C3) para momento e de 9\%, $18 \%$ e $22 \%, \mathrm{C} 1, \mathrm{C} 2$ e C3, respectivamente, em relação aos resultados experimentais.

- A última viga analisada, VP-12, nos momentos do estádio I, foi observado um aumento de $6 \%$ do momento, enquanto que a curvatura reduziu em $36 \%$, para todas as análises. E no estádio II, o acréscimo de momento foi de $9 \%$, $18 \%$ e $36 \%$ (C1, C2 e C3, respectivamente) e a redução na curvatura foi de $10 \%, 21 \%$ e $38 \%$, para C1, C2 e C3, respectivamente.

A implementação desenvolvida para a abordagem momento-rotação permitiu ainda definir as contribuições isoladas de cada mecanismo atuante na capacidade resistente da seção da viga. A parcela de compressão ascendente é calculada a partir da recomendação da NBR 6118 (2014) com a expressão (2.1); a de tração ascendente é dada pela lei de Hooke; a tração descendente é obtida com a expressão tensão x abertura de fissuras (3.73); a parcela mecânica do aço é obtida por meio da lei constitutiva sugerida pela norma brasileira, dada pela expressão (2.5) e a parcela de contribuição do concreto entre fissuras é obtida com o uso da expressão (2.56), sendo que de posse da força total atuante na armadura na face fissurada, retira-se a parcela referente à mecânica do aço, resultando assim na parcela de contribuição do concreto. Os resultados obtidos podem ser vistos nos gráficos a seguir. 


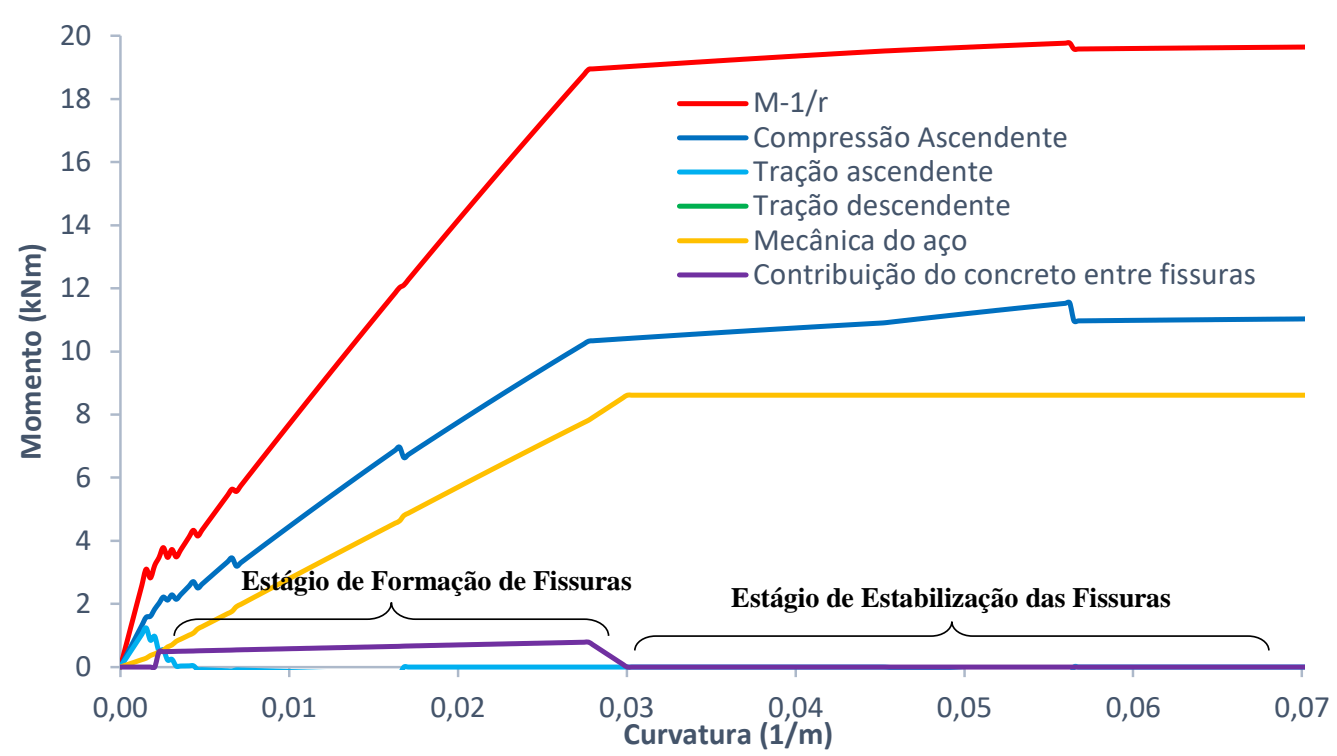

Figura 36. Contribuição das parcelas resistentes - viga VA-12

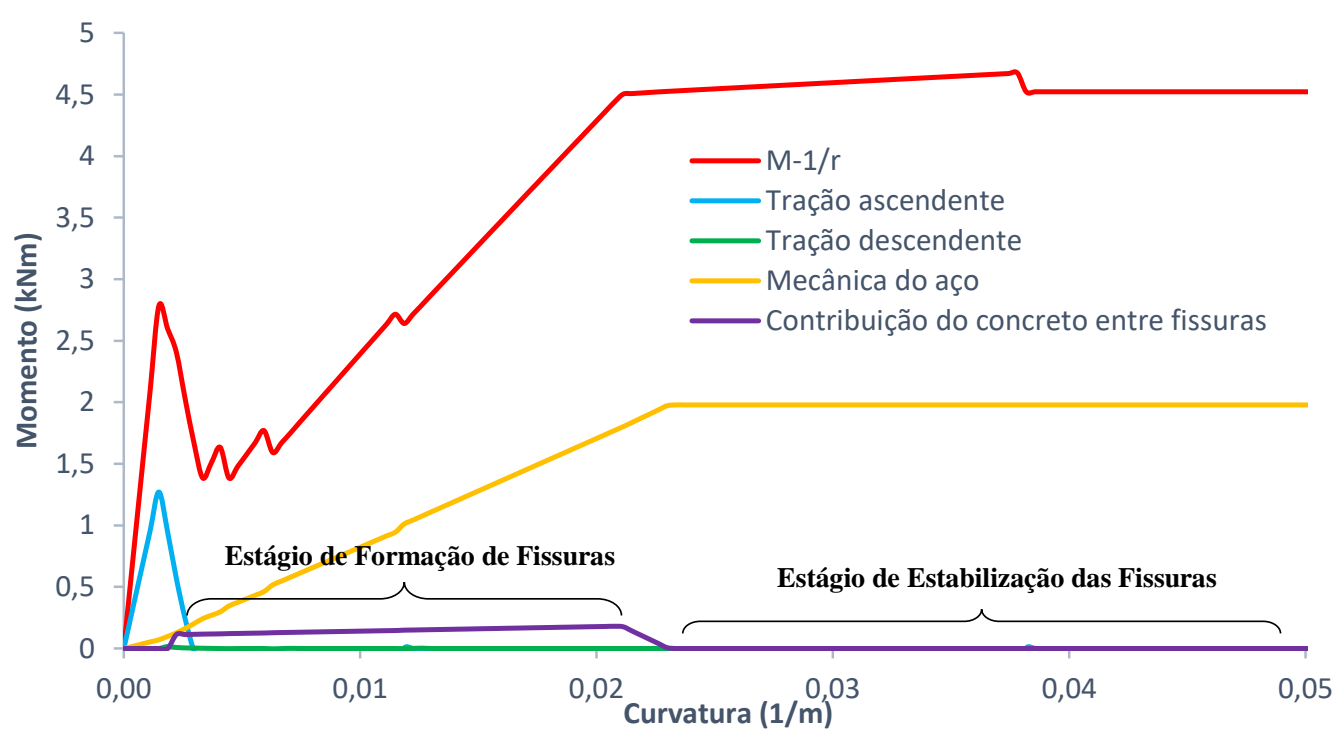

Figura 37. Contribuição das parcelas resistentes - viga VA-5 


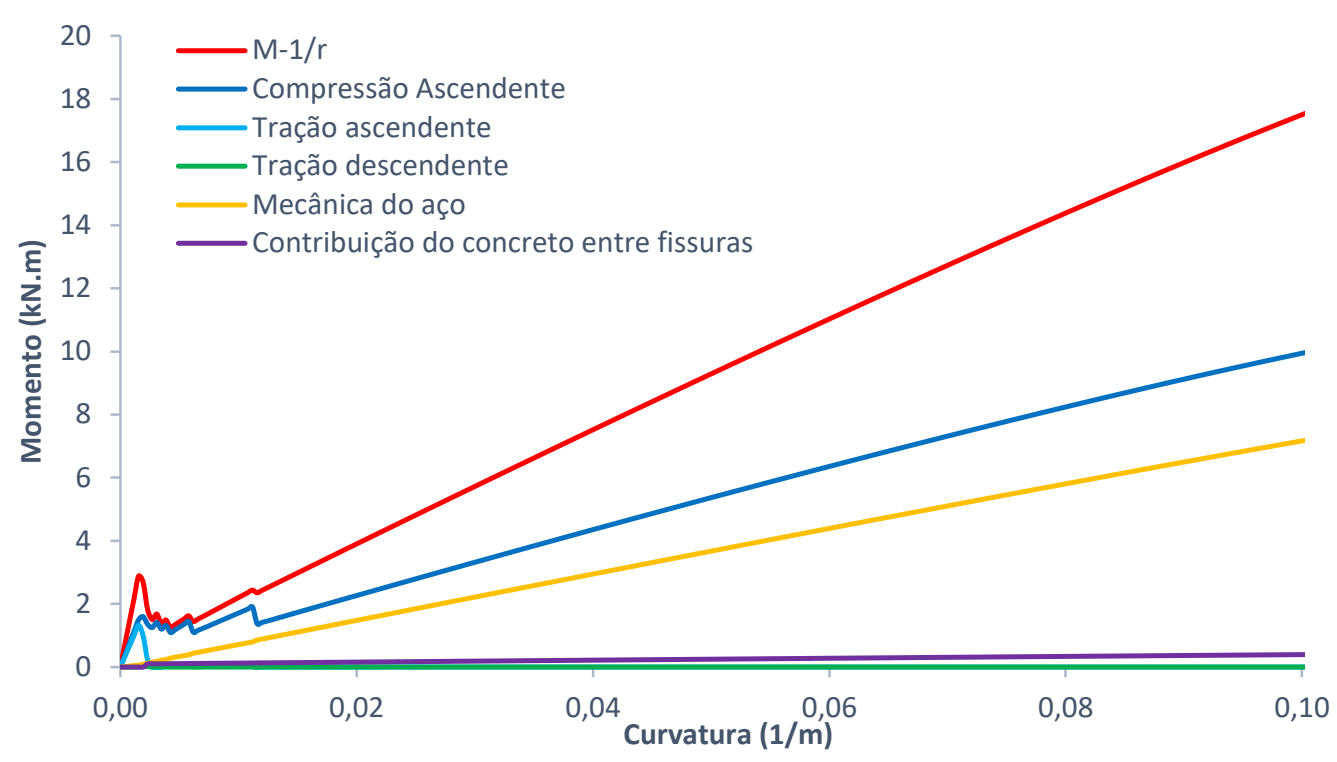

Figura 38. Contribuição das parcelas resistentes - viga VP-12

É possível observar como cada mecanismo atua e evidenciar alguns pontos importantes. Não foi detectado em nenhuma das vigas analisadas a contribuição de formação de cunhas de concreto. Além disso, é possível observar que, quando a resistência à tração do concreto é atingida, forma-se a primeira fissura e inicia-se o estágio de formação de fissuras, como indicado. Os gráficos permitem ainda observar que o concreto entre fissuras é responsável por uma pequena parcela na resistência à deformação. Para as vigas armadas com barras de aço, o estágio de formação de fissuras cessa no momento em que o aço atinge o escoamento, iniciando-se a fase de estabilização das fissuras. A partir desse ponto, a capacidade resistente é dada apenas por meio das contribuições mecânicas das barras e do concreto comprimido. Com isso, explica-se o fato de a capacidade resistente da seção ser a mesma para uma análise de interação completa e parcial.

Os modelos de interação completa e parcial apesar de manterem a mesma capacidade resistente da seção, pois se trata de uma viga isostática, possuem, conforme esperado, curvas com significativa diferença de rigidez. É importante frisar que não foi implementado, no modelo de interação completa, nenhuma contribuição do concreto à tração, tal decisão foi tomada a fim comparar uma situação hipotética comum considerada em projeto com um comportamento real no qual uma estrutura está submetida. 
Além dos resultados apresentados, o modelo é capaz de fornecer também resultados em termos da abertura de fissura, como o gráfico momento - abertura de fissura mostrado a seguir. Neste, foram gerados os resultados para uma análise de interação parcial considerando a contribuição $\mathrm{C} 3$, que indica a viga em seu estágio mais fissurado, sendo possível a comparação com os resultados experimentais das vigas armadas com barras de aço (vigas VA-12 e VA-5).

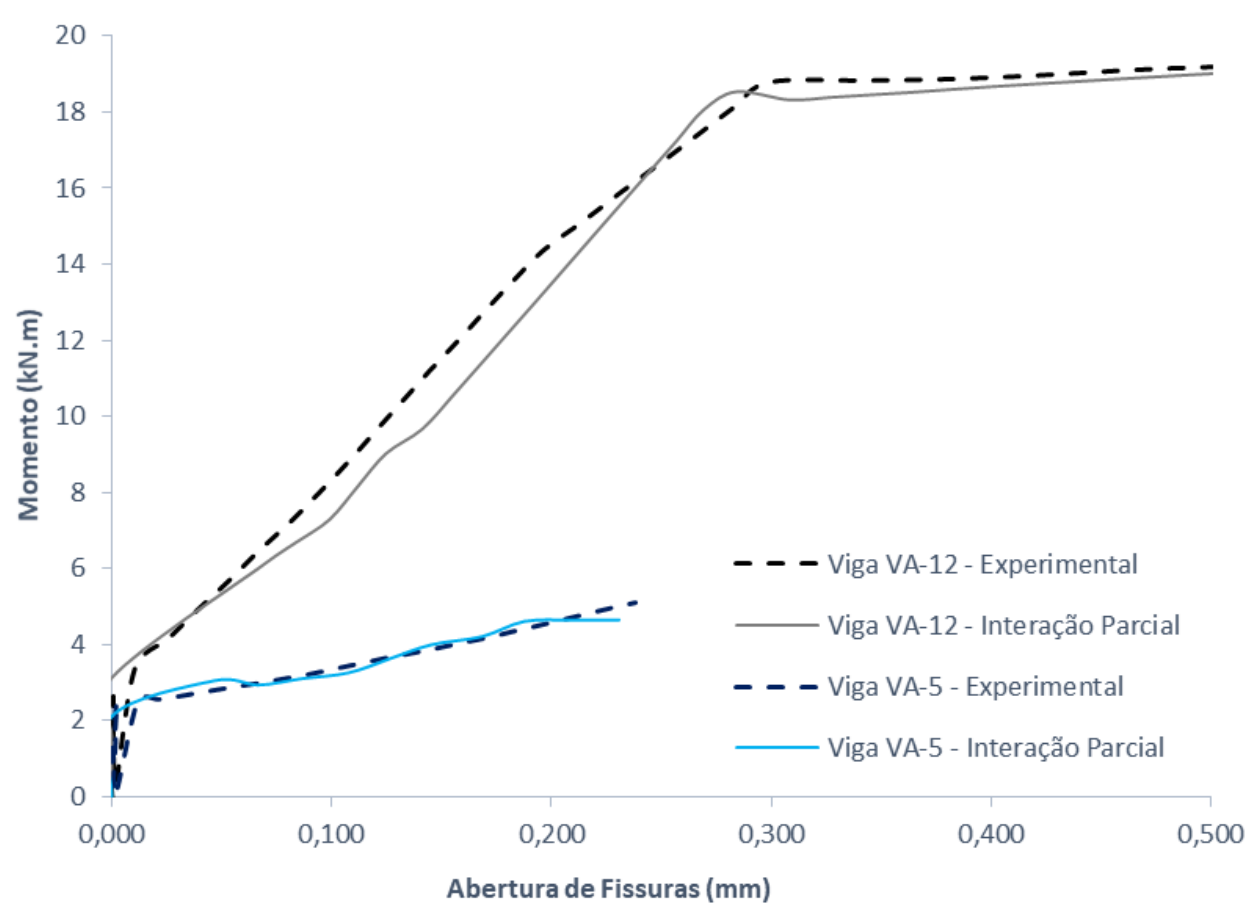

Figura 39. Momento - abertura de fissuras

Observa-se que os resultados numéricos obtidos se apresentaram bem próximos dos resultados experimentais, indicando que em uma análise local o modelo se mostrou bastante eficaz. 


\section{5 \\ Considerações Finais}

São apresentadas neste capítulo as conclusões obtidas durante o desenvolvimento deste trabalho e as sugestões para trabalhos futuros acerca do modelo mecânico apresentado baseado na abordagem momento-rotação.

\section{1. \\ Conclusões}

Nesta pesquisa apresentou-se um modelo mecânico baseado na abordagem momento-rotação, que possui como princípios básicos dois mecanismos de interação parcial: amolecimento do concreto e enrijecimento à tração. $\mathrm{O}$ primeiro insere no modelo o efeito da formação de cunhas, responsáveis pela zona de amolecimento do concreto, normalmente negligenciada nos modelos mecânicos de análise de estruturas. Já o segundo mecanismo adiciona fenômeno de contribuição do concreto à tração entre fissuras, que consiste no acréscimo de rigidez atribuído durante o estágio de formação de fissuras.

Para validação do modelo apresentado foram necessárias, além de sua implementação, a de mais dois algoritmos: uma de momento-curvatura baseada em interação completa e um algoritmo para análise de vigas, baseada na analogia de Mohr, que recebe as curvaturas obtidas dos diagramas momento-curvatura vindos das implementações de interação completa ou de interação parcial e as transformam em carregamentos, sendo por fim, obtidos os deslocamentos do elemento.

Com os modelos implementados, os diagramas momento-curvatura foram traçados, sendo possível avaliar a degradação da rigidez seccional das vigas estudadas à medida que havia curvaturas ou rotações incrementadas. Além disso, com as curvas carga-deslocamento, foi possível avaliar e comparar a flexibilidade das vigas à medida que carregamentos eram incrementados.

Portanto, é possível destacar algumas conclusões importantes que são apresentadas a seguir. 
A partir das curvas de carga-deslocamento plotadas observa-se que há um comportamento mais flexível para as vigas ensaiadas quando comparadas aos resultados numéricos. Tal comportamento pode ser explicado pelo fato das vigas possuírem um vão pequeno de cisalhamento, podendo estar submetidas à esforços cisalhantes consideráveis, o que pode ter acarretado no acréscimo dessa flexibilidade. Observa-se ainda que, para uma análise de interação completa as curvas apresentadas são mais flexíveis que as curvas de interação parcial, o que representa um comportamento coerente com o que era esperado, porém essas são mais rígidas que as curvas experimentais. É importante notar ainda, que a viga VA12 apresentou um comportamento bastante similar ao experimental no trecho linear, porém a partir de um determinado ponto, a rigidez experimental teve uma queda mais acentuada quando comparada às curvas analíticas.

A partir dos diagramas momento-curvatura é possível concluir que para o estádio I os diagramas apresentaram boa concordância com os ensaios experimentais, porém a partir daí as curvas, principalmente das vigas VA-5 e VP12, apresentaram um comportamento divergente.

Além disso, é importante notar ainda que as curvas C1 apresentaram um comportamento mais próximo das curvas experimentais, indicando que tal consideração levaria a um modelo mecânico mais realístico nesse estudo.

É apresentado ainda uma boa concordância para o resultado de momentoabertura de fissuras quando comparado ao experimental, mostrando a relevância do uso do modelo apresentado para análises cujo o comportamento em termos de abertura de fissuras seja uma questão importante.

As curvas analisadas que incluíram os mecanismos de interação parcial apresentaram um ganho de rigidez quando comparadas às curvas que consideraram interação completa entre materiais, porém mantendo aproximadamente a mesma capacidade resistente por se tratar de vigas isostáticas.

\section{2.}

\section{Sugestões para Trabalhos Futuros}

Uma forma eficiente de expandir, melhorar ou criar novos códigos normativos é desenvolver modelos mecânicos que possam ser capazes de realizar uma análise comportamental de estruturas de concreto representando de forma 
segura todos mecanismos observáveis. Sendo assim, de forma a contribuir com o desenvolvimento de tais modelos, sugere-se como trabalhos futuros:

- Aplicação do modelo para pilares de concreto armado, identificando e comparando o efeito do enrijecimento do concreto entre fissuras para pilares de diferentes esbeltezes, além verificar o impacto nos deslocamentos laterais do elemento.

- Incluir na formulação outros modelos de leis de aderência.

- Implementação do modelo para concretos com fibras.

- Evoluir a implementação do diagrama momento-rotação, considerando a integração analítica das tensões para o cálculo da capacidade resistente da seção.

- Inserir no modelo os efeitos de retração e fluência dos materiais constituintes.

- Desenvolver um processo iterativo para o cálculo da rotação eliminando a necessidade de plotar o diagrama, similar ao implementado para a abordagem de interação completa, como apresentado na seção 3.2 .

- Realizar comparações com modelos de elementos finitos.

- Inserir no modelo a contribuição de forças cisalhantes. 


\section{Referências Bibliográficas}

ABDALLA, H. A. Evaluation of deflection in concrete members reinforced with fibre reinforced polymer (FRP) bars. Composite Structures, v. 56, n. 1, p. 63-71, 2002.

ABREU, R. O. A., COSTA, G. C. C., AGUiAR, E. A. B.. Aplicação do método de Newton-Raphson na análise de seções retangulares de concreto armado submetidas à flexão composta normal segundo a ABNT NBR 6118:2014. In: Congresso Brasileiro do Concreto (CBC), 2017, Bento Gonçalves. Anais de Congresso, v. 59. São Paulo: IBRACON, 2017.

ACHILLIDES, Z.; PILAKOUTAS, K. Bond behavior of fiber reinforced polymer bars under direct pullout conditions. Journal of Composites for Construction, v. 8, n. 2, p. 173-181, 2004.

ALI, M. S. M.; OEHLERS, D. J.; GRIFFITH, M. C.; SERACINO, R. Interfacial stress transfer of near surface-mounted FRP-to-concrete joints. Engineering Structures, v. 30, n. 7, p. 1861-1868, 2008.

ALI, M. S. M.; OEHLERS, D. J.; HASKETT, M.; GRIFFITH, M. C. Discrete rotation in RC beams. Journal of Engineering Mechanics, v. 138, n. 11, p. $1317-$ $1325,2012$.

ASSOCIAÇÃO BRASILEIRA DE NORMAS TÉCNICAS - ABNT. NBR 6118: Projeto de estruturas de concreto - Procedimento. Rio de Janeiro, 2014.

AYDIN, H.; GRAVINA, R. J.; VISINTIN, P. A partial-interaction approach for extracting FRP-to-concrete bond characteristics from environmentally loaded flexural tests. Composites Part B: Engineering, v. 132, p. 214-228, 2018.

BAENA, M.; TORRES, L.; TURON, A.; BARRIS, C. Experimental study of bond behaviour between concrete and FRP bars using a pull-out test. Composites Part B: Engineering, v. 40, n. 8, p. 784-797, 2009.

BAENA, M.; TORRES, L.; TURON, A.; MIÀS, C. Analysis of cracking behaviour and tension stiffening in FRP reinforced concrete tensile elements. Composites Part B: Engineering, v. 45, n. 1, p. 1360-1367, 2013. 
BARROS, J. A. O.; TAHERI, M.; SALEHIAN, H. A model to simulate the moment-rotation and crack width of FRC members reinforced with longitudinal bars. Engineering Structures, v. 100, p. 43-56, 2015.

BAŽANT, Z. P. Mechanics of distributed cracking. Applied Mechanics Reviews, v. 39, n. 5, p. 675-705, 1986.

BERTERO, V.V.; POPOV, E. P.; ELIGEHAUSEN, R. Local bond stress-slip relationships of deformed bars under generalized excitations. 1983. 180f. Relatório - Centro de Pesquisa de Engenharia de Terremoto, Universidade da Califórnia, Berkeley, 1983.

BRANSON, D. E. Deformation of concrete structures. New York: McGraw Hill Book Co., 1977.

CEB-FIB. Model Code 1990 - design code. International Federation for Structural Concrete. Lausanne, Suíça, 1993

CEB-FIB. Model Code 2010 - first complete draft, volume 2. International Federation for Structural Concrete. Lausanne, Suíça, 2008

CERONI, F.; PECCE, M.; BILOTTA, A.; NIGRO, E. Bond behavior of FRP NSM systems in concrete elements. Composites Part B: Engineering, v. 43, n. 2, p. $99-109,2012$.

CHAN, H. C.; CHEUNG, Y. K.; HUANG, Y. P. Analytical crack model for reinforced-concrete structures. Journal of Structural Engineering, v. 119, n. 5, p. 1339-1357, 1993.

CHEN, Y. Quantifying the compressive ductility of concrete in RC members through shear friction mechanics. 2014. 333f. Tese (Doutorado) - Departamento de Engenharia Civil, Meio Ambiente e Mineração, Universidade de Adelaide, Adelaide, 2014.

CHEN, Y.; VISINTIN, P.; OEHLERS, D. J. Concrete shear-friction material properties: derivation from actively confined compression cylinder tests. Advances in Structural Engineering, v. 18, n. 8, p. 1173-1186, 2015.

CHEN, Y.; VISINTIN, P.; OEHLERS, D. J.; ALENGARAM, U. J. Sizedependent stress-strain model for unconfined concrete. Journal of Structural Engineering, v. 140, n. 4, p. 4013088, 2013.

CHEN, Y.; ZHANG, T.; VISINTIN, P.; OEHLERS, D. J. Concrete shear-friction material properties: application to shear capacity of $\mathrm{RC}$ beams of all sizes. Advances in Structural Engineering, v. 18, n. 8, p. 1187-1198, 2015.

CHOO, C. C.; HARIK, I. E.; GESUND, H. Strength of rectangular concrete columns reinforced with fiber-reinforced polymer bars. ACI Structural Journal, v. 103, n. 3, p. 452-459, 2006. 
COSENZA, E.; MANFREDI, G.; REALFONZO, R. Behavior and modelling of bond of FRP rebars to concrete. Journal of Composites for Construction, v. 1, n. 2, p. 40-51, 1997.

COSENZA, E.; MANFREDI, G.; REALFONZO, R.; RILEM. Analytical modelling of bond between FRP reinforcing bars and concrete. In: 2nd International symposium - Non-metallic (FRP) reinforcement for concrete structures, 1995, Gante. RILEM PROCEEDINGS, v. 29. Londres: Spon, 1995, p. $164-171$.

CRUZ, J. S.; BARROS, J. Bond between near-surface mounted carbon-fiberreinforced polymer laminate strips and concrete. Journal of Composites for Construction, v. 8, n. 6, p. 519-527, 2004.

DARAIN, K. M.; JUMAAT, M. Z.; SHUKRI, A. A.; OBAYDULLAH, M.; HUDA, M. N.; HOSEN, M. A.; HOQUE, N. Strengthening of RC beams using externally bonded reinforcement combined with near-surface mounted technique. Polymers, v. 8, n. 261, 2016.

DE LORENZIS, L.; GALATI, D.; LA TEGOLA, A. Stiffness and ductility of fibre-reinforced polymer-strengthened reinforced concrete members. Proceedings of the Institution of Civil Engineers: Structures and Buildings, v. 157, n. 1, p. 31-51, 2004.

DE LORENZIS, L.; RIZZO, A.; LA TEGOLA, A. A modified pull-out test for bond of near-surface mounted FRP rods in concrete. Composites Part B: Engineering, v. 33, n. 8, p. 589-603, 2002.

DEITZ, D. H.; HARIK, I. E.; GESUND, H. Physical Properties of Glass Fiber Reinforced Polymer Rebars in Compression. Journal of Composites for Construction, v. 7, n. 4, p. 363-366, 2003.

FIB. FIB Bulletin 40 - FRP reinforcement in RC structures. Relatório Técnico. International Federation for Structural Concrete. Lausanne, Suíça, 2007

FIB. FIB Bulletin 42 - Constitutive modelling of high strength/high performance concrete. State-of-art. Relatório Técnico. International Federation for Structural Concrete. Lausanne, Suíça, 2008

GUDONIS, E.; TIMINSKAS, E.; GRIBNIAK, V.; KAKLAUSKAS, G.; ARNAUTOV, A. K.; TAMULENAS, V. FRP reinforcement for concrete structures: state-of-the-art review of application and design. Engineering Structures and Technologies, v. 5, n. 4, p. 147-158, 2014.

GUPTA, A. K.; MAESTRINI, S. R. Tension-stiffness model for reinforced concrete bars. Journal of Structural Engineering, v. 116, n. 3, p. 769-790, 1990.

HASKETT, M.; OEHLERS, D. J.; ALI, M. S. M.; WU, C. Rigid body momentrotation mechanism for reinforced concrete beam hinges. Engineering Structures, v. 31, n. 5, p. 1032-1041, 2009a. 
HASKETT, M.; OEHLERS, D. J.; ALI, M. S. M.; WU, C. Yield Penetration Hinge Rotation in Reinforced Concrete Beams. Journal of Structural Engineering, v. 135, n. 2, p. 130-138, 2009b.

HASKETT, M.; ALI, M. S. M.; OEHLERS, D. J.; WU, C. Influence of bond on the hinge rotation of FRP plated beams. Advances in Structural Engineering, v. 12 , n. 6 , p. 833-843, 2009c.

HASKETT, M.; OEHLERS, D. J.; ALI, M. S. M.; SHARMA, S. K. The shear friction aggregate interlock resistance across sliding planes in concrete. Magazine of Concrete Research, v. 62, n. 12, p. 907-924, 2010.

HASKETT, M.; OEHLERS, D. J.; ALI, M. S. M. Local and global bond characteristics of steel reinforcing bars. Engineering Structures, v. 30, n. 2, p. 376-383, 2008.

HASKETT, M.; OEHLERS, D. J.; ALI, M. S. M.; SHARMA, S. K. Evaluating the shear-friction resistance across sliding planes in concrete. Engineering Structures, v. 33, n. 4, p. 1357-1364, 2011.

HOSEN, M. A.; JUMAAT, M. Z.; ALENGARAM, U. J.; ISLAM, A. B. M. S.; HASHIM, H. BIN. Near surface mounted composites for flexural strengthening of reinforced concrete beams. Polymers, v. 8, n. 3, 2016.

LIN, X.; ZHANG, Y. X. Evaluation of bond stress-slip models for FRP reinforcing bars in concrete. Composite Structures, v. 107, n. 1, p. 131-141, 2014.

LORENZIS, L. DE; RIZZO, A.; TEGOLA, A. LA. A modified pull-out test for bond of near-surface mounted FRP rods in concrete. Composites Part B: Engineering, v. 33, n. 8, p. 589-603, 2002.

LUCAS, W.; OEHLERS, D. J.; ALI, M. S. M.; GRIFFITH, M. C. The FRP reinforced shear-friction mechanism. Advances in Structural Engineering, v. 15, n. 4, p. 615-624, 2012.

MALVAR, L. J. Bond stress-slip characteristics of frp rebars. 1994. 50f. Relatório Técnico - Naval Facilities Engineering Service Center, Defense Technical Information Center, Port Hueneme, 1994.

MARTHA, L. F. Análise de Estruturas: conceitos e métodos básicos. Rio de Janeiro: Elsevier, 2010.

MATTOCK, A. H. Shear friction and high-strength concrete. ACI Structural Journal, v. 98, n. 1, p. 50-59, 2001.

MAZAHERIPOUR, H.; BARROS, J. A. O.; CRUZ, J. S. Tension-stiffening model for FRC reinforced by hybrid FRP and steel bars. Composites Part B: Engineering, v. 88, p. 162-181, 2016. 
MENDES NETO, F. Concreto Estrutural Avançado: Análise de seções transversais sob flexão normal composta. São Paulo: Pini, 2009.

MUHAMAD, R.; ALI, M. S. M.; OEHLERS, D. J.; GRIFFITH, M. The tension stiffening mechanism in reinforced concrete prisms. Advances in Structural Engineering, v. 15, n. 12, p. 2053-2069, 2012.

MUHAMAD, R.; ALI, M. S. M.; OEHLERS, D.; HAMID SHEIKH, A. Load-slip relationship of tension reinforcement in reinforced concrete members. Engineering Structures, v. 33, n. 4, p. 1098-1106, 2011.

MURRAY, Y. D., ODEH, A. A. \& BLIGH, R., 2007. Evaluation of LS-DYNA concrete material model 159, McLean: U.S. Department of Transportation Federal Highway Administration.

NOVIDIS, D.; PANTAZOPOULOU, S. J.; TENTOLOURIS, E. Experimental study of bond of NSM-FRP reinforcement. Construction and Building Materials, v. 21, n. 8, p. 1760-1770, 2007.

OEHLERS, D. J.; ALI, M. S. M.; HASKETT, M.; LUCAS, W.; MUHAMAD, R.; VISINTIN, P. FRP-Reinforced Concrete Beams: Unified Approach Based on IC Theory. Journal of Composites for Construction, v. 15, n. 3, p. 293-303, 2011a.

OEHLERS, D. J.; HASKETT, M.; ALI, M. H. M.; LUCAS, W.; MUHAMAD, R. Our Obsession with Curvature in RC Beam Modelling. Advances in Structural Engineering, v. 14, n. 3, p. 391-404, 2011b.

OEHLERS, D. J.; ALI, M. S. M.; GRIFFITH, M. C.; HASKETT, M.; LUCAS, W. A generic unified reinforced concrete model. Proceedings of the Institution of Civil Engineers - Structures and Buildings, v. 165, n. 1, p. 27-49, 2012a.

OEHLERS, D. J. Ductility of FRP plated flexural members. Cement and Concrete Composites, v. 28, n. 10, p. 898-905, 2006.

OEHLERS, D. J.; ALI, M. S. M.; GRIFFITH, M. C. Concrete Component of the Rotational Ductility of Reinforced Concrete Flexural Members. Advances in Structural Engineering, v. 11, n. 3, p. 281-291, 2008.

OEHLERS, D. J.; LIU, I. S. T.; SERACINO, R. The gradual formation of hinges throughout reinforced concrete beams. Mechanics Based Design of Structures and Machines, v. 33, n. 3-4, p. 373-398, 2005.

OEHLERS, D. J.; MUHAMAD, R.; ALI, M. S. M. Serviceability flexural ductility of FRP RC beams: A discrete rotation approach. Construction and Building Materials, v. 49, p. 974-984, 2013.

OEHLERS, D. J.; VISINTIN, P.; CHEN, J.-F.; SERACINO, R.; WU, Y.; LUCAS, W. Reinforced Concrete Behavior, Research, Development, and Design through Partial-Interaction Mechanics. Journal of Structural Engineering, v. 143, n. 7, p. 02517002, 2017. 
OEHLERS, D. J.; VISINTIN, P.; CHEN, J.-F.; IBELL, T. J. Simulating reinforced concrete members. Part 1: partial interaction properties. Proceedings of the Institution of Civil Engineers - Structures and Buildings, v. 167, n. 11, p. 646-653, 2014a.

OEHLERS, D. J.; VISINTIN, P.; CHEN, J.-F.; IBELL, T. J. Simulating reinforced concrete members. Part 2: displacement-based analyses. Proceedings of the Institution of Civil Engineers - Structures and Buildings, v. 167, n. 12, p. 718-727, 2014b.

OEHLERS, D. J.; VISINTIN, P.; HASKETT, M.; SEBASTIAN, W. M. Flexural ductility fundamental mechanisms governing all $\mathrm{RC}$ members in particular FRP RC. Construction and Building Materials, v. 49, p. 985-997, 2013.

OEHLERS, D. J.; VISINTIN, P.; LUCAS, W. Flexural Strength and ductility of FRP-plated RC beams: fundamental mechanics incorporating local and global IC debonding. Journal of Composites for Construction, v. 20, n. 2, p. 04015046, 2016.

OEHLERS, D.; VISINTIN, P.; ZHANG, T.; CHEN, Y.; KNIGHT, D. Flexural rigidity of reinforced concrete members using a deformation based analysis. Concrete in Australia, v. 38, n. 4, p. 50-56, 2012b.

REIS, V. L. F. Construção de estruturas de betão armado com varões de FRP. 2009. 196f. Dissertação (Mestrado) - Departamento de Engenharia Civil, Universidade do Porto, Porto, 2009.

RILEM. Recommendations of RILEM TC 162-TDF: Test and design methods for steel fibre reinforced concrete: bending test. RILEM Journal Materials and Structures, v. 35, n. 253, p. 579 - 582, 2002.

RUSSO, G.; ROMANO, F. Cracking response of RC members subjected to uniaxial tension. Journal of Structural Engineering, v. 118, n. 5, p. 1172-1190, 1992.

SÁ, F. R. G. Influência da adição de fibras de polipropileno no comportamento de elementos estruturais de concreto armado com barras de GFRP. 2018. 100f. Dissertação (Mestrado) - Departamento de Engenharia Civil e Ambiental, Pontifícia Universidade Católica do Rio de Janeiro, Rio de Janeiro, 2018.

SANTOS, L. M. Instabilidade nas Estruturas de Concreto: Análise de Pilares. 1987. 112f. Apostila (Pós-Graduação). Universidade de São Paulo - USP, São Paulo, 1987.

SERACINO, R.; JONES, N. M.; ALI, M. S. M.; PAGE, M. W.; OEHLERS, D. J. Bond strength of near-surface mounted FRP strip-to-concrete joints. Journal of Composites for Construction, v. 11, n. 4, p. 401-409, 2007.

SERACINO, R.; RAIZAL, M. R. S.; OEHLERS, D. J. Generic debonding resistance of EB and NSM plate-to-concrete joints. Journal of Composites for Construction, v. 11, n. 1, p. 62-70, 2007. 
SHUKRI, A. A.; DARAIN, K. M.; JUMAAT, M. Z. The tension-stiffening contribution of NSM CFRP to the behavior of strengthened RC beams. Materials, v. 8, n. 7, p. 4131-4136, 2015.

TAHERI, M.; BARROS, J. A. O. An analytical model to simulate tension stiffening mechanism in rotation response of FRC flexural members with tensile longitudinal reinforcement. 2012. 39f. Relatório - Departamento de Engenharia Civil, Universidade do Minho, Guimarães, 2012.

VISINTIN, P.; CHEN, Y.; OEHLERS, D. J. Simulating the behavior of FRPconfined cylinders using the shear-friction mechanism. Journal of Composites for Construction, v. 19, n. 6, p. 04015014, 2015.

VISINTIN, P. A generic segmental analysis of all types of RC members. 2012. 269f. Tese (Doutorado) - Departamento de Engenharia Civil, Meio Ambiente e Mineração, Universidade de Adelaide, Adelaide, 2012.

VISINTIN, P.; OEHLERS, D. J. Mechanics-based closed-form solutions for moment redistribution in $\mathbf{R C}$ beams. Structural Concrete, v. 17, n. 3, p. 377-389, 2016.

VISINTIN, P.; OEHLERS, D. J.; HASKETT, M. Partial-interaction time dependent behaviour of reinforced concrete beams. Engineering Structures, v. 49, p. 408-420, 2013.

VISINTIN, P.; OEHLERS, D. J.; HASKETT, M.; WU, C. Mechanics-based hinge analysis for reinforced concrete columns. Journal of Structural Engineering, v. 139, n. 11, p. 1973-1980, 2013.

VISINTIN, P.; OEHLERS, D. J.; STURM, A. B. Mechanics solutions for deflection and cracking in concrete. Proceedings of the Institution of Civil Engineers - Structures and Buildings, v. 169, n. 12, p. 912-924, 2016.

VISINTIN, P.; OEHLERS, D. J.; WU, C.; HASKETT, M. A mechanics solution for hinges in RC beams with multiple cracks. Engineering Structures, v. 36, p. 61-69, 2012.

WANG, H.; BELARBI, A. Ductility characteristics of fiber-reinforced-concrete beams reinforced with FRP rebars. Construction and Building Materials, v. 25, n. 5, p. 2391-2401, 2011.

WU, H. Q.; GILBERT, R. I. Modeling short-term tension stiffening in reinforced concrete prisms using a continuum-based finite element model. Engineering Structures, v. 31, n. 10, p. 2380-2391, 2009.

YANKELEVSKY, D. Z. Analytical Model for Bond-slip Behavior Under Monotonic Loading. Building and Enviroment, v. 20, p. 163-168, 1985. 
YANKELEVSKY, D. Z.; JABAREEN, M.; ABUTBUL, A. D. One-dimensional analysis of tension stiffening in reinforced concrete with discrete cracks. Engineering Structures, v. 30, n. 1, p. 206-217, 2008.

ZHANG, S. S.; TENG, J. G.; ASCE, M.; YU, T. Bond Strength Model for CFRP Strips Near-Surface Mounted to Concrete. Journal of Composites for Construction, v. 18, n. 3, p. 383-388, 2014.

ZHANG, S. S.; YU, T.; CHEN, G. M. Reinforced concrete beams strengthened in flexure with near-surface mounted (NSM) CFRP strips: Current status and research needs. Composites Part B: Engineering, v. 131, p. 30-42, 2017.

ZHANG, T.; VISINTIN, P.; OEHLERS, D. J. Partial-interaction tensionstiffening properties for numerical simulations. Advances in Structural Engineering, v. 20, n. 5, p. 812-821, 2017. 